Article

\title{
Synthesis of 2,4-Diaminopyrimidine Core-Based Derivatives and Biological Evaluation of Their Anti-Tubercular Activities
}

\author{
Yifan Ouyang ${ }^{1,+}{ }^{,}$, Hao Yang ${ }^{1,+}$, Peng Zhang ${ }^{1}$, Yu Wang ${ }^{1}$, Sargit Kaur ${ }^{2}$, Xuanli Zhu ${ }^{1}$, Zhe Wang ${ }^{1}$, \\ Yutong Sun ${ }^{1}$, Wei Hong ${ }^{3, *}$, Yun Fong Ngeow ${ }^{2, *}$ and Hao Wang ${ }^{1,4, *}$ \\ 1 School of Pharmacy, Ningxia Medical University, Yinchuan 750004, China; \\ ouyang_pharmacy@163.com (Y.O.); yhao246@163.com (H.Y.); zpzzjzp@163.com (P.Z.); \\ wangyuxingfu@163.com (Y.W.); jf18700994479@163.com (X.Z.); 13239935127@163.com (Z.W.); \\ syt931115@163.com (Y.S.) \\ 2 Department of Pre-Clinical Sciences, Faculty of Medicine and Health Sciences, Universiti Tunku \\ Abdul Rahman, Sungai Long campus, Kajang 43000, Selangor, Malaysia; sargitk3@gmail.com \\ 3 School of Chemistry and Chemical Engineering, North Minzu University, Yinchuan 750021, China \\ 4 KeyLaboratory of Hui Ethnic Medicine Modernization, Ministry of Education, Ningxia Medical University, \\ Yinchuan 750004, China \\ * Correspondence: hongwei136@hotmail.com (W.H.); ngeowyf@utar.edu.my (Y.F.N.); paxhw@yahoo.co.uk \\ (H.W.); Tel.: +86-135-1920-2157 (W.H.); +60-390-860-288 (Y.F.N.); +86-135-1929-8012 (H.W.) \\ $\dagger$ These authors contributed equally to this work.
}

Received: 4 September 2017; Accepted: 20 September 2017; Published: 22 September 2017

\begin{abstract}
Tuberculosis (TB) is a chronic, potentially fatal disease caused by Mycobacterium tuberculosis (Mtb). The dihyrofolate reductase in $M t b$ ( $m t$-DHFR) is believed to be an important drug target in anti-TB drug development. This enzyme contains a glycerol (GOL) binding site, which is assumed to be a useful site to improve the selectivity towards human dihyrofolate reductase ( $h$-DHFR). There have been previous attempts to design drugs targeting the GOL binding site, but the designed compounds contain a hydrophilic group, which may prevent the compounds from crossing the cell wall of $M t b$ to function at the whole cell level. In the current study, we designed and synthesized a series of $m t$-DHFR inhibitors that contain a 2,4-diaminopyrimidine core with side chains to occupy the glycerol binding site with proper hydrophilicity for cell entry, and tested their anti-tubercular activity against $M t b$ H37Ra. Among them, compound 161 showed a good anti-TB activity ( $\mathrm{MIC}=6.25 \mu \mathrm{g} / \mathrm{mL}$ ) with a significant selectivity against vero cells. In the molecular simulations performed to understand the binding poses of the compounds, it was noticed that only side chains of a certain size can occupy the glycerol binding site. In summary, the novel synthesized compounds with appropriate side chains, hydrophobicity and selectivity could be important lead compounds for future optimization towards the development of future anti-TB drugs that can be used as monotherapy or in combination with other anti-TB drugs or antibiotics. These compounds can also provide much information for further studies on $m t$-DHFR. However, the enzyme target of the compounds still needs to be confirmed by pure $m t$-DHFR binding assays.
\end{abstract}

Keywords: anti-tuberculosis; 2,4-diaminopyrimidine derivatives; synthesis

\section{Introduction}

There is an urgent need to develop new drugs for the treatment of tuberculosis (TB), a chronic disabling infection caused by Mycobacterium tuberculosis $(M t b)$. This pathogen has developed resistance to standard first- and second-line anti-TB drugs, leaving very few options for effective therapy. para-Aminosalicylic acid (PAS) is a key anti-TB drug that has been in use for over 60 years. 
Its anti-mycobacterial mechanism was not clearly understood until recently, when it was reported to be the pro-drug of an inhibitor of the $M t b$ dihyrofolate reductase ( $m t$-DHFR) [1]. $m t$-DHFR catalyzes the reduction of dihydrofolate to tetrahydrolate in the folate metabolic pathway that leads to the synthesis of purines, pyrimidines and other proteins. Inhibition of the enzyme would cause cell death via the inhibition of DNA synthesis. This association of PAS with $m t$-DHFR inhibition encouraged scientists to focus once again on $m t$-DHFR as a potential target for anti-TB drugs.

According to their chemical structures, DHFR inhibitors can be divided into "classical" and "non-classical" types [2,3]. The structures of classical inhibitors are similar to that of folate, as in methotrexate (Figure 1), which is a commonly used anticancer drug [4-6]. The core structure of non-classical inhibitors is 2,4-diaminopyrimidine, as in trimethoprim (Figure 1), an anti-bacterial drug [7-9]. The crystal structures of $m t$-DHFR (PDB ID: 1DF7, Figure 2) and human DHFR (h-DHFR, PDB ID: 1OHJ), show a glycerol (GOL) binding site in $m t$-DHFR that does not exist in $h$-DHFR. To take advantage of this difference, Threadgill evaluated a group of compounds containing glycerol-like side chains, among which one compound, El-7a (Figure 1) showed notable selectivity for $m t$-DHFR inhibition over $h$-DHFR [10]. However, this evaluation was conducted using TB5 Saccharomyces cerevisiae carrying $m t$-DHFR and $h$-DHFR genes, therefore, there is no direct evidence to show that El-7a can inhibit the growth of $M t b$. Furthermore, the inhibition of $M t b$ may require an appropriate lipophilicity in the compound [11]. Even if El-7a were able to selectively inhibit the $m t$-DHFR, its low hydrophobicity may prevent it from passing through the Mtb cell wall. Hence, we designed and synthesized a series of compounds containing more hydrophobic groups on the 6-position of 2,4-diaminopyrimidine to evaluate the ability of these compounds to inhibit $M t b$ cells directly.<smiles>CCOC(C)(C)CCCCC(=O)NC(CCC(=O)O)C(=O)c1ccc(N(C)Cc2cnc3nc(N)nc(N)c3n2)cc1</smiles><smiles>COc1cc(Cc2cnc(N)nc2N)cc(OC)c1OC</smiles>

Trimethoprim<smiles>Nc1nc(N)c(-c2ccccc2)c(CC[C@H](O)[C@H](O)CO)n1</smiles>

El-7a

Figure 1. The structures of "classical" and "non-classical" DHFR inhibitors.

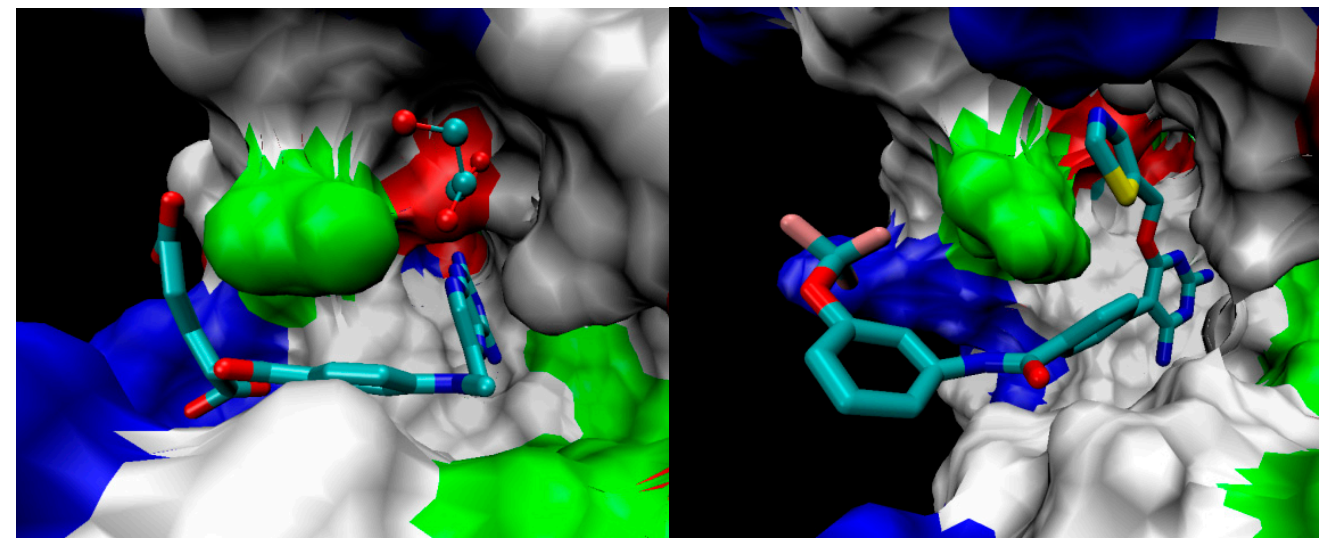

Figure 2. Left: the binding sites of methotrexate (MTX) and glycerol (GOL) in $m t$-DHFR, in which MTX is represented as a sticks model, GOL as a ball-stick model, and protein as a molecular surface; Right: the designed molecule is predicted to be able to occupy the GOL binding site, in which the molecule is represented as sticks and protein as a molecular surface. 


\section{Results and Discussion}

\subsection{Chemistry}

The synthesis of the designed compounds $10 \mathbf{a}-\mathbf{q}$ or $11 \mathbf{a}-\mathbf{q}$ was carried out in five steps-chlorination, nucleophilic substitution, iodination, Suzuki reaction and deprotection-according to our patented method [12], with 2,4-diamino-6-hydroxypyrimidine (1) as the starting material (Scheme 1). Initially, 2,4-diamino-6-chloropyrimidine (2) was generated from 1 by treatment with phosphorus oxychloride. After the reaction was quenched with ice water, the solution was hydrolyzed at $90{ }^{\circ} \mathrm{C}$ to obtain a good yield (85\%) of the target intermediate [13]. This procedure yields pure 2 without the need for chromatography.
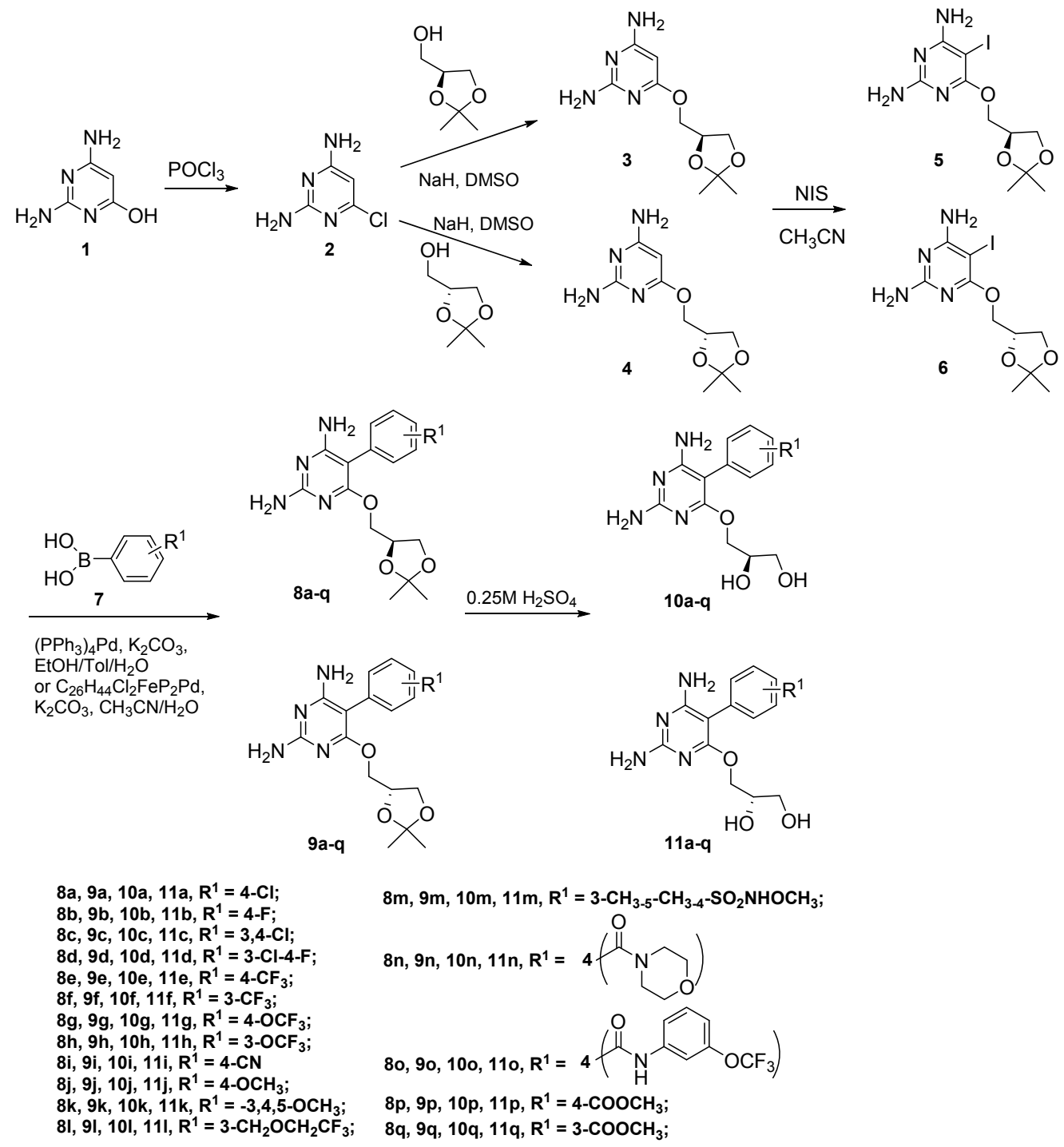

Scheme 1. Synthesis of 2,4-diamino-5-aryl-6-substituted pyrimidine derivatives 10a-q and 11a-q.

The treatment of $(S)$-2,3-isopropylidene glycerol or $(R)$-2,3-isopropylidene glycerol with sodium hydride in dry DMSO generated the corresponding nucleophile, which was then reacted with 2 to give 2,4-diamino-6-substituted pyrimidines 3 or 4 in good yield (77\%) [14]. Subsequently, the 5-positions of 3 or 4 were iodinated with $N$-iodosuccinimide in dry acetonitrile to produce the precursor 2,4-diamino-5-iodo-6-substituted pyrimidine derivatives 5 or 6 in 96-98\% yields [15]. Initially, we used a previously synthesized 2,4-diamino-5-bromo-6-substituted pyrimidine derivative as the starting 
material in the model reaction of the Suzuki reactions in order to introduce a substituted aryl group in the 5-position of the 2,4-diaminopyrimidine core. We tried several conditions, such as reacting with phenylboronic acid, 4-chlorophenylboronic acid and 4-methoxycarbonylphenylboronic acid, different catalysts $\left(\mathrm{Pd}\left(\mathrm{PPh}_{3}\right)_{4}\right.$ [16], $\left.\mathrm{Pd}(\mathrm{dbpf}) \mathrm{Cl}_{2}\right)$ [17], different bases $\left(\mathrm{K}_{2} \mathrm{CO}_{3}, \mathrm{~K}_{2} \mathrm{HPO}_{4}\right)$, different solvents (EtOH/Toluene $/ \mathrm{H}_{2} \mathrm{O}, \mathrm{THF} / \mathrm{H}_{2} \mathrm{O}, \mathrm{CH}_{3} \mathrm{CN} / \mathrm{H}_{2} \mathrm{O}$, Dimethoxyethane $/ \mathrm{H}_{2} \mathrm{O}$ ), different temperatures $\left(70,80,90,120^{\circ} \mathrm{C}\right)$, and different heating modes (microwave or oil bath). Unfortunately, all these reactions failed. Subsequently, we realized that the iodide replacement in the 5-position of the 2,4-diaminopyrimidine core in the Suzuki reaction might be easier than with a bromide. Hence, the iodides $\mathbf{5}$ or $\mathbf{6}$ were allowed to react with substituted phenylboronic acids $\mathbf{7}$ under Suzuki reaction conditions $\left(\mathrm{Pd}\left(\mathrm{PPh}_{3}\right)_{4}\right.$ as catalyst, $\mathrm{K}_{2} \mathrm{CO}_{3}$ as base, and $\mathrm{EtOH} /$ toluene $/ \mathrm{H}_{2} \mathrm{O}$ as solvent). However, the products $8 \mathbf{a}-\mathbf{o}$ or $9 \mathrm{a}-\mathbf{o}$ were only obtained in $52-78 \%$ yields. Moreover, the presence of an electron donating $\left(\mathrm{OCH}_{3}\right)$ or electron withdrawing $\left(\mathrm{F}, \mathrm{CF}_{3}, \mathrm{OCF}_{3}\right.$, ester, amide) group on the substituted phenylboronic acid 7 did not show high effect of the reaction yields. However, when the products $8 p-q$ or $9 p-q$ were synthesized by reacting 5 or 6 with 4- or 3-methoxycarbonylphenylboronic acids $7 p$ or $7 \mathbf{q}$ in $\mathrm{EtOH} /$ toluene $/ \mathrm{H}_{2} \mathrm{O}$, the transesterification product was detected in the ${ }^{1} \mathrm{H}-\mathrm{NMR}$ sprectrum. Hence, different Suzuki reaction conditions were chosen, in which $\mathbf{5}$ or $\mathbf{6}$ was reacted with $\mathbf{7 p}$ or $\mathbf{7 q}$ with $\mathrm{Pd}(\mathrm{dbpf}) \mathrm{Cl}_{2}$ as catalyst, $\mathrm{K}_{2} \mathrm{CO}_{3}$ as base and $\mathrm{CH}_{3} \mathrm{CN} / \mathrm{H}_{2} \mathrm{O}$ as solvent, to give $8 \mathbf{p}$-q or $\mathbf{9} \mathbf{p}$-q with 63-78\% yields. Subsequently, the compounds 8a-q or $9 \mathbf{a}-\mathbf{q}$ were deprotected in $0.25 \mathrm{M} \mathrm{H}_{2} \mathrm{SO}_{4}$ solution to generate the target compounds 10a-q or 11a-q in $68-95 \%$ yields.

Subsequently 2,4-diamino-5-aryl-6-substituted pyrimidine derivatives 16a-p were synthesized from 2,4-diamino-6-chloropyrimidine (2, Scheme 2) following our patented approach [18]. The treatment of substituted methanols 12a-d with sodium hydride in dry DMSO or THF generated the corresponding nucleophiles, which were reacted with 2 to give 2,4-diamino-6-substituted pyrimidines 13a-d in moderate to good yields (61-79\%) [14]. Subsequently, the 5-positions of 13a-d were iodinated with $\mathrm{N}$-iodosuccinimide in dry acetonitrile to produce the precursor 2,4-diamino-5-iodo-6-substituted pyrimidine derivatives 14a-d [15], which were used in subsequent Suzuki reactions to generate the target compounds 16a-p in good yields (70-92\%) [17].
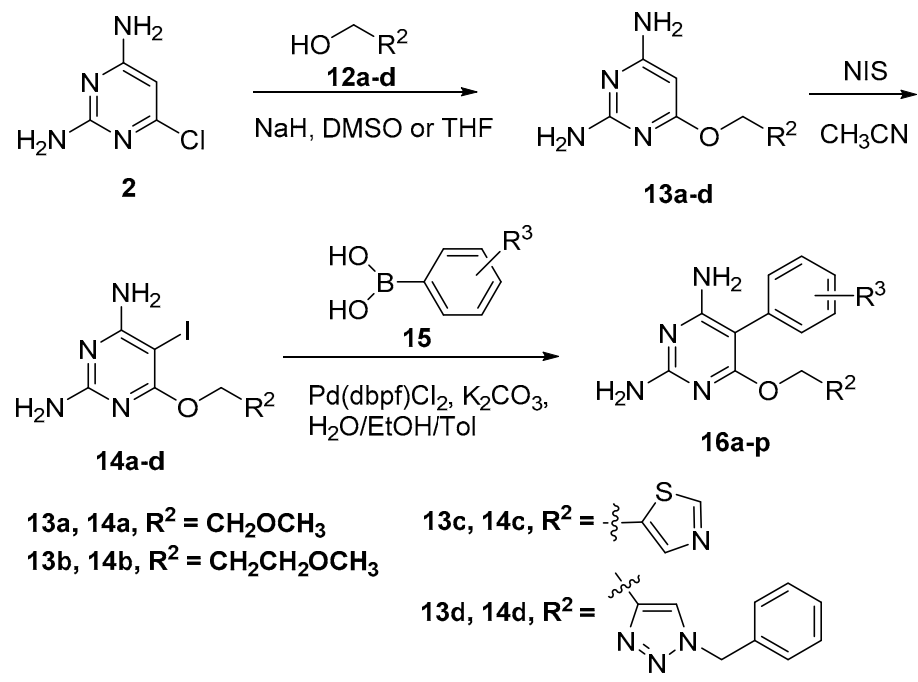

Scheme 2. Synthesis of 2,4-diamino-5-aryl-6-substituted pyrimidine derivatives 16a-p.

A series of reactions in which iodides 14a-d were used as staring material, was investigated as shown in Table 1. The iodides 14a-d were reacted with substituted phenylboronic acid $\mathbf{1 5}$ in the presence of $\mathrm{Pd}(\mathrm{dbpf}) \mathrm{Cl}_{2}$ and $\mathrm{K}_{2} \mathrm{CO}_{3}$ in $\mathrm{EtOH} /$ toluene $/ \mathrm{H}_{2} \mathrm{O}$ at $90^{\circ} \mathrm{C}$ for $24 \mathrm{~h}$ (Table 1, Entries 1-14) or in the presence of $\mathrm{Pd}(\mathrm{dbpf}) \mathrm{Cl}_{2}$ and $\mathrm{K}_{2} \mathrm{CO}_{3}$ in THF $/ \mathrm{H}_{2} \mathrm{O}$ at $70{ }^{\circ} \mathrm{C}$ for $20 \mathrm{~h}$ in a sealed tube (Table 1, Entries 15,16) to generate the desired compounds 16a-p with moderate to good 
yields (51-99\%). For the iodide 14a, treatment with different substituted phenylboronic acids 15 (Table 1, Entries 1-5) resulted in similar yields. For the iodide 14b, reaction with 15 bearing a 3-trifloromethoxy group resulted in higher yields (Table 1, Entry 7) than when 15 bore a 4-trifloromethoxy group (Table 1, Entry 6). For the iodide 14c, treatment with 15 substituted with a 3-trifloromethoxyanilinocarbonyl group or 3-(2,2,2-trifloroethoxymethyl) group (Table 1, Entries 10,12) resulted in higher yields than with 4-trifloromethoxy, 3-trifloromethoxy and 3,5-dimethyl-4-(N-methoxyaminosulfonyl) groups substituted on 15 (Table 1, Entries 8, 9, 11). Especially for the iodide 14d, reaction with $\mathbf{1 5}$ bearing a 4-trifloromethoxy or 3-trifloromethoxy group (Table 1, Entries 13, 14) resulted in much higher yields than with 15 bearing a 4-methoxycarbonyl or 3-methoxycarbonyl group (Table 1, Entries 15,16). The presumption is that the ester group on this Suzuki reaction could be affected by transesterification in the solvent $\left(\mathrm{EtOH} /\right.$ toluene $\left./ \mathrm{H}_{2} \mathrm{O}\right)$, which could be detected in ${ }^{1} \mathrm{H}-\mathrm{NMR}$. Thus, in these reactions, we chose THF $/ \mathrm{H}_{2} \mathrm{O}$ as the solvent to avoid the transesterification.

Table 1. Synthesis of 2,4-diamino-5-aryl-6-substituted pyrimidine derivatives 16a-p via Suzuki reactions.

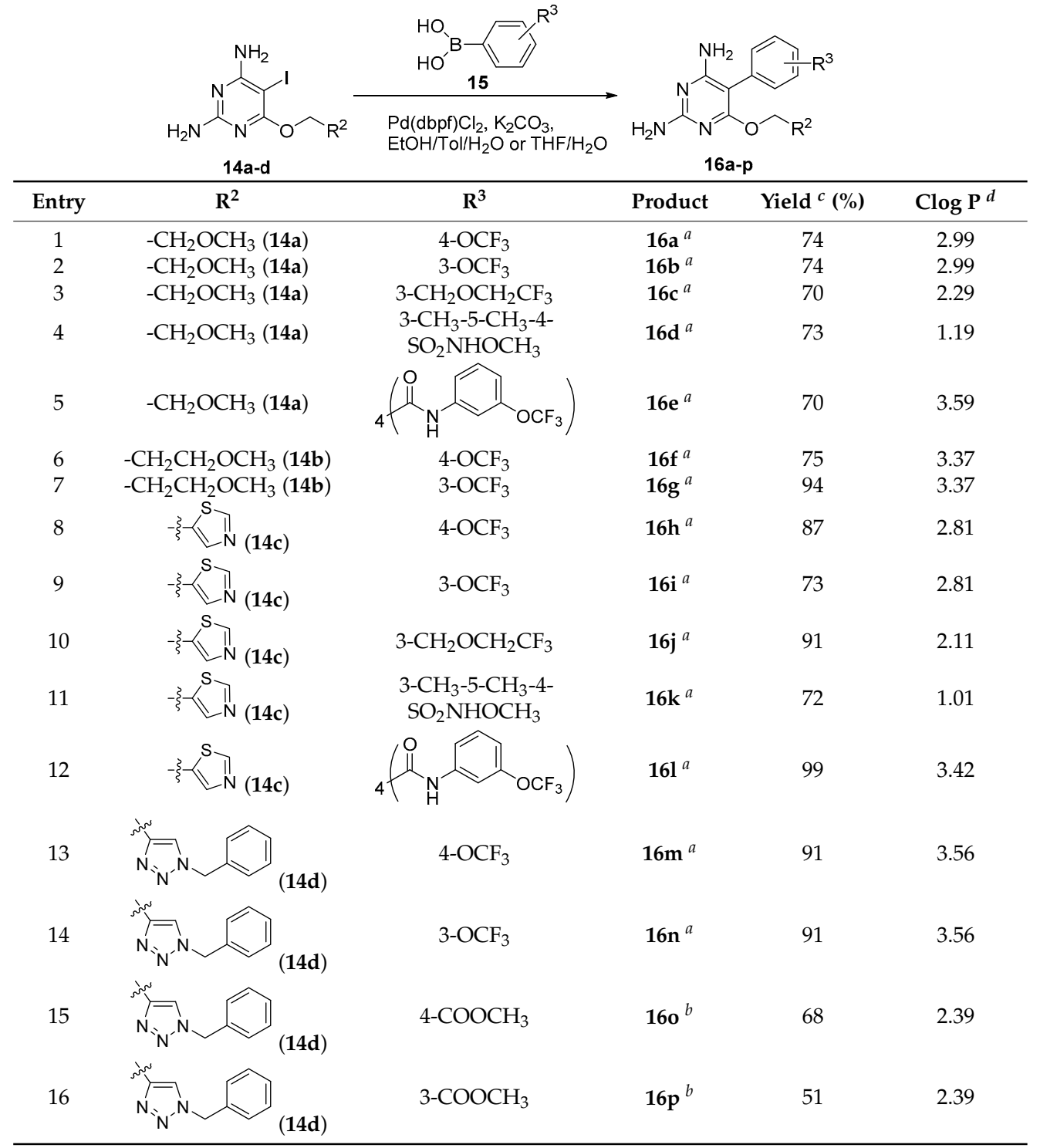

Reaction Conditions: ${ }^{a} \mathrm{Pd}(\mathrm{dbpf}) \mathrm{Cl}_{2}(0.02 \mathrm{mmol})$ and $\mathrm{K}_{2} \mathrm{CO}_{3}$ in $\mathrm{EtOH} /$ toluene $/ \mathrm{H}_{2} \mathrm{O}$ at $90^{\circ} \mathrm{C}$ for $24 \mathrm{~h} ;{ }^{b} \mathrm{Pd}(\mathrm{dbpf}) \mathrm{Cl}_{2}$ $(0.02 \mathrm{mmol})$ and $\mathrm{K}_{2} \mathrm{CO}_{3}$ in THF $/ \mathrm{H}_{2} \mathrm{O}$ at $70{ }^{\circ} \mathrm{C}$ for $20 \mathrm{~h}$ in sealed tube; ${ }^{c}$ Isolated yields; ${ }^{d}$ Calculated using ChemBioDraw (PerkinElmer, Waltham, MA, USA) 12.0. 


\subsection{Determination of In Vitro Anti-Tubercular Activity}

Based on the different $\mathrm{R}^{2}$ substituents on the 2,4-diamino-5-aryl-6-substituted pyrimidine derivatives, the compounds can be divided into four types: (1) the $R^{2}$ substituents bearing hydroxy groups (10a-q, 11a-q); (2) the $R^{2}$ substituents bearing alkoxy groups (16a-g); (3) the $R^{2}$ substituents bearing thiazole groups (16h-1); (4) the $\mathrm{R}^{2}$ substituents bearing phenyl substituted triazole groups (16m-p). Only compounds containing the thiazole group act as $M t b$ inhibitors. Among this group of compounds, five compounds (16h-1) showed potentially useful inhibitory effects, with $\mathbf{1 6 1}$ showing the lowest MIC $(6.25 \mu \mathrm{g} / \mathrm{mL}$ or $12.45 \mu \mathrm{M})$ and MBC $(12.5 \mu \mathrm{g} / \mathrm{mL})$ (Table 2). In order to see the selectivity of 161 against mammalian cells, the MTT assay was performed on vero cells, and the $\mathrm{IC}_{50}$ on cells viability was found to be around $50.22 \mu \mathrm{M}$. The selectivity ratio of $\mathbf{1 6 1}$ on H37Ra vs vero cells is around 4-fold.

Table 2. Minimum inhibitory concentrations (MIC) and minimum bactericidal concentrations (MBC) of compounds 16h-1 showing anti-tubercular activity.

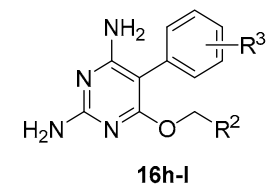

\begin{tabular}{|c|c|c|c|}
\hline Compound & $\mathbf{R}^{2}$ & $\mathbf{R}^{3}$ & $\mathrm{MIC} / \mathrm{MBC}(\mu \mathrm{g} / \mathrm{mL})$ \\
\hline $16 \mathrm{~h}$ & & $4-\mathrm{OCF}_{3}$ & $25 / 25$ \\
\hline $16 i$ & & $3-\mathrm{OCF}_{3}$ & $50 / 50$ \\
\hline $16 j$ & & $3-\mathrm{CH}_{2} \mathrm{OCH}_{2} \mathrm{CF}_{3}$ & $25 / 25$ \\
\hline $16 k$ & & $\begin{array}{c}3-\mathrm{CH}_{3}-5-\mathrm{CH}_{3}-4- \\
\mathrm{SO}_{2} \mathrm{NHOCH}_{3}\end{array}$ & $100 / 100$ \\
\hline 161 & & & $6.25 / 12.5$ \\
\hline Rifampicin & & & $0.313 / 0.313$ \\
\hline
\end{tabular}

\subsection{Molecular Docking and Simulation}

Through the structural analysis of the compounds, the Clog P of El-7a was noticed to be -0.17 , which showed the compound El-7a to be very hydrophilic, and led us to assume it would not be able to cross the $M t b$ cell wall. This assumption was indirectly confirmed by the observation that the hydrophilic compounds 10a-q and 11a-q (analogs of El-7a, with Clog P around -1 to 2), could not inhibit the growth of $M t b$. Based on the above assumption, more hydrophobic compounds were analyzed by using molecular docking and molecular dynamic simulations, and based on the size of the substituents on the 6-position of 2,4-diaminopyrimidine, they were divided into three groups, which are large side chain groups (compounds 16m-p), medium side chain groups (compounds 16h-1) and small side chain groups (compounds 16a-g). With molecular docking, it was noticed that the large side chain group, which contains the 1-benzyl-1H-1,2,3-triazole-4-methoxy group on the 6-position, cannot fit into the GOL binding site (Figure 3a), and this could be the reason why this group of compounds did not show any inhibition effects on $M t b$. Although the small side chain group derivatives (compounds 16a-g), which contain the methoxyethoxy or methoxypropoxy group on the 6-positions, can fit into the GOL binding site (Figure $3 b, c)$, they cannot form strong interactions or fully fill the GOL binding site. 


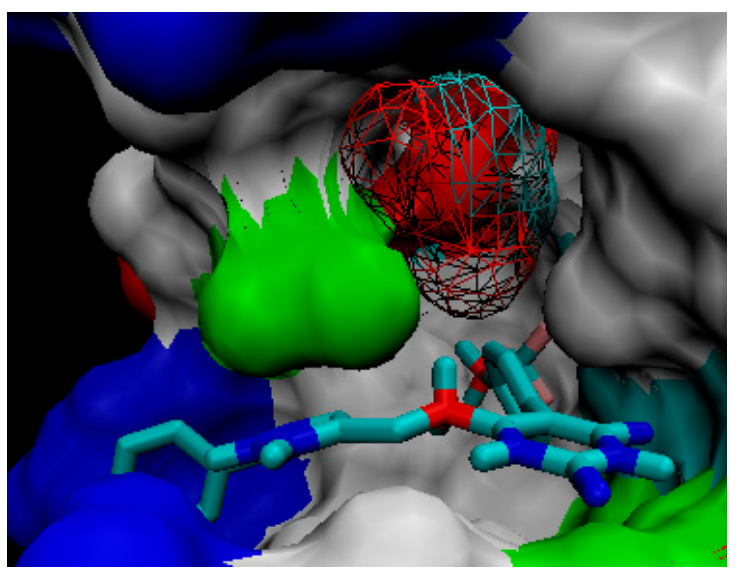

(a)

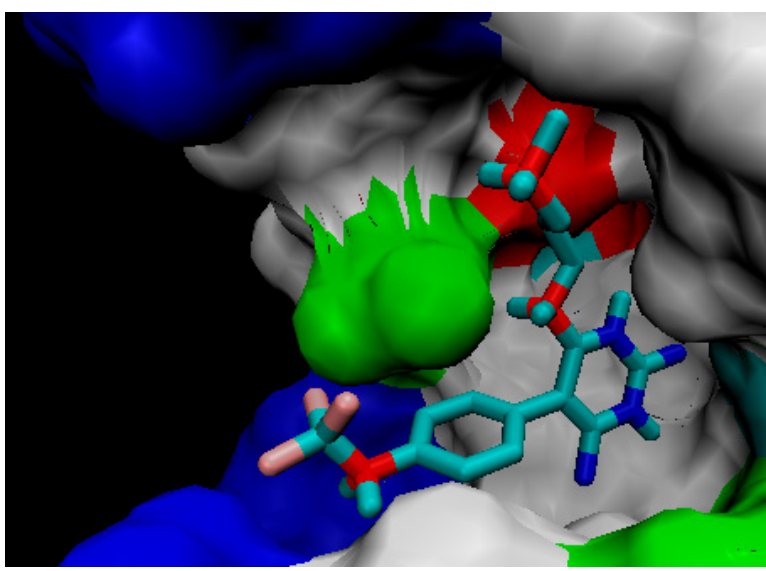

(b)

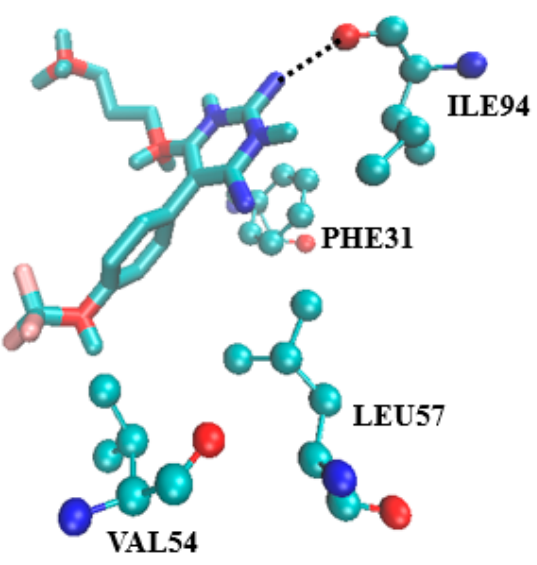

(c)

Figure 3. (a) Compound 16m with large side chain group and the binding sites of glycerol (GOL) in $m t$-DHFR, in which compound $\mathbf{1 6 m}$ is represented as a sticks model, GOL as a dotted line model and protein as a molecular surface; $(\mathbf{b}, \mathbf{c})$ the small side chain group of compound $\mathbf{1 6 f}$ can fit into the GOL binding site, in which the molecule is represented as sticks and protein as a molecular surface.

The molecular docking showed that the medium side chain group (compounds 16h-1), which contain a (thiazol-5-yl)methoxy on the 6-position, can fit into the GOL binding site properly, and a molecular dynamics simulation was performed to understand the binding of compound 161 to $m t$-DHFR. During 100 ns simulations, 161 was stable in the binding site, and the side chain of compounds 16h-1 occupied the GOL binding site along the full simulation (Figure 2). The free energy calculation showed that the binding free energy was $-3.47 \mathrm{Kcal} / \mathrm{mol}$ (Table 3), which indicated that 161 can bind with $m t$-DHFR tightly. The free energy contributions of each residue was calculated, and contributions greater than $-0.5 \mathrm{Kcal} / \mathrm{mol}$ were recorded (Ile20, Arg23, Phe31, Leu50, Pro51 and Val54) (Figure 4 Left). Most of these residues showed a strong VDW interaction, except Phe31 and Arg23 which formed a H-bond with 161. Arg23 could also form strong interactions with the trifluoromethoxy group (Figure 4 Right).

Table 3. Binding free energies (Kcal/mol) of compound 161 in $m t$-DHFR.

\begin{tabular}{cccccccccc}
\hline Simulations & $\boldsymbol{\Delta} \mathrm{E}_{\mathbf{v d w}}$ & $\boldsymbol{\Delta} \mathrm{E}_{\text {ele }}$ & $\Delta \mathrm{G}_{\mathbf{p b}}$ & $\Delta \mathbf{G}_{\mathbf{n p}}$ & $\Delta \mathrm{G}_{\text {gas }}$ & $\Delta \mathbf{G}_{\text {solv }}$ & $\Delta \mathbf{G}_{\text {mmpbsa }}$ & $\mathbf{T} \boldsymbol{\Delta S}$ & $\Delta \mathbf{G}_{\text {binding }}$ \\
\hline \multirow{2}{*}{$\mathbf{1 6 1}$} & -42.37 & -18.16 & $37.55 \pm$ & -5.62 & -60.53 & $31.93 \pm$ & -28.60 & -25.13 & -3.47 \\
& \pm 0.14 & \pm 0.24 & 0.33 & \pm 0.01 & \pm 0.30 & 0.32 & \pm 0.18 & \pm 0.73 & \\
\hline
\end{tabular}



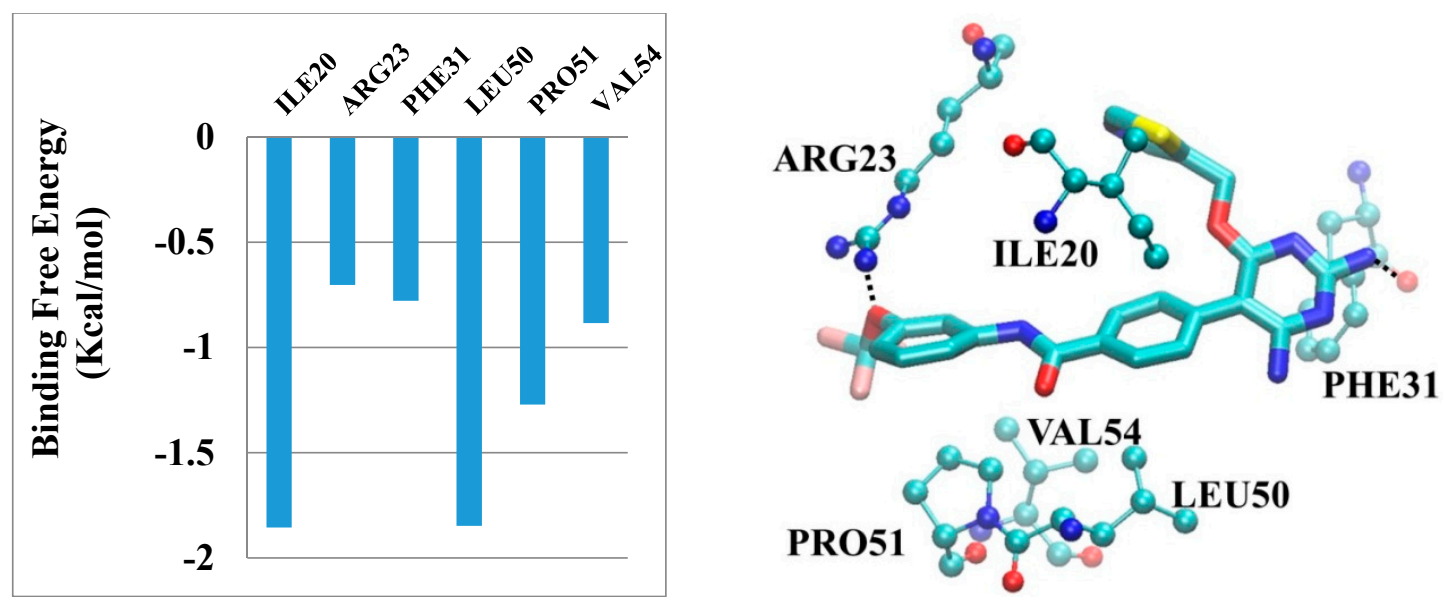

Figure 4. Left: The residues whose binding free energy contributions are greater than $-0.5 \mathrm{Kcal} / \mathrm{mol}$;

Right: The interactions between key residues and compound $\mathbf{1 6 1 .}$

Therefore, through the molecular docking and molecular dynamic simulations, we believe that the compounds containing the (thiazol-5-yl)methoxy side chain (medium size group), can fully occupy the GOL binding site, and have reasonable properties. Therefore, such compounds could be used as the lead compounds for further anti-TB drug discovery studies.

\section{Materials and Methods}

\subsection{General Information}

All reagents and solvents were purchased from the suppliers and used directly in the experiments. THF was dried by distillation ver sodium benzophenone. TLC was carried out using silica gel 60 pre-coated aluminium plates ( $0.20 \mathrm{~mm}$ thickness) from Macherey-Nagel (Darmstadt, Germany) with visualisation by UV light $(254 \mathrm{~nm})$. Flash chromatography was performed on silica gel (particle size 40-63 $\mu \mathrm{m}$ ). IR spectra were recorded on a Tensor 27 spectrometer (Bruker, Ettlingen, Germany) using KBr discs. ${ }^{1} \mathrm{H}-\mathrm{NMR}$ spectra were obtained from an AVANCE III 400 spectrometer (Bruker, Fällanden Switzerland). The chemical shifts, given as $\delta$ values, were quoted in parts per million (ppm); ${ }^{1} \mathrm{H}-\mathrm{NMR}$ chemical shifts were measured relative to internal tetramethylsilane; Apparent coupling constants (absolute values), J, were measured in Hertz and multiplicities quoted as singlet (s), doublet (d), triplet $(\mathrm{t})$, quartet $(\mathrm{q})$ or combinations thereof as appropriate. Mass spectra were obtained from an 6545 Accurate-Mass Q-TOF LC/MS (Agilent Technologies, Santa Clara, CA, USA). Melting points were determined using a WRS-1B melting point measurement instrument (Shanghai, China) and were uncorrected.

\subsection{ChemistryIt}

2,4-Diamino-6-chloropyrimidine (2). 2,4-Diamino-6-hydroxypyrimidine (1) (1.00 g, $7.93 \mathrm{mmol})$ was added to $\mathrm{POCl}_{3}(9 \mathrm{~mL})$, and stirred at $97^{\circ} \mathrm{C}$ for $17 \mathrm{~h}$. The reaction solution was added to ice water slowly, and then stirred at $90{ }^{\circ} \mathrm{C}$ for $1 \mathrm{~h}$. The $\mathrm{pH}$ of this solution was adjusted to 8 with $\mathrm{NaOH}$, and then it was extracted with EtOAC $(150 \mathrm{~mL} \times 3)$. The combined organic layers were dried with $\mathrm{Na}_{2} \mathrm{SO}_{4}$, filtered and concentrated to give white solid $0.97 \mathrm{~g}$, yield $85 \%$. m.p. $200.2-200.4{ }^{\circ} \mathrm{C}$; IR $(\mathrm{KBr}): v_{\max } / \mathrm{cm}^{-1} 3449(\mathrm{NH}), 3327(\mathrm{NH}), 1642(\mathrm{C}=\mathrm{N}), 1581(\mathrm{C}=\mathrm{C}), 1551(\mathrm{C}=\mathrm{C}), 795(\mathrm{C}-\mathrm{Cl}) ;{ }^{1} \mathrm{H}-\mathrm{NMR}$ $\left(\mathrm{DMSO}_{-} d_{6}\right) \delta 6.57\left(\mathrm{~s}, 2 \mathrm{H}, \mathrm{NH}_{2}\right), 6.31\left(\mathrm{~s}, 2 \mathrm{H}, \mathrm{NH}_{2}\right), 5.69(\mathrm{~s}, 1 \mathrm{H}, \mathrm{Ar}-H)$; ES-MS $145.0(\mathrm{M}+\mathrm{H})^{+}$; HRMS Calcd. for $\mathrm{C}_{16} \mathrm{H}_{20} \mathrm{ClN}_{4} \mathrm{O}_{3}{ }^{+}$145.0281, found 145.0276. 
General Procedure for the Synthesis of Compounds 3 and 4

Under argon, to a solution of (S)-2,3-isopropylideneglycerol or $(R)$-2,3-isopropylideneglycerol $0.50 \mathrm{~mL}(4.0 \mathrm{mmol})$ in dry DMSO $(5 \mathrm{~mL})$ was added $\mathrm{NaH} 0.20 \mathrm{~g}(60 \%, 5.0 \mathrm{mmol})$ and stirred at room temperature for $1 \mathrm{~h}$. 2,4-Diamino-6-chloropyrimidine (2, $0.29 \mathrm{~g}, 2.0 \mathrm{mmol})$ was added and stirred at $90{ }^{\circ} \mathrm{C}$ for $8 \mathrm{~h}$. The reaction solution was quenched with sat $\mathrm{NH}_{4} \mathrm{Cl}(20 \mathrm{~mL})$ and extracted with EtOAc $(30 \mathrm{~mL} \times 3)$, and the combined organic layers dried with $\mathrm{Na}_{2} \mathrm{SO}_{4}$, filtered and concentrated. The residue was purified by column chromatography on silica gel using $\mathrm{CH}_{2} \mathrm{Cl}_{2} / \mathrm{CH}_{3} \mathrm{OH}(50: 1, v / v)$ as the eluting solvent to give compounds 3 or 4 .

(R)-2,4-Diamino-6-[4-(2,2-dimethyl-1,3-dioxolane)methoxy]pyrimidine (3). White solid $0.37 \mathrm{~g}$, yield 77\%; m.p. 89.7-91.0 ${ }^{\circ} \mathrm{C}$; IR: $v_{\max } / \mathrm{cm}^{-1} 3474(\mathrm{NH}), 3452(\mathrm{NH}), 3373(\mathrm{NH}), 3359(\mathrm{NH}), 1668(\mathrm{C}=\mathrm{N})$, 1627 (C=N), 1593 (C=C), 1200 (C-O-C), 1157 (C-O-C), 1082 (C-O-C), 1052 (C-O-C); $\left.{ }^{1} \mathrm{H}-\mathrm{NMR}_{(\mathrm{CDCl}}\right)$ $\delta 5.28(\mathrm{~s}, 1 \mathrm{H}, \mathrm{Ar}-\mathrm{H}), 4.71\left(\mathrm{~s}, 2 \mathrm{H}, \mathrm{NH}_{2}\right), 4.53\left(\mathrm{~s}, 2 \mathrm{H}, \mathrm{NH}_{2}\right), 4.41(\mathrm{q}, J=6.0,1 \mathrm{H}, \mathrm{CH}), 4.25(\mathrm{~d}, J=5.6,2 \mathrm{H}$, $\left.\mathrm{OCH}_{2}\right), 4.11\left(\mathrm{dd}, J_{1}=8.2, J_{2}=6.4,1 \mathrm{H}, \mathrm{OCH}_{2}\right), 3.81\left(\mathrm{dd}, J_{1}=8.4, J_{2}=6.4,1 \mathrm{H}, \mathrm{OCH}_{2}\right), 1.44\left(\mathrm{~s}, 3 \mathrm{H}, \mathrm{CH}_{3}\right)$, $1.38\left(\mathrm{~s}, 3 \mathrm{H}, \mathrm{CH}_{3}\right)$; ES-MS 241.1 (M + H) ${ }^{+}$; HRMS Calcd. for $\mathrm{C}_{16} \mathrm{H}_{20} \mathrm{ClN}_{4} \mathrm{O}_{3}{ }^{+}$241.1301, found 241.1303.

(S)-2,4-Diamino-6-[4-(2,2-dimethyl-1,3-dioxolane)methoxy]pyrimidine (4). White solid 10.32 g, yield 77\%; m.p. $87.6-88.9{ }^{\circ} \mathrm{C}$; IR: $v_{\max } / \mathrm{cm}^{-1} 3474(\mathrm{NH}), 3451(\mathrm{NH}), 3373(\mathrm{NH}), 3358(\mathrm{NH}), 1670(\mathrm{C}=\mathrm{N})$, 1626 (C=N), 1592 (C=C), 1199 (C-O-C), 1159 (C-O-C), 1085 (C-O-C), 1054 (C-O-C); ${ }^{1} \mathrm{H}-\mathrm{NMR}\left(\mathrm{CDCl}_{3}\right)$ $\delta 5.29(\mathrm{~s}, 1 \mathrm{H}, \mathrm{Ar}-\mathrm{H}), 4.67\left(\mathrm{~s}, 2 \mathrm{H}, \mathrm{NH} \mathrm{H}_{2}\right), 4.50\left(\mathrm{~s}, 2 \mathrm{H}, \mathrm{NH}_{2}\right), 4.41(\mathrm{q}, J=6.0,1 \mathrm{H}, \mathrm{CH}), 4.29-4.22(\mathrm{~m}, 2 \mathrm{H}$, $\left.\mathrm{OCH}_{2}\right), 4.11\left(\mathrm{dd}, J_{1}=8.8, J_{2}=6.4,1 \mathrm{H}, \mathrm{OCH}_{2}\right), 3.82\left(\mathrm{dd}, J_{1}=8.4, J_{2}=6.0,1 \mathrm{H}, \mathrm{OCH}_{2}\right), 1.45\left(\mathrm{~s}, 3 \mathrm{H}, \mathrm{CH}_{3}\right)$, $1.38\left(\mathrm{~s}, 3 \mathrm{H}, \mathrm{CH}_{3}\right)$; ES-MS 241.1 (M+ H) ${ }^{+}$; HRMS Calcd. for $\mathrm{C}_{16} \mathrm{H}_{20} \mathrm{ClN}_{4} \mathrm{O}_{3}{ }^{+}$241.1301, found 241.1306.

General Procedure for the Synthesis of Compounds 5 and 6

Under argon, to a solution of 3 or $4(7.18 \mathrm{~g}, 29.88 \mathrm{mmol})$ in dry $\mathrm{CH}_{3} \mathrm{CN}(100 \mathrm{~mL})$ was added $\mathrm{N}$-iodosuccinimide $10.09 \mathrm{~g}(44.83 \mathrm{mmol})$ and stirred at room temperature for $1 \mathrm{~h}$. The reaction solution was diluted with EtOAc $(500 \mathrm{~mL})$, washed by $5 \% \mathrm{NaHSO}_{3}(500 \mathrm{~mL}), \mathrm{NaHCO}_{3}(500 \mathrm{~mL})$ and $\mathrm{H}_{2} \mathrm{O}(500 \mathrm{~mL})$, and dried with $\mathrm{Na}_{2} \mathrm{SO}_{4}$, filtered and concentrated. The residue was purified by column chromatography on silica gel using $\mathrm{CH}_{2} \mathrm{Cl}_{2} / \mathrm{CH}_{3} \mathrm{OH}(100: 1, v / v)$ as the eluting solvent to give compounds 5 or 6 .

(R)-2,4-Diamino-5-iodo-6-[4-(2,2-dimethyl-1,3-dioxolane)methoxy]pyrimidine (5). White solid $13.42 \mathrm{~g}$, yield 98\%; m.p. 135.5-136.8 ${ }^{\circ} \mathrm{C}$; IR: $v_{\max } / \mathrm{cm}^{-1} 3464(\mathrm{NH}), 3402(\mathrm{NH}), 3356(\mathrm{NH}), 1649(\mathrm{C}=\mathrm{N}), 1627(\mathrm{C}=\mathrm{N})$, 1550 (C=C), 1200 (C-O-C), 1157 (C-O-C), 1082 (C-O-C), 1052 (C-O-C), 476 (C-I); ${ }^{1} \mathrm{H}-\mathrm{NMR}\left(\mathrm{CDCl}_{3}\right) \delta$ $5.06\left(\mathrm{~s}, 2 \mathrm{H}, \mathrm{NH}_{2}\right), 4.69\left(\mathrm{~s}, 2 \mathrm{H}, \mathrm{NH}_{2}\right), 4.44-4.37\left(\mathrm{~m}, 2 \mathrm{H}, \mathrm{OCH}_{2}\right.$ and $\left.\mathrm{CH}\right), 4.30-4.25\left(\mathrm{~m}, 1 \mathrm{H}, \mathrm{OCH}_{2}\right), 4.12$ $\left(\mathrm{dd}, J_{1}=8.4, J_{2}=6.4,1 \mathrm{H}, \mathrm{OCH}_{2}\right), 3.96\left(\mathrm{dd}, J_{1}=8.4, J_{2}=6.0,1 \mathrm{H}, \mathrm{OCH}_{2}\right), 1.47\left(\mathrm{~s}, 3 \mathrm{H}, \mathrm{CH}_{3}\right), 1.39(\mathrm{~s}, 3 \mathrm{H}$, $\left.\mathrm{CH}_{3}\right)$; ES-MS $367.0(\mathrm{M}+\mathrm{H})^{+}$; HRMS Calcd. for $\mathrm{C}_{16} \mathrm{H}_{20} \mathrm{ClN}_{4} \mathrm{O}_{3}{ }^{+} 367.0267$, found 367.0265.

(S)-2,4-Diamino-5-iodo-6-[4-(2,2-dimethyl-1,3-dioxolane)methoxy]pyrimidine (6). White solid $10.72 \mathrm{~g}$, yield 96\%; m.p. 135.4-136.7 ${ }^{\circ} \mathrm{C}$; IR: $v_{\max } / \mathrm{cm}^{-1} 3465(\mathrm{NH}), 3401(\mathrm{NH}), 3360(\mathrm{NH}), 3310(\mathrm{NH}), 1650(\mathrm{C}=\mathrm{N})$, 1623 (C=N), 1549 (C=C), 1200 (C-O-C), 1157 (C-O-C), 1133 (C-O-C), 1096 (C-O-C), 1071 (C-O-C), 1045 (C-O-C), $478(\mathrm{C}-\mathrm{I}) ;{ }^{1} \mathrm{H}-\mathrm{NMR}\left(\mathrm{CDCl}_{3}\right) \delta 5.05\left(\mathrm{~s}, 2 \mathrm{H}, \mathrm{NH}_{2}\right), 4.68\left(\mathrm{~s}, 2 \mathrm{H}, \mathrm{NH}_{2}\right), 4.37-4.34\left(\mathrm{~m}, 2 \mathrm{H}, \mathrm{OCH}_{2}\right.$ and $\mathrm{CH}), 4.30-4.25\left(\mathrm{~m}, 1 \mathrm{H}, \mathrm{CH}_{2}\right), 4.12\left(\mathrm{dd}, J_{1}=8.4, J_{2}=6.4,1 \mathrm{H}, \mathrm{OCH}_{2}\right), 3.96\left(\mathrm{dd}, J_{1}=8.4, J_{2}=6.0,1 \mathrm{H}\right.$, $\left.\mathrm{OCH}_{2}\right), 1.47\left(\mathrm{~s}, 3 \mathrm{H}, \mathrm{CH}_{3}\right), 1.39\left(\mathrm{~s}, 3 \mathrm{H}, \mathrm{CH}_{3}\right)$; ES-MS $367.0(\mathrm{M}+\mathrm{H})^{+}$; HRMS Calcd. for $\mathrm{C}_{16} \mathrm{H}_{20} \mathrm{ClN}_{4} \mathrm{O}_{3}{ }^{+}$ 367.0267 , found 367.0268 .

General Procedure for the Synthesis of Compounds 8a-q and $\mathbf{9 a - q}$

(A) Under argon, to a mixed solution of $\mathrm{EtOH} /$ toluene $(1: 2,60 \mathrm{~mL})$ was added compound 5 or 6 (2.73 mmol), substituted phenylboronic acid (7) (3.00-5.46 mmol), $\mathrm{Pd}\left(\mathrm{PPh}_{3}\right)_{4}\left(1.38 \times 10^{-4} \mathrm{mmol}\right)$ and $\mathrm{K}_{2} \mathrm{CO}_{3}(3 \mathrm{M}, 3.00-5.50 \mathrm{~mL})$ consecutively and then stirred at $90{ }^{\circ} \mathrm{C}$ for $1-2 \mathrm{~h}$. The reaction solution was extracted with EtOAc $(30 \mathrm{~mL} \times 3)$, and the combined organic layers were washed by $\mathrm{H}_{2} \mathrm{O}$ and 
dried with $\mathrm{Na}_{2} \mathrm{SO}_{4}$, filtered and concentrated. The residue was purified by column chromatography on silica gel using $\mathrm{CH}_{2} \mathrm{Cl}_{2} / \mathrm{CH}_{3} \mathrm{OH}(80: 1, v / v)$ as the eluting solvent to the desired compounds.

(B) In a pressure tube, to a mixed solution of $\mathrm{CH}_{3} \mathrm{CN} / \mathrm{H}_{2} \mathrm{O}(1: 1,40 \mathrm{~mL})$ was added compound 5 or 6 (2.73 mmol), substituted phenylboronic acid $7 \mathbf{p}$ or $7 \mathbf{q}(4.10 \mathrm{mmol}), \mathrm{Pd}(\mathrm{dbpf}) \mathrm{Cl}_{2}\left(2.73 \times 10^{-4} \mathrm{mmol}\right)$ and $\mathrm{K}_{2} \mathrm{CO}_{3}(4.10 \mathrm{mmol})$ consecutively and then stirred at $60{ }^{\circ} \mathrm{C}$ for $8 \mathrm{~h}$. The reaction solution was extracted with EtOAc $(30 \mathrm{~mL} \times 3)$, and the combined organic layers were washed by $\mathrm{H}_{2} \mathrm{O}$ and dried with $\mathrm{Na}_{2} \mathrm{SO}_{4}$, filtered and concentrated. The residue was purified by column chromatography on silica gel using $\mathrm{CH}_{2} \mathrm{Cl}_{2} / \mathrm{CH}_{3} \mathrm{OH}(60: 1, v / v)$ as the eluting solvent to the desired compounds.

(R)-2,4-Diamino-5-(4-chlorophenyl)-6-[4-(2,2-dimethyl-1,3-dioxolane)methoxy]pyrimidine (8a). Method A. White solid 0.64 g, yield 67\%; m.p. 171.2-172.8 ${ }^{\circ} \mathrm{C}$; IR: $v_{\max } / \mathrm{cm}^{-1} 3475(\mathrm{NH}), 3454(\mathrm{NH}), 3305(\mathrm{NH})$, $3315(\mathrm{NH}), 1649(\mathrm{C}=\mathrm{N}), 1620(\mathrm{C}=\mathrm{N}), 1592(\mathrm{C}=\mathrm{C}), 1549(\mathrm{C}=\mathrm{C}), 1479(\mathrm{C}=\mathrm{C}), 1160(\mathrm{C}-\mathrm{O}-\mathrm{C}), 1144(\mathrm{C}-\mathrm{O}-\mathrm{C})$, $1089(\mathrm{C}-\mathrm{O}-\mathrm{C}), 794(\mathrm{C}-\mathrm{Cl}){ }^{1} \mathrm{H}-\mathrm{NMR}\left(\mathrm{CDCl}_{3}\right) \delta 7.36(\mathrm{~d}, J=8.4,2 \mathrm{H}, \mathrm{Ar}-\mathrm{H}), 7.25(\mathrm{~d}, J=8.0,2 \mathrm{H}, \mathrm{Ar}-\mathrm{H}), 4.69$ $\left(\mathrm{s}, 2 \mathrm{H}, \mathrm{NH}_{2}\right), 4.52\left(\mathrm{~s}, 2 \mathrm{H}, \mathrm{NH}_{2}\right), 4.36\left(\mathrm{dd}, J_{1}=10.8, J_{2}=4.4,1 \mathrm{H}, \mathrm{OCH}_{2}\right), 4.31-4.26(\mathrm{~m}, 1 \mathrm{H}, \mathrm{CH}), 4.20$ $\left(\mathrm{dd}, J_{1}=10.8, J_{2}=5.6,1 \mathrm{H}, \mathrm{OCH}_{2}\right), 3.97\left(\mathrm{dd}, J_{1}=8.4, J_{2}=6.4,1 \mathrm{H}, \mathrm{OCH}_{2}\right), 3.72\left(\mathrm{dd}, J_{1}=8.4, J_{2}=6.0,1 \mathrm{H}\right.$, $\left.\mathrm{OCH}_{2}\right), 1.32\left(\mathrm{~s}, 3 \mathrm{H}, \mathrm{CH}_{3}\right), 1.28\left(\mathrm{~s}, 3 \mathrm{H}, \mathrm{CH}_{3}\right)$; ES-MS $351.1(\mathrm{M}+\mathrm{H})^{+}$; HRMS Calcd. for $\mathrm{C}_{16} \mathrm{H}_{20} \mathrm{ClN}_{4} \mathrm{O}_{3}{ }^{+}$ 351.1224, found 351.1222 .

(R)-2,4-Diamino-5-(4-fluorophenyl)-6-[4-(2,2-dimethyl-1,3-dioxolane)methoxy]pyrimidine (8b). Method A. White solid $0.61 \mathrm{~g}$, yield 74\%; m.p. $162.3-163.0^{\circ} \mathrm{C}$; IR: $v_{\max } / \mathrm{cm}^{-1} 3526(\mathrm{NH}), 3483(\mathrm{NH}), 3369(\mathrm{NH})$, $3312(\mathrm{NH}), 1647(\mathrm{C}=\mathrm{N}), 1626(\mathrm{C}=\mathrm{N}), 1593(\mathrm{C}=\mathrm{C}), 1558(\mathrm{C}=\mathrm{C}), 1510(\mathrm{C}=\mathrm{C}), 1485(\mathrm{C}=\mathrm{C}), 1383(\mathrm{C}-\mathrm{F}), 1160$ (C-O-C), 1128 (C-O-C), 1105 (C-O-C), 1090 (C-O-C); ${ }^{1} \mathrm{H}-\mathrm{NMR}\left(\mathrm{CDCl}_{3}\right) \delta 7.27$ (dd, $J_{1}=8.8, J_{2}=5.6$, $2 \mathrm{H}, \mathrm{Ar}-H), 7.08(\mathrm{t}, J=8.8,2 \mathrm{H}, \mathrm{Ar}-H), 4.69\left(\mathrm{~s}, 2 \mathrm{H}, \mathrm{NH}_{2}\right), 4.52\left(\mathrm{~s}, 2 \mathrm{H}, \mathrm{NH}_{2}\right), 4.36\left(\mathrm{dd}, J_{1}=10.8, J_{2}=4.0\right.$, $\left.1 \mathrm{H}, \mathrm{OCH}_{2}\right), 4.31-4.26(\mathrm{~m}, 1 \mathrm{H}, \mathrm{CH}), 4.20\left(\mathrm{dd}, J_{1}=10.8, J_{2}=5.6,1 \mathrm{H}, \mathrm{OCH}_{2}\right), 3.96\left(\mathrm{dd}, J_{1}=8.4, J_{2}=6.4\right.$, $\left.1 \mathrm{H}, \mathrm{OCH}_{2}\right), 3.71\left(\mathrm{dd}, J_{1}=8.4, J_{2}=6.0,1 \mathrm{H}, \mathrm{OCH}_{2}\right), 1.32\left(\mathrm{~s}, 3 \mathrm{H}, \mathrm{CH}_{3}\right), 1.27\left(\mathrm{~s}, 3 \mathrm{H}, \mathrm{CH}_{3}\right)$; ES-MS 335.2 $(\mathrm{M}+\mathrm{H})^{+}$; HRMS Calcd. for $\mathrm{C}_{16} \mathrm{H}_{20} \mathrm{FN}_{4} \mathrm{O}_{3}{ }^{+} 335.1519$, found 335.1515 .

(R)-2,4-Diamino-5-(3,4-dichlorophenyl)-6-[4-(2,2-dimethyl-1,3-dioxolane)methoxy]pyrimidine (8c). Method A. White solid 0.55 g, yield 52\%; m.p. 164.1-165.9 ${ }^{\circ} \mathrm{C}$; IR: $v_{\max } / \mathrm{cm}^{-1} 3487(\mathrm{NH}), 3378(\mathrm{NH}), 3316(\mathrm{NH})$, $1651(\mathrm{C}=\mathrm{N}), 1624(\mathrm{C}=\mathrm{N}), 1600(\mathrm{C}=\mathrm{C}), 1556(\mathrm{C}=\mathrm{C}), 1489(\mathrm{C}=\mathrm{C}), 1154$ (C-O-C), 1134 (C-O-C), 1191 (C-O-C), 1073 (C-O-C), $795(\mathrm{C}-\mathrm{Cl}) ;{ }^{1} \mathrm{H}-\mathrm{NMR}\left(\mathrm{CDCl}_{3}\right) \delta 7.45(\mathrm{~d}, J=8.0,1 \mathrm{H}, \mathrm{Ar}-\mathrm{H}), 7.44(\mathrm{~d}, J=2.0,1 \mathrm{H}, \mathrm{Ar}-H)$, $7.17\left(\mathrm{dd}, J_{1}=8.0, J_{2}=2.0,1 \mathrm{H}, \mathrm{Ar}-\mathrm{H}\right), 4.73\left(\mathrm{~s}, 2 \mathrm{H}, \mathrm{NH} H_{2}\right), 4.56\left(\mathrm{~s}, 2 \mathrm{H}, \mathrm{NH}_{2}\right), 4.35\left(\mathrm{dd}, J_{1}=10.4, J_{2}=4.4\right.$, $\left.1 \mathrm{H}, \mathrm{OCH}_{2}\right), 4.33-4.27(\mathrm{~m}, 1 \mathrm{H}, \mathrm{CH}), 4.22\left(\mathrm{dd}, J_{1}=10.4, J_{2}=5.2,1 \mathrm{H}, \mathrm{OCH}_{2}\right), 3.99\left(\mathrm{dd}, J_{1}=8.4, J_{2}=6.0\right.$, $\left.1 \mathrm{H}, \mathrm{OCH}_{2}\right), 3.73\left(\mathrm{dd}, \mathrm{J}_{1}=8.4, \mathrm{~J}_{2}=6.0,1 \mathrm{H}, \mathrm{OCH}_{2}\right), 1.33\left(\mathrm{~s}, 3 \mathrm{H}, \mathrm{CH}_{3}\right), 1.30\left(\mathrm{~s}, 3 \mathrm{H}, \mathrm{CH}_{3}\right) ;$ ES-MS 385.1 $(\mathrm{M}+\mathrm{H})^{+}$; HRMS Calcd. for $\mathrm{C}_{16} \mathrm{H}_{19} \mathrm{Cl}_{2} \mathrm{~N}_{4} \mathrm{O}_{3}{ }^{+} 385.0834$, found 385.0830 .

(R)-2,4-Diamino-5-(3-chloro-4-fluorophenyl)-6-[4-(2,2-dimethyl-1,3-dioxolane)methoxy]pyrimidine (8d). Method A. White solid 0.64 g, yield 64\%; m.p. 149.1-150.1 ${ }^{\circ} \mathrm{C}$; IR: $v_{\max } / \mathrm{cm}^{-1} 3484(\mathrm{NH}), 3382(\mathrm{NH})$, $3320(\mathrm{NH}), 1650(\mathrm{C}=\mathrm{N}), 1621(\mathrm{C}=\mathrm{N}), 1594(\mathrm{C}=\mathrm{C}), 1553(\mathrm{C}=\mathrm{C}), 1502(\mathrm{C}=\mathrm{C}), 1372(\mathrm{C}-\mathrm{F}), 1160(\mathrm{C}-\mathrm{O}-\mathrm{C})$, 1092 (C-O-C), 1065 (C-O-C), $797(\mathrm{C}-\mathrm{Cl}) ;{ }^{1} \mathrm{H}-\mathrm{NMR}\left(\mathrm{CDCl}_{3}\right) \delta 7.37\left(\mathrm{dd}, J_{1}=7.2, J_{2}=1.6,1 \mathrm{H}, \mathrm{Ar}-H\right)$, 7.20-7.14 (m, 2H, Ar-H), $4.71\left(\mathrm{~s}, 2 \mathrm{H}, \mathrm{NH}_{2}\right), 4.53\left(\mathrm{~s}, 2 \mathrm{H}, \mathrm{NH}_{2}\right), 4.35\left(\mathrm{dd}, J_{1}=10.6, J_{2}=4.2,1 \mathrm{H}, \mathrm{OCH}_{2}\right)$, $4.32-4.27(\mathrm{~m}, 1 \mathrm{H}, \mathrm{CH}), 4.22\left(\mathrm{dd}, J_{1}=10.6, J_{2}=5.4,1 \mathrm{H}, \mathrm{OCH}_{2}\right), 3.98\left(\mathrm{dd}, J_{1}=8.4, J_{2}=6.0,1 \mathrm{H}, \mathrm{OCH}_{2}\right)$, $3.72\left(\mathrm{dd}, J_{1}=8.4, J_{2}=6.0,1 \mathrm{H}, \mathrm{OCH}_{2}\right), 1.33\left(\mathrm{~s}, 3 \mathrm{H}, \mathrm{CH}_{3}\right), 1.29\left(\mathrm{~s}, 3 \mathrm{H}, \mathrm{CH}_{3}\right)$; ES-MS $369.1(\mathrm{M}+\mathrm{H})^{+}$; HRMS Calcd. for $\mathrm{C}_{16} \mathrm{H}_{19} \mathrm{ClFN}_{4} \mathrm{O}_{3}{ }^{+}, 369.1130$, found 369.1128.

(R)-2,4-Diamino-5-(4-trifluoromethylphenyl)-6-[4-(2,2-dimethyl-1,3-dioxolane)methoxy]pyrimidine (8e). Method A. Light yellow solid 0.72 g, yield 69\%; m.p. $126.6-127.2^{\circ} \mathrm{C}$; IR: $v_{\max } / \mathrm{cm}^{-1} 3530(\mathrm{NH}), 3511$ $(\mathrm{NH}), 3444(\mathrm{NH}), 3420(\mathrm{NH}), 1649(\mathrm{C}=\mathrm{N}), 1609(\mathrm{C}=\mathrm{N}), 1593(\mathrm{C}=\mathrm{C}), 1558(\mathrm{C}=\mathrm{C}), 1491(\mathrm{C}=\mathrm{C}), 1171$ (C-O-), 1128 (C-O-C), 1094 (C-O-C), 1072 (C-O-C), 1046 (C-O-C); ${ }^{1} \mathrm{H}-\mathrm{NMR}\left(\mathrm{CDCl}_{3}\right) \delta 7.64$ (d, J = 8.2, $2 \mathrm{H}, \mathrm{Ar}-H), 7.46(\mathrm{~d}, J=8.2,2 \mathrm{H} \mathrm{Ar}-H), 4.73\left(\mathrm{~s}, 2 \mathrm{H}, \mathrm{NH}_{2}\right), 4.56\left(\mathrm{~s}, 2 \mathrm{H}, \mathrm{NH}_{2}\right), 4.37\left(\mathrm{dd}, J_{1}=11.2, J_{2}=4.2\right.$, $\left.1 \mathrm{H}, \mathrm{OCH}_{2}\right), 4.32-4.27(\mathrm{~m}, 1 \mathrm{H}, \mathrm{CH}), 4.22\left(\mathrm{dd}, J_{1}=11.2, J_{2}=5.6,1 \mathrm{H}, \mathrm{OCH}_{2}\right), 3.97\left(\mathrm{dd}, J_{1}=8.4, J_{2}=6.0\right.$, $\left.1 \mathrm{H}, \mathrm{OCH}_{2}\right), 3.71\left(\mathrm{dd}, \mathrm{J}_{1}=8.4, \mathrm{~J}_{2}=6.0,1 \mathrm{H}, \mathrm{OCH}_{2}\right), 1.32\left(\mathrm{~s}, 3 \mathrm{H}, \mathrm{CH}_{3}\right), 1.24\left(\mathrm{~s}, 3 \mathrm{H}, \mathrm{CH}_{3}\right) ; \mathrm{ES}-\mathrm{MS} 385.1$ $(\mathrm{M}+\mathrm{H})^{+}$; HRMS Calcd. for $\mathrm{C}_{17} \mathrm{H}_{20} \mathrm{~F}_{3} \mathrm{~N}_{4} \mathrm{O}_{3}{ }^{+} 385.1488$, found 385.1485 . 
(R)-2,4-Diamino-5-(3-trifluoromethylphenyl)-6-[4-(2,2-dimethyl-1,3-dioxolane)methoxy]pyrimidine

(8f). Method A. Light yellow solid 0.64 g, yield 68\%; m.p. $126.0-126.8{ }^{\circ} \mathrm{C}$; IR: $v_{\max } / \mathrm{cm}^{-1} 3467(\mathrm{NH}), 3418$ (NH), $3336(\mathrm{NH}), 1650(\mathrm{C}=\mathrm{N}), 1625(\mathrm{C}=\mathrm{N}), 1593(\mathrm{C}=\mathrm{C}), 1556(\mathrm{C}=\mathrm{C}), 1523(\mathrm{C}=\mathrm{C}), 1163(\mathrm{C}-\mathrm{O}-\mathrm{C}), 1118$ (C-O-C), 1106 (C-O-C), 1068 (C-O-C); ${ }^{1} \mathrm{H}-\mathrm{NMR}\left(\mathrm{CDCl}_{3}\right) \delta 7.61$ (s, 1H, Ar-H), 7.56-7.49 (m, 3H, Ar-H), $4.73\left(\mathrm{~s}, 2 \mathrm{H}, \mathrm{NH}_{2}\right), 4.55\left(\mathrm{~s}, 2 \mathrm{H}, \mathrm{NH}_{2}\right), 4.36\left(\mathrm{dd}, J_{1}=10.6, J_{2}=4.2,1 \mathrm{H}, \mathrm{OCH}_{2}\right), 4.31-4.26(\mathrm{~m}, 1 \mathrm{H}, \mathrm{CH}), 4.22$ $\left(\mathrm{dd}, J_{1}=10.6, J_{2}=5.8,1 \mathrm{H}, \mathrm{OCH}_{2}\right), 3.96\left(\mathrm{dd}, J_{1}=8.4, J_{2}=6.4,1 \mathrm{H}, \mathrm{OCH}_{2}\right), 3.70\left(\mathrm{dd}, J_{1}=8.4, J_{2}=6.0,1 \mathrm{H}\right.$, $\left.\mathrm{OCH}_{2}\right), 1.32\left(\mathrm{~s}, 3 \mathrm{H}, \mathrm{CH}_{3}\right), 1.25\left(\mathrm{~s}, 3 \mathrm{H}, \mathrm{CH}_{3}\right)$; ES-MS $385.1(\mathrm{M}+\mathrm{H})^{+}$; HRMS Calcd. for $\mathrm{C}_{17} \mathrm{H}_{20} \mathrm{~F}_{3} \mathrm{~N}_{4} \mathrm{O}_{3}{ }^{+}$ 385.1488 , found 385.1491 .

(R)-2,4-Diamino-5-(4-trifluoromethoxyphenyl)-6-[4-(2,2-dimethyl-1,3-dioxolane)methoxy]pyrimidine (8g). Method A. Yellow solid 0.77 g, yield 70\%; m.p. 37.1-38.0 ${ }^{\circ} \mathrm{C}$; IR: $v_{\max } / \mathrm{cm}^{-1} 3482(\mathrm{NH}), 3368(\mathrm{NH})$, 1611 (C=N), 1560 (C=C), 1510 (C=C), 1374 (C-F), 1161 (C-O-C), 1092 (C-O-C), 1052 (C-O-C); ${ }^{1} \mathrm{H}-\mathrm{NMR}$ $\left(\mathrm{CDCl}_{3}\right) \delta 7.35(\mathrm{~d}, J=8.4,2 \mathrm{H}, \mathrm{Ar}-H), 7.24(\mathrm{~d}, J=8.4,1 \mathrm{H}, \mathrm{Ar}-H), 4.71\left(\mathrm{~s}, 2 \mathrm{H}, \mathrm{NH}_{2}\right), 4.54(\mathrm{~s}, 2 \mathrm{H}, \mathrm{NH})_{2}$, $4.38\left(\mathrm{dd}, J_{1}=10.8, J_{2}=4.0,1 \mathrm{H}, \mathrm{OCH}_{2}\right), 4.32-4.27(\mathrm{~m}, 1 \mathrm{H}, \mathrm{CH}), 4.21\left(\mathrm{dd}, J_{1}=10.8, J_{2}=5.6,1 \mathrm{H}, \mathrm{OCH}_{2}\right)$, $3.96\left(\mathrm{dd}, J_{1}=8.4, J_{2}=6.4,1 \mathrm{H}, \mathrm{OCH}_{2}\right), 3.72\left(\mathrm{dd}, J_{1}=8.4, J_{2}=6.4,1 \mathrm{H}, \mathrm{OCH}_{2}\right), 1.32\left(\mathrm{~s}, 3 \mathrm{H}, \mathrm{CH}_{3}\right), 1.23(\mathrm{~s}$, $\left.3 \mathrm{H}, \mathrm{CH}_{3}\right)$; ES-MS 401.1(M + H) ${ }^{+}$; HRMS Calcd. for $\mathrm{C}_{17} \mathrm{H}_{20} \mathrm{~F}_{3} \mathrm{~N}_{4} \mathrm{O}_{4}{ }^{+}$401.1437, found 401.1434.

(R)-2,4-Diamino-5-(3-trifluoromethoxyphenyl)-6-[4-(2,2-dimethyl-1,3-dioxolane)methoxy]pyrimidine (8h). Method A. Yellow solid 0.72 g, yield 66\%; m.p. 36.2-37.1 ${ }^{\circ} \mathrm{C}$; IR: $v_{\max } / \mathrm{cm}^{-1} 3488(\mathrm{NH}), 3361(\mathrm{NH})$, 1611 (C=N), 1560 (C=C), 1379 (C-F), 1158 (C-O-C), 1082 (C-O-C), 1047 (C-O-C); ${ }^{1} \mathrm{H}-\mathrm{NMR}\left(\mathrm{CDCl}_{3}\right) \delta$ $7.41(\mathrm{t}, J=8.0,1 \mathrm{H}, \mathrm{Ar}-H), 7.28-7.26(\mathrm{~m}, 1 \mathrm{H} \mathrm{Ar}-H), 7.21(\mathrm{~s}, 1 \mathrm{H}, \mathrm{Ar}-H), 7.14(\mathrm{~d}, J=8.4,1 \mathrm{H}, \mathrm{Ar}-H), 4.73$ $\left(\mathrm{s}, 2 \mathrm{H}, \mathrm{NH}_{2}\right), 4.58\left(\mathrm{~s}, 2 \mathrm{H}, \mathrm{NH}_{2}\right), 4.36\left(\mathrm{dd}, J_{1}=10.8, J_{2}=4.0,1 \mathrm{H}, \mathrm{OCH}_{2}\right), 4.32-4.26(\mathrm{~m}, 1 \mathrm{H}, \mathrm{CH}), 4.21$ $\left(\mathrm{dd}, J_{1}=10.8, J_{2}=6.0,1 \mathrm{H}, \mathrm{OCH}_{2}\right), 3.97\left(\mathrm{dd}, J_{1}=8.4, J_{2}=6.4,1 \mathrm{H}, \mathrm{OCH}_{2}\right), 3.72\left(\mathrm{dd}, J_{1}=8.4, J_{2}=6.0,1 \mathrm{H}\right.$, $\left.\mathrm{OCH}_{2}\right), 1.32\left(\mathrm{~s}, 3 \mathrm{H}, \mathrm{CH}_{3}\right), 1.27\left(\mathrm{~s}, 3 \mathrm{H}, \mathrm{CH}_{3}\right)$; ES-MS $401.1(\mathrm{M}+\mathrm{H})^{+}$; HRMS Calcd. for $\mathrm{C}_{17} \mathrm{H}_{20} \mathrm{~F}_{3} \mathrm{~N}_{4} \mathrm{O}_{4}{ }^{+}$ 401.1437, found 401.1440 .

(R)-2,4-Diamino-5-(4-cyanophenyl)-6-[4-(2,2-dimethyl-1,3-dioxolane)methoxy]pyrimidine (8i). Method A. White solid 0.62 g, yield 67\%; m.p. 209.3-209.9 ${ }^{\circ} \mathrm{C}$; IR: $v_{\max } / \mathrm{cm}^{-1} 3482(\mathrm{NH}), 3456(\mathrm{NH}), 3370(\mathrm{NH})$, $3332(\mathrm{NH}), 2228(\mathrm{CN}), 1655(\mathrm{C}=\mathrm{N}), 1621(\mathrm{C}=\mathrm{N}), 1585(\mathrm{C}=\mathrm{C}), 1564(\mathrm{C}=\mathrm{C}), 1157$ (C-O-C), 1091 (C-O-C), $1051(\mathrm{C}-\mathrm{O}-\mathrm{C}) ;{ }^{1} \mathrm{H}-\mathrm{NMR}\left(\mathrm{CDCl}_{3}\right) \delta 7.68(\mathrm{~d}, J=8.4,2 \mathrm{H}, \mathrm{Ar}-H), 7.47(\mathrm{~d}, J=8.4,2 \mathrm{H} \mathrm{Ar}-H), 4.76(\mathrm{~s}, 2 \mathrm{H}, \mathrm{NH})_{2}$, $4.57\left(\mathrm{~s}, 2 \mathrm{H}, \mathrm{NH}_{2}\right), 4.36\left(\mathrm{dd}, J_{1}=10.8, J_{2}=4.0,1 \mathrm{H}, \mathrm{OCH}_{2}\right), 4.32-4.27(\mathrm{~m}, 1 \mathrm{H}, \mathrm{CH}), 4.23\left(\mathrm{dd}, J_{1}=10.8\right.$, $\left.J_{2}=6.0,1 \mathrm{H}, \mathrm{OCH}_{2}\right), 3.97\left(\mathrm{dd}, J_{1}=8.4, J_{2}=6.4,1 \mathrm{H}, \mathrm{OCH}_{2}\right), 3.70\left(\mathrm{dd}, J_{1}=8.4, J_{2}=6.0,1 \mathrm{H}, \mathrm{OCH}_{2}\right), 1.32$ $\left(\mathrm{s}, 3 \mathrm{H}, \mathrm{CH}_{3}\right), 1.28\left(\mathrm{~s}, 3 \mathrm{H}, \mathrm{CH}_{3}\right)$; ES-MS $342.1(\mathrm{M}+\mathrm{H})^{+}$; HRMS Calcd. for $\mathrm{C}_{17} \mathrm{H}_{20} \mathrm{~N}_{5} \mathrm{O}_{3}{ }^{+} 342.1566$, found 342.1570 .

(R)-2,4-Diamino-5-(4-methoxyphenyl)-6-[4-(2,2-dimethyl-1,3-dioxolane)methoxy]pyrimidine (8j). Method A. White solid 0.64 g, yield 68\%; m.p. 119.7-120.2 ${ }^{\circ} \mathrm{C}$; IR: $v_{\max } / \mathrm{cm}^{-1} 3456(\mathrm{NH}), 3348(\mathrm{NH}), 1643$ $(\mathrm{C}=\mathrm{N}), 1617(\mathrm{C}=\mathrm{N}), 1594(\mathrm{C}=\mathrm{C}), 1560(\mathrm{C}=\mathrm{C}), 1512(\mathrm{C}=\mathrm{C}), 1171(\mathrm{C}-\mathrm{O}-\mathrm{C}), 1082(\mathrm{C}-\mathrm{O}-\mathrm{C}), 1050(\mathrm{C}-\mathrm{O}-\mathrm{C})$; ${ }^{1} \mathrm{H}-\mathrm{NMR}\left(\mathrm{CDCl}_{3}\right) \delta 7.21(\mathrm{~d}, J=8.8,2 \mathrm{H}, \mathrm{Ar}-\mathrm{H}), 6.93(\mathrm{~d}, J=8.8,2 \mathrm{H}, \mathrm{Ar}-H), 4.65(\mathrm{~s}, 2 \mathrm{H}, \mathrm{NH} 2), 4.53(\mathrm{~s}, 2 \mathrm{H}$, $\left.\mathrm{NH}_{2}\right), 4.37\left(\mathrm{dd}, J_{1}=10.8, J_{2}=4.0,1 \mathrm{H}, \mathrm{OCH}_{2}\right), 4.32-4.26(\mathrm{~m}, 1 \mathrm{H}, \mathrm{CH}), 4.19\left(\mathrm{dd}, J_{1}=10.8, J_{2}=6.0,1 \mathrm{H}\right.$, $\left.\mathrm{OCH}_{2}\right), 3.96\left(\mathrm{dd}, J_{1}=8.4, J_{2}=6.4,1 \mathrm{H}, \mathrm{OCH}_{2}\right), 3.82\left(\mathrm{~s}, 3 \mathrm{H}, \mathrm{OCH}_{3}\right), 3.74\left(\mathrm{dd}, J_{1}=8.4, J_{2}=6.4,1 \mathrm{H}, \mathrm{OCH}_{2}\right)$, $1.32\left(\mathrm{~s}, 3 \mathrm{H}, \mathrm{CH}_{3}\right), 1.28\left(\mathrm{~s}, 3 \mathrm{H}, \mathrm{CH}_{3}\right)$; ES-MS 347.2 (M + H) ${ }^{+}$; HRMS Calcd. for $\mathrm{C}_{17} \mathrm{H}_{23} \mathrm{~N}_{4} \mathrm{O}_{4}{ }^{+}$347.1719, found 347.1723 .

(R)-2,4-Diamino-5-(3,4,5-trimethoxyphenyl)-6-[4-(2,2-dimethyl-1,3-dioxolane)methoxy]pyrimidine (8k). Method A. White solid 0.70 g, yield 63\%; m.p. 183.8-184.1 ${ }^{\circ} \mathrm{C} ; \mathrm{IR}: v_{\max } / \mathrm{cm}^{-1} 3458(\mathrm{NH}), 3421(\mathrm{NH})$, $3339(\mathrm{NH}), 1661(\mathrm{C}=\mathrm{N}), 1631(\mathrm{C}=\mathrm{N}), 1588(\mathrm{C}=\mathrm{C}), 1557(\mathrm{C}=\mathrm{C}), 1511(\mathrm{C}=\mathrm{C}), 1164(\mathrm{C}-\mathrm{O}-\mathrm{C}), 1128(\mathrm{C}-\mathrm{O}-\mathrm{C})$, $1074(\mathrm{C}-\mathrm{O}-\mathrm{C}) ;{ }^{1} \mathrm{H}-\mathrm{NMR}\left(\mathrm{CDCl}_{3}\right) \delta 6.54(\mathrm{~s}, 2 \mathrm{H}, \mathrm{Ar}-\mathrm{H}), 4.67$ (s, 2H, NH$)_{2}, 4.62\left(\mathrm{~s}, 2 \mathrm{H}, \mathrm{NH}_{2}\right), 4.38-4.31(\mathrm{~m}$, $\left.2 \mathrm{H}, \mathrm{OCH}_{2}\right), 4.27-4.20(\mathrm{~m}, 1 \mathrm{H}, \mathrm{CH}), 4.01\left(\mathrm{dd}, J_{1}=8.4, J_{2}=6.4,1 \mathrm{H}, \mathrm{OCH}_{2}\right), 3.87\left(\mathrm{~s}, 3 \mathrm{H}, \mathrm{OCH}_{3}\right), 3.84(\mathrm{~s}$, $\left.6 \mathrm{H}, \mathrm{OCH}_{3} \times 2\right), 3.77\left(\mathrm{dd}, J_{1}=8.0, J_{2}=6.0,1 \mathrm{H}, \mathrm{OCH}_{2}\right), 1.32\left(\mathrm{~s}, 3 \mathrm{H}, \mathrm{CH}_{3}\right), 1.28\left(\mathrm{~s}, 3 \mathrm{H}, \mathrm{CH}_{3}\right) ; \mathrm{ES}-\mathrm{MS} 407.2$ $(\mathrm{M}+\mathrm{H})^{+} ;$HRMS Calcd. for $\mathrm{C}_{19} \mathrm{H}_{27} \mathrm{~N}_{4} \mathrm{O}_{6}{ }^{+}$407.1931, found 407.1927.

(R)-2,4-Diamino-5-[3-(2,2,2-trifloroethoxymethyl)phenyl]-6-[4-(2,2-dimethyl-1,3-dioxolane)methoxy]-pyrimidine (81). Method A. Yellow solid 0.72 g, yield 62\%; m.p. 32.2-33.2 ${ }^{\circ}$ C; IR: $v_{\max } / \mathrm{cm}^{-1} 3485$ (NH), 3367 
(NH), 1609 (C=N), 1559 (C=C), 1491 (C=C), 1373 (C-F), 1159 (C-O-C), 1093 (C-O-C), 1049 (C-O-C); ${ }^{1} \mathrm{H}-\mathrm{NMR}\left(\mathrm{CDCl}_{3}\right) \delta 7.40(\mathrm{t}, J=7.6,1 \mathrm{H}, \mathrm{Ar}-\mathrm{H}), 7.30-7.27(\mathrm{~m}, 3 \mathrm{H}, \mathrm{Ar}-\mathrm{H}), 4.68\left(\mathrm{~s}, 4 \mathrm{H}, \mathrm{CH}_{2}, \mathrm{NH}_{2}\right), 4.56(\mathrm{~s}$, $\left.2 \mathrm{H}, \mathrm{NH}_{2}\right), 4.35\left(\mathrm{dd}, J_{1}=10.8, J_{2}=4.0,1 \mathrm{H}, \mathrm{OCH}_{2}\right), 4.32-4.26(\mathrm{~m}, 1 \mathrm{H}, \mathrm{CH}), 4.22\left(\mathrm{dd}, J_{1}=10.4, J_{2}=5.6\right.$, $\left.1 \mathrm{H}, \mathrm{OCH}_{2}\right), 3.96\left(\mathrm{dd}, J_{1}=8.4, J_{2}=6.4,1 \mathrm{H}, \mathrm{OCH}_{2}\right), 3.87\left(\mathrm{q}, J=8.8,2 \mathrm{H}, \mathrm{CF}_{3} \mathrm{CH}_{2}\right), 3.73\left(\mathrm{dd}, J_{1}=8.0\right.$, $\left.\mathrm{J}_{2}=5.8,1 \mathrm{H}, \mathrm{OCH}_{2}\right), 1.31\left(\mathrm{~s}, 3 \mathrm{H}, \mathrm{CH}_{3}\right), 1.25\left(\mathrm{~s}, 3 \mathrm{H}, \mathrm{CH}_{3}\right)$; ES-MS $429.2(\mathrm{M}+\mathrm{H})^{+}$; HRMS Calcd. for $\mathrm{C}_{19} \mathrm{H}_{24} \mathrm{~F}_{3} \mathrm{~N}_{4} \mathrm{O}_{4}{ }^{+}$429.1750, found 429.1747.

(R)-2,4-Diamino-5-[3,5-dimethyl-4-(N-methoxyaminosulfonyl)phenyl]-6-[4-(2,2-dimethyl-1,3-dioxolane)methoxy]pyrimidine (8m). Method A. Light yellow solid 0.69 g, yield 56\%; m.p. 157.7-158.8 ${ }^{\circ} \mathrm{C}$; IR: $v_{\max } / \mathrm{cm}^{-1} 3485(\mathrm{NH}), 3446(\mathrm{NH}), 3347(\mathrm{NH}), 3223(\mathrm{NH}), 1640(\mathrm{C}=\mathrm{N}), 1617(\mathrm{C}=\mathrm{N}), 1591(\mathrm{C}=\mathrm{C}), 1562$ $(\mathrm{C}=\mathrm{C}), 1490(\mathrm{C}=\mathrm{C}), 1170$ (C-O-C), 1096 (C-O-C), 1053 (C-O-C); ${ }^{1} \mathrm{H}-\mathrm{NMR}\left(\mathrm{CDCl}_{3}\right) \delta 7.43(\mathrm{~s}, 1 \mathrm{H}, \mathrm{NH})$, $7.18(\mathrm{~s}, 2 \mathrm{H}, \mathrm{Ar}-\mathrm{H}), 4.74\left(\mathrm{~s}, 2 \mathrm{H}, \mathrm{NH}_{2}\right), 4.61\left(\mathrm{~s}, 2 \mathrm{H}, \mathrm{NH}_{2}\right), 4.35\left(\mathrm{dd}, \mathrm{J}_{1}=10.2, J_{2}=5.0,1 \mathrm{H}, \mathrm{OCH}_{2}\right), 4.32-4.27$ $(\mathrm{m}, 1 \mathrm{H}, \mathrm{CH}), 4.24\left(\mathrm{dd}, J_{1}=10.2, J_{2}=5.0,1 \mathrm{H}, \mathrm{OCH}_{2}\right), 3.99\left(\mathrm{dd}, J_{1}=8.2, J_{2}=6.2,1 \mathrm{H}, \mathrm{OCH}_{2}\right), 3.75-3.72$ $\left(\mathrm{m}, 4 \mathrm{H}, \mathrm{OCH}_{3}\right.$ and $\left.\mathrm{OCH}_{2}\right), 2.69\left(\mathrm{~s}, 6 \mathrm{H}, \mathrm{CH}_{3} \times 2\right), 1.33\left(\mathrm{~s}, 3 \mathrm{H}, \mathrm{CH}_{3}\right), 1.29\left(\mathrm{~s}, 3 \mathrm{H}, \mathrm{CH}_{3}\right) ; \mathrm{ES}-\mathrm{MS} 454.2$ $(\mathrm{M}+\mathrm{H})^{+}$; HRMS Calcd. for $\mathrm{C}_{19} \mathrm{H}_{28} \mathrm{~N}_{5} \mathrm{O}_{6} \mathrm{~S}^{+} 454.1760$, found 454.1756 .

(R)-2,4-Diamino-5-[4-(morpholine-4-carbonyl)phenyl]-6-[4-(2,2-dimethyl-1,3-dioxolane)methoxy]pyrimidine (8n). Method A. Yellow solid 0.90 g, yield 77\%; m.p. 189.4-190.5 ${ }^{\circ} \mathrm{C}$; IR: $v_{\max } / \mathrm{cm}^{-1} 3492(\mathrm{NH}), 3430$ $(\mathrm{NH}), 3334(\mathrm{NH}), 1659(\mathrm{C}=\mathrm{N}), 1611(\mathrm{C}=\mathrm{N}), 1588(\mathrm{C}=\mathrm{C}), 1560(\mathrm{C}=\mathrm{C}), 1516(\mathrm{C}=\mathrm{C}), 1488(\mathrm{C}=\mathrm{C}), 1156$ (C-O-C), 1114 (C-O-C), 1070 (C-O-C), 1051(C-O-C); ${ }^{1} \mathrm{H}-\mathrm{NMR}\left(\mathrm{CDCl}_{3}\right) \delta 7.44$ (d, J = 8.4, 2H, Ar-H), 7.38 $(\mathrm{d}, J=8.4,2 \mathrm{H}, \mathrm{Ar}-H), 4.71\left(\mathrm{~s}, 2 \mathrm{H}, \mathrm{NH}_{2}\right), 4.57\left(\mathrm{~s}, 2 \mathrm{H}, \mathrm{NH}_{2}\right), 4.35\left(\mathrm{dd}, J_{1}=10.8, J_{2}=4.2,1 \mathrm{H}, \mathrm{OCH}_{2}\right)$, $4.32-4.29(\mathrm{~m}, 1 \mathrm{H}, \mathrm{CH}), 4.22\left(\mathrm{dd}, J_{1}=10.8, J_{2}=5.6,1 \mathrm{H}, \mathrm{OCH}_{2}\right), 3.97\left(\mathrm{dd}, J_{1}=8.4, J_{2}=6.4,1 \mathrm{H}, \mathrm{OCH}_{2}\right)$, $3.82-3.51\left(\mathrm{~m}, 8 \mathrm{H}, \mathrm{CH}_{2} \times 4\right), 3.73\left(\mathrm{dd}, J_{1}=8.0, J_{2}=6.0,1 \mathrm{H}, \mathrm{OCH}_{2}\right), 1.32\left(\mathrm{~s}, 3 \mathrm{H}, \mathrm{CH}_{3}\right), 1.27\left(\mathrm{~s}, 3 \mathrm{H}, \mathrm{CH}_{3}\right)$; ES-MS 430.2 $(\mathrm{M}+\mathrm{H})^{+}$; HRMS Calcd. for $\mathrm{C}_{21} \mathrm{H}_{28} \mathrm{~N}_{5} \mathrm{O}_{5}{ }^{+} 430.2090$, found 430.2092.

(R)-2,4-Diamino-5-[4-(3-trifloromethoxyanilinocarbonyl)phenyl]-6-[4-(2,2-dimethyl-1,3-dioxolane)-methoxy] pyrimidine (8o). Method A. White solid $0.73 \mathrm{~g}$, yield 52\%; m.p. $122.9-124.5^{\circ} \mathrm{C}$; IR: $v_{\max } / \mathrm{cm}^{-1} 3496$ $(\mathrm{NH}), 3340(\mathrm{NH}), 3192(\mathrm{CONH}), 1655(\mathrm{C}=\mathrm{N}), 1607(\mathrm{C}=\mathrm{C}), 1565(\mathrm{C}=\mathrm{C}), 1492(\mathrm{C}=\mathrm{C}), 1156(\mathrm{C}-\mathrm{O}-\mathrm{C}), 1082$ (C-O-C); ${ }^{1} \mathrm{H}-\mathrm{NMR}\left(\mathrm{CDCl}_{3}\right) \delta 8.07(\mathrm{~s}, 1 \mathrm{H}, \mathrm{NH}), 7.85(\mathrm{~d}, J=8.4,2 \mathrm{H}, \mathrm{Ar}-\mathrm{H}), 7.71(\mathrm{~s}, 1 \mathrm{H}, \mathrm{Ar}-\mathrm{H}), 7.54(\mathrm{dd}$, $\left.J_{1}=8.0, J_{2}=1.2,1 \mathrm{H}, \mathrm{Ar}-H\right), 7.45(\mathrm{~d}, J=8.4,2 \mathrm{H}, \mathrm{Ar}-H), 7.38(\mathrm{t}, J=8.0,1 \mathrm{H}, \mathrm{Ar}-H), 7.02(\mathrm{~d}, J=8.0,1 \mathrm{H}$, Ar- $H), 4.74\left(\mathrm{~s}, 2 \mathrm{H}, \mathrm{NH}_{2}\right), 4.58\left(\mathrm{~s}, 2 \mathrm{H}, \mathrm{NH}_{2}\right), 4.35\left(\mathrm{dd}, J_{1}=9.6, J_{2}=3.8,1 \mathrm{H}, \mathrm{OCH}_{2}\right), 4.32-4.29(\mathrm{~m}, 1 \mathrm{H}$, $\mathrm{CH}), 4.27\left(\mathrm{dd}, J_{1}=9.6, J_{2}=4.6,1 \mathrm{H}, \mathrm{OCH}_{2}\right), 3.99\left(\mathrm{dd}, J_{1}=8.4, J_{2}=6.0,1 \mathrm{H}, \mathrm{OCH}_{2}\right), 3.73\left(\mathrm{dd}, J_{1}=8.2\right.$, $\left.\mathrm{J}_{2}=5.4,1 \mathrm{H}, \mathrm{OCH}_{2}\right), 1.30\left(\mathrm{~s}, 3 \mathrm{H}, \mathrm{CH}_{3}\right), 1.29\left(\mathrm{~s}, 3 \mathrm{H}, \mathrm{CH}_{3}\right)$; ES-MS $520.2(\mathrm{M}+\mathrm{H})^{+}$; HRMS Calcd. for $\mathrm{C}_{24} \mathrm{H}_{25} \mathrm{~F}_{3} \mathrm{~N}_{5} \mathrm{O}_{5}{ }^{+} 520.1808$, found 520.1810 .

(R)-2,4-Diamino-5-(4-methoxycarbonylphenyl)-6-[4-(2,2-dimethyl-1,3-dioxolane)methoxy]pyrimidine (8p). Method B. White solid 0.64 g, yield 63\%; m.p. 151.3-152.4 ${ }^{\circ} \mathrm{C}$; IR: $v_{\max } / \mathrm{cm}^{-1} 3500(\mathrm{NH}), 3443$ $(\mathrm{NH}), 3391(\mathrm{NH}), 3335(\mathrm{NH}), 1709(\mathrm{C}=\mathrm{O}), 1657(\mathrm{C}=\mathrm{N}), 1608(\mathrm{C}=\mathrm{N}), 1568(\mathrm{C}=\mathrm{C}), 1556(\mathrm{C}=\mathrm{C}), 1513$ $(\mathrm{C}=\mathrm{C}), 1194$ (C-O-C), 1180 (C-O-C), 1152 (C-O-C), 1116 (C-O-C), 1067 (C-O-C); ${ }^{1} \mathrm{H}-\mathrm{NMR}\left(\mathrm{CDCl}_{3}\right) \delta 8.05$ $\left(\mathrm{dd}, J_{1}=6.8, J_{2}=1.6,2 \mathrm{H}, \mathrm{Ar}-H\right), 7.42\left(\mathrm{dd}, J_{1}=6.8, J_{2}=1.6,2 \mathrm{H}, \mathrm{Ar}-H\right), 4.72\left(\mathrm{~s}, 2 \mathrm{H}, \mathrm{NH} H_{2}\right), 4.58(\mathrm{~s}, 2 \mathrm{H}$, $\left.\mathrm{NH}_{2}\right), 4.36\left(\mathrm{dd}, J_{1}=10.4, J_{2}=4.0,1 \mathrm{H}, \mathrm{OCH}_{2}\right), 4.31-4.26(\mathrm{~m}, 1 \mathrm{H}, \mathrm{CH}), 4.22\left(\mathrm{dd}, J_{1}=10.4, J_{2}=6.0,1 \mathrm{H}\right.$, $\left.\mathrm{OCH}_{2}\right), 3.96\left(\mathrm{dd}, J_{1}=8.0, J_{2}=6.0,1 \mathrm{H}, \mathrm{OCH}_{2}\right), 3.93\left(\mathrm{~s}, 3 \mathrm{H}, \mathrm{OCH}_{3}\right), 3.72\left(\mathrm{dd}, J_{1}=8.4, J_{2}=6.0,1 \mathrm{H}, \mathrm{OCH}_{2}\right)$, $1.32\left(\mathrm{~s}, 3 \mathrm{H}, \mathrm{CH}_{3}\right), 1.27\left(\mathrm{~s}, 3 \mathrm{H}, \mathrm{CH}_{3}\right)$; ES-MS 375.2(M + H) ${ }^{+}$; HRMS Calcd. for $\mathrm{C}_{18} \mathrm{H}_{23} \mathrm{~N}_{4} \mathrm{O}_{5}{ }^{+} 375.1668$, found 375.1664 .

(R)-2,4-Diamino-5-(3-methoxycarbonylphenyl)-6-[4-(2,2-dimethyl-1,3-dioxolane)methoxy]pyrimidine (8q). Method B. White solid 0.66 g, yield 65\%; m.p. $181.4-181.6{ }^{\circ} \mathrm{C}$; IR: $v_{\max } / \mathrm{cm}^{-1} 3477(\mathrm{NH}), 3373$ $(\mathrm{NH}), 3326(\mathrm{NH}), 1708(\mathrm{C}=\mathrm{O}), 1651(\mathrm{C}=\mathrm{N}), 1626(\mathrm{C}=\mathrm{N}), 1597(\mathrm{C}=\mathrm{C}), 1558(\mathrm{C}=\mathrm{C}), 1490(\mathrm{C}=\mathrm{C}), 1158$ (C-O-C), 1115 (C-O-C), 1084 (C-O-C), 1049 (C-O-C); ${ }^{1} \mathrm{H}-\mathrm{NMR}\left(\mathrm{CDCl}_{3}\right) \delta 8.00$ (t, J = 1.6, 1H, Ar-H), 7.96 $\left(\mathrm{dt}, J_{1}=7.6, J_{2}=1.6,1 \mathrm{H}, \mathrm{Ar}-H\right), 7.52\left(\mathrm{dt}, J_{1}=7.6, J_{2}=1.6,1 \mathrm{H}, \mathrm{Ar}-H\right), 7.47(\mathrm{t}, J=7.6,1 \mathrm{H}, \mathrm{Ar}-H), 4.71$ $\left(\mathrm{s}, 2 \mathrm{H}, \mathrm{NH}_{2}\right), 4.54\left(\mathrm{~s}, 2 \mathrm{H}, \mathrm{NH}_{2}\right), 4.37\left(\mathrm{dd}, J_{1}=10.8, J_{2}=4.0,1 \mathrm{H}, \mathrm{OCH}_{2}\right), 4.30-4.25(\mathrm{~m}, 1 \mathrm{H}, \mathrm{CH}), 4.19$ $\left(\mathrm{dd}, J_{1}=10.8, J_{2}=6.0,1 \mathrm{H}, \mathrm{OCH}_{2}\right), 3.96\left(\mathrm{dd}, J_{1}=8.4, J_{2}=6.0,1 \mathrm{H}, \mathrm{OCH}_{2}\right), 3.92\left(\mathrm{~s}, 3 \mathrm{H}, \mathrm{OCH}_{3}\right), 3.73(\mathrm{dd}$, 
$\left.J_{1}=8.4, J_{2}=6.0,1 \mathrm{H}, \mathrm{OCH}_{2}\right), 1.31\left(\mathrm{~s}, 3 \mathrm{H}, \mathrm{CH}_{3}\right), 1.25\left(\mathrm{~s}, 3 \mathrm{H}, \mathrm{CH}_{3}\right)$; ES-MS 375.2(M + H $)^{+}$; HRMS Calcd for $\mathrm{C}_{18} \mathrm{H}_{23} \mathrm{~N}_{4} \mathrm{O}_{5}{ }^{+}$375.1668, found 375.1670.

(S)-2,4-Diamino-5-(4-chlorophenyl)-6-[4-(2,2-dimethyl-1,3-dioxolane)methoxy]pyrimidine (9a). Method A. White solid 0.58 g, yield 61\%; m.p. 171.9-172.1 ${ }^{\circ} \mathrm{C}$; IR: $v_{\max } / \mathrm{cm}^{-1} 3475(\mathrm{NH}), 3454(\mathrm{NH}), 3396(\mathrm{NH})$, $3315(\mathrm{NH}), 1649(\mathrm{C}=\mathrm{N}), 1620(\mathrm{C}=\mathrm{N}), 1593(\mathrm{C}=\mathrm{C}), 1549(\mathrm{C}=\mathrm{C}), 1479(\mathrm{C}=\mathrm{C}), 1160(\mathrm{C}-\mathrm{O}-\mathrm{C}), 1141$ (C-O-C), 1089(C-O-C), $794(\mathrm{C}-\mathrm{Cl}) ;{ }^{1} \mathrm{H}-\mathrm{NMR}\left(\mathrm{CDCl}_{3}\right) \delta 7.36(\mathrm{~d}, J=8.2,2 \mathrm{H}, \mathrm{Ar}-\mathrm{H}), 7.25(\mathrm{~d}, J=8.2,2 \mathrm{H}, \mathrm{Ar}-H), 4.69$ $\left(\mathrm{s}, 2 \mathrm{H}, \mathrm{NH}_{2}\right), 4.53\left(\mathrm{~s}, 2 \mathrm{H}, \mathrm{NH}_{2}\right), 4.36\left(\mathrm{dd}, J_{1}=10.8, J_{2}=4.0,1 \mathrm{H}, \mathrm{OCH}_{2}\right), 4.31-4.26(\mathrm{~m}, 1 \mathrm{H}, \mathrm{CH}), 4.20(\mathrm{dd}$, $\left.J_{1}=10.8, J_{2}=5.6,1 \mathrm{H}, \mathrm{OCH}_{2}\right), 3.97\left(\mathrm{dd}, J_{1}=8.4, J_{2}=6.4,1 \mathrm{H}, \mathrm{OCH}_{2}\right), 3.72\left(\mathrm{dd}, J_{1}=8.4, J_{2}=6.0,1 \mathrm{H}\right.$, $\left.\mathrm{OCH}_{2}\right), 1.32\left(\mathrm{~s}, 3 \mathrm{H}, \mathrm{CH}_{3}\right), 1.28\left(\mathrm{~s}, 3 \mathrm{H}, \mathrm{CH}_{3}\right)$; ES-MS $351.1(\mathrm{M}+\mathrm{H})^{+}$; HRMS Calcd. for $\mathrm{C}_{16} \mathrm{H}_{20} \mathrm{ClN}_{4} \mathrm{O}_{3}{ }^{+}$ 351.1224, found 351.1220 .

(S)-2,4-Diamino-5-(4-fluorophenyl)-6-[4-(2,2-dimethyl-1,3-dioxolane)methoxy]pyrimidine (9b). Method A. White solid 0.57 g, yield $62 \%$; m.p. $164.1-164.5^{\circ} \mathrm{C}$; IR: $v_{\max } / \mathrm{cm}^{-1} 3527(\mathrm{NH}), 3482(\mathrm{NH}), 3370(\mathrm{NH})$, $3312(\mathrm{NH}), 1646(\mathrm{C}=\mathrm{N}), 1626(\mathrm{C}=\mathrm{N}), 1593(\mathrm{C}=\mathrm{C}), 1558(\mathrm{C}=\mathrm{C}), 1512(\mathrm{C}=\mathrm{C}), 1484(\mathrm{C}=\mathrm{C}), 1380(\mathrm{C}-\mathrm{F}), 1159$ (C-O-C), 1130 (C-O-C), 1091 (C-O-C); ${ }^{1} \mathrm{H}-\mathrm{NMR}\left(\mathrm{CDCl}_{3}\right) \delta 7.26\left(\mathrm{dd}, \mathrm{J}_{1}=8.8, J_{2}=5.2,2 \mathrm{H}, \mathrm{Ar}-\mathrm{H}\right), 7.08(\mathrm{t}$, $J=8.8,2 \mathrm{H}, \mathrm{Ar}-\mathrm{H}), 4.67\left(\mathrm{~s}, 2 \mathrm{H}, \mathrm{NH}_{2}\right), 4.50\left(\mathrm{~s}, 2 \mathrm{H}, \mathrm{NH}_{2}\right), 4.36\left(\mathrm{dd}, J_{1}=10.8, J_{2}=4.0,1 \mathrm{H}, \mathrm{OCH}_{2}\right), 4.31-4.26$ $(\mathrm{m}, 1 \mathrm{H}, \mathrm{CH}), 4.20\left(\mathrm{dd}, J_{1}=10.8, J_{2}=5.6,1 \mathrm{H}, \mathrm{OCH}_{2}\right), 3.96\left(\mathrm{dd}, J_{1}=8.4, J_{2}=6.4,1 \mathrm{H}, \mathrm{OCH}_{2}\right), 3.72(\mathrm{dd}$, $\left.J_{1}=8.4, J_{2}=6.0,1 \mathrm{H}, \mathrm{OCH}_{2}\right), 1.32\left(\mathrm{~s}, 3 \mathrm{H}, \mathrm{CH}_{3}\right), 1.27\left(\mathrm{~s}, 3 \mathrm{H}, \mathrm{CH}_{3}\right)$; ES-MS $335.2(\mathrm{M}+\mathrm{H})^{+}$; HRMS Calcd . for $\mathrm{C}_{16} \mathrm{H}_{20} \mathrm{FN}_{4} \mathrm{O}_{3}{ }^{+}$335.1519, found 335.1521.

(S)-2,4-Diamino-5-(3,4-dichlorophenyl)-6-[4-(2,2-dimethyl-1,3-dioxolane)methoxy]pyrimidine (9c). Method A. White solid 0.58 g, yield 55\%; m.p. $167.3-167.7^{\circ} \mathrm{C}$; IR: $v_{\max } / \mathrm{cm}^{-1} 3487(\mathrm{NH}), 3434(\mathrm{NH}), 3378(\mathrm{NH})$, $3318(\mathrm{NH}), 1650(\mathrm{C}=\mathrm{N}), 1624(\mathrm{C}=\mathrm{N}), 1600(\mathrm{C}=\mathrm{C}), 1558(\mathrm{C}=\mathrm{C}), 1487(\mathrm{C}=\mathrm{C}), 1155$ (C-O-C), 1093 (C-O-C), 1047 (C-O-C), $795(\mathrm{C}-\mathrm{Cl}){ }^{1} \mathrm{H}-\mathrm{NMR}\left(\mathrm{CDCl}_{3}\right) \delta 7.47(\mathrm{~d}, J=8.4,1 \mathrm{H}, \mathrm{Ar}-\mathrm{H}), 7.44(\mathrm{~d}, J=2.0,1 \mathrm{H}, \mathrm{Ar}-\mathrm{H})$, $7.18\left(\mathrm{dd}, J_{1}=8.4, J_{2}=2.0,1 \mathrm{H}, \mathrm{Ar}-H\right), 4.71\left(\mathrm{~s}, 2 \mathrm{H}, \mathrm{NH}_{2}\right), 4.54\left(\mathrm{~s}, 2 \mathrm{H}, \mathrm{NH}_{2}\right), 4.35\left(\mathrm{dd}, J_{1}=10.4, J_{2}=4.4\right.$, $\left.1 \mathrm{H}, \mathrm{OCH}_{2}\right), 4.33-4.27(\mathrm{~m}, 1 \mathrm{H}, \mathrm{CH}), 4.22\left(\mathrm{dd}, J_{1}=10.4, J_{2}=5.2,1 \mathrm{H}, \mathrm{OCH}_{2}\right), 3.99\left(\mathrm{dd}, J_{1}=8.4, J_{2}=6.0\right.$, $\left.1 \mathrm{H}, \mathrm{OCH}_{2}\right), 3.73\left(\mathrm{dd}, J_{1}=8.4, J_{2}=6.0,1 \mathrm{H}, \mathrm{OCH}_{2}\right), 1.34\left(\mathrm{~s}, 3 \mathrm{H}, \mathrm{CH}_{3}\right), 1.30\left(\mathrm{~s}, 3 \mathrm{H}, \mathrm{CH}_{3}\right)$; ES-MS 385.1 $(\mathrm{M}+\mathrm{H})^{+}$; HRMS Calcd. for $\mathrm{C}_{16} \mathrm{H}_{19} \mathrm{Cl}_{2} \mathrm{~N}_{4} \mathrm{O}_{3}{ }^{+}$385.0834, found 385.0838 .

(S)-2,4-Diamino-5-(3-chloro-4-fluorophenyl)-6-[4-(2,2-dimethyl-1,3-dioxolane)methoxy]pyrimidine (9d). Method A. White solid 0.56 g, yield 56\%; m.p. 152.4-152.6 ${ }^{\circ} \mathrm{C}$; IR: $v_{\max } / \mathrm{cm}^{-1} 3527(\mathrm{NH}), 3477(\mathrm{NH})$, $3377(\mathrm{NH}), 3355(\mathrm{NH}), 1626(\mathrm{C}=\mathrm{N}), 1598(\mathrm{C}=\mathrm{C}), 1559(\mathrm{C}=\mathrm{C}), 1482(\mathrm{C}=\mathrm{C}), 1376(\mathrm{C}-\mathrm{F}), 1163$ (C-O-C), 1128 (C-O-C), 1093 (C-O-C), 1043 (C-O-C), 798 (C-Cl); ${ }^{1} \mathrm{H}-\mathrm{NMR}\left(\mathrm{CDCl}_{3}\right) \delta 7.37$ (dd, $J_{1}=7.0, J_{2}=1.8$, $1 \mathrm{H}, \operatorname{Ar}-H), 7.21-7.14(\mathrm{~m}, 2 \mathrm{H}, \mathrm{Ar}-H), 4.71\left(\mathrm{~s}, 2 \mathrm{H}, \mathrm{NH} \mathrm{H}_{2}\right), 4.53\left(\mathrm{~s}, 2 \mathrm{H}, \mathrm{NH}_{2}\right), 4.35\left(\mathrm{dd}, J_{1}=10.6, J_{2}=4.2\right.$, $\left.1 \mathrm{H}, \mathrm{OCH}_{2}\right), 4.32-4.27(\mathrm{~m}, 1 \mathrm{H}, \mathrm{CH}), 4.22\left(\mathrm{dd}, J_{1}=10.6, J_{2}=5.4,1 \mathrm{H}, \mathrm{OCH}_{2}\right), 3.98\left(\mathrm{dd}, J_{1}=8.4, J_{2}=6.4\right.$, $\left.1 \mathrm{H}, \mathrm{OCH}_{2}\right), 3.72\left(\mathrm{dd}, J_{1}=8.4, J_{2}=6.0,1 \mathrm{H}, \mathrm{OCH}_{2}\right), 1.33\left(\mathrm{~s}, 3 \mathrm{H}, \mathrm{CH}_{3}\right), 1.29\left(\mathrm{~s}, 3 \mathrm{H}, \mathrm{CH}_{3}\right) ; \mathrm{ES}-\mathrm{MS} 369.1$ $(\mathrm{M}+\mathrm{H})^{+}$; HRMS Calcd. for $\mathrm{C}_{16} \mathrm{H}_{19} \mathrm{ClFN}_{4} \mathrm{O}_{3}{ }^{+}, 369.1130$, found 369.1132 .

(S)-2,4-Diamino-5-(4-trifluoromethylphenyl)-6-[4-(2,2-dimethyl-1,3-dioxolane)methoxy]pyrimidine (9e). Method A. Light yellow solid 0.64 g, yield 61\%; m.p. 130.0-131.6 ${ }^{\circ} \mathrm{C}$; IR: $v_{\max } / \mathrm{cm}^{-1} 3467(\mathrm{NH}), 3418$ $(\mathrm{NH}), 3336(\mathrm{NH}), 1650(\mathrm{C}=\mathrm{N}), 1625(\mathrm{C}=\mathrm{N}), 1593(\mathrm{C}=\mathrm{C}), 1556(\mathrm{C}=\mathrm{C}), 1523(\mathrm{C}=\mathrm{C}), 1163(\mathrm{C}-\mathrm{O}-\mathrm{C}), 1118$ (C-O-C), 1106 (C-O-C), 1068 (C-O-C); ${ }^{1} \mathrm{H}-\mathrm{NMR}\left(\mathrm{CDCl}_{3}\right) \delta 7.64$ (d, J = 8.0, 2H, Ar-H), $7.46(\mathrm{~d}, J=8.0,2 \mathrm{H}$, $\mathrm{Ar}-\mathrm{H}), 4.72\left(\mathrm{~s}, 2 \mathrm{H}, \mathrm{NH}_{2}\right), 4.55\left(\mathrm{~s}, 2 \mathrm{H}, \mathrm{NH}_{2}\right), 4.37\left(\mathrm{dd}, J_{1}=10.8, J_{2}=4.2,1 \mathrm{H}, \mathrm{OCH}_{2}\right), 4.32-4.27(\mathrm{~m}, 1 \mathrm{H}$, $\mathrm{CH}), 4.22\left(\mathrm{dd}, J_{1}=10.8, J_{2}=5.6,1 \mathrm{H}, \mathrm{OCH}_{2}\right), 3.97\left(\mathrm{dd}, J_{1}=8.4, J_{2}=6.0,1 \mathrm{H}, \mathrm{OCH}_{2}\right), 3.71\left(\mathrm{dd}, J_{1}=8.4\right.$, $\left.J_{2}=6.0,1 \mathrm{H}, \mathrm{OCH}_{2}\right), 1.32\left(\mathrm{~s}, 3 \mathrm{H}, \mathrm{CH}_{3}\right), 1.24\left(\mathrm{~s}, 3 \mathrm{H}, \mathrm{CH}_{3}\right)$; ES-MS $385.1(\mathrm{M}+\mathrm{H})^{+}$; HRMS Calcd. for $\mathrm{C}_{17} \mathrm{H}_{20} \mathrm{~F}_{3} \mathrm{~N}_{4} \mathrm{O}_{3}{ }^{+}$385.1488, found 385.1490 .

(S)-2,4-Diamino-5-(3-trifluoromethylphenyl)-6-[4-(2,2-dimethyl-1,3-dioxolane)methoxy]pyrimidine (9f). Method A. Light yellow solid 0.74 g, yield 71\%; m.p. $126.3-126.5^{\circ} \mathrm{C}$; IR: $v_{\max } / \mathrm{cm}^{-1} 3512(\mathrm{NH}), 3420$ $(\mathrm{NH}), 3382(\mathrm{NH}), 3327(\mathrm{NH}), 1650(\mathrm{C}=\mathrm{N}), 1612(\mathrm{C}=\mathrm{N}), 1593(\mathrm{C}=\mathrm{C}), 1559(\mathrm{C}=\mathrm{C}), 1171(\mathrm{C}-\mathrm{O}-\mathrm{C}), 1128$ (C-O-C), 1094 (C-O-C), 1072 (C-O-C), 1046 (C-O-C); ${ }^{1} \mathrm{H}-\mathrm{NMR}\left(\mathrm{CDCl}_{3}\right) \delta 7.61$ (s, 1H, Ar-H), 7.56-7.49 $(\mathrm{m}, 3 \mathrm{H}, \mathrm{Ar}-\mathrm{H}), 4.73\left(\mathrm{~s}, 2 \mathrm{H}, \mathrm{NH}_{2}\right), 4.55\left(\mathrm{~s}, 2 \mathrm{H}, \mathrm{NH}_{2}\right), 4.36\left(\mathrm{dd}, J_{1}=10.8, J_{2}=4.0,1 \mathrm{H}, \mathrm{OCH}_{2}\right), 4.31-4.25$ $(\mathrm{m}, 1 \mathrm{H}, \mathrm{CH}), 4.21\left(\mathrm{dd}, J_{1}=10.8, J_{2}=5.6,1 \mathrm{H}, \mathrm{OCH}_{2}\right), 3.97\left(\mathrm{dd}, J_{1}=8.2, J_{2}=6.0,1 \mathrm{H}, \mathrm{OCH}_{2}\right), 3.71(\mathrm{dd}$, 
$\left.J_{1}=8.2, J_{2}=6.0,1 \mathrm{H}, \mathrm{OCH}_{2}\right), 1.32\left(\mathrm{~s}, 3 \mathrm{H}, \mathrm{CH}_{3}\right), 1.25\left(\mathrm{~s}, 3 \mathrm{H}, \mathrm{CH}_{3}\right)$; ES-MS $385.1(\mathrm{M}+\mathrm{H})^{+}$; HRMS Calcd . for $\mathrm{C}_{17} \mathrm{H}_{20} \mathrm{~F}_{3} \mathrm{~N}_{4} \mathrm{O}_{3}+385.1488$, found 385.1491 .

(S)-2,4-Diamino-5-(4-trifluoromethoxyphenyl)-6-[4-(2,2-dimethyl-1,3-dioxolane)methoxy]pyrimidine (9g). Method A. Yellow solid 0.80 g, yield 73\%; m.p. $36.7-37.7^{\circ} \mathrm{C}$; IR: $v_{\max } / \mathrm{cm}^{-1} 3487(\mathrm{NH}), 3358(\mathrm{NH})$, 1612 (C=N), 1559 (C=C), 1510 (C=C), 1374 (C-F), 1160 (C-O-C), 1092 (C-O-C), 1053 (C-O-C); ${ }^{1} \mathrm{H}-\mathrm{NMR}$ $\left(\mathrm{CDCl}_{3}\right) \delta 7.35(\mathrm{~d}, J=8.4,2 \mathrm{H}, \mathrm{Ar}-\mathrm{H}), 7.24(\mathrm{~d}, J=8.4,1 \mathrm{H}, \mathrm{Ar}-\mathrm{H}), 4.70\left(\mathrm{~s}, 2 \mathrm{H}, \mathrm{NH}_{2}\right), 4.53\left(\mathrm{~s}, 2 \mathrm{H}, \mathrm{NH}_{2}\right)$, $4.38\left(\mathrm{dd}, J_{1}=11.2, J_{2}=4.0,1 \mathrm{H}, \mathrm{OCH}_{2}\right), 4.32-4.26(\mathrm{~m}, 1 \mathrm{H}, \mathrm{CH}), 4.21\left(\mathrm{dd}, J_{1}=11.2, J_{2}=5.4,1 \mathrm{H}, \mathrm{OCH}_{2}\right)$, $3.96\left(\mathrm{dd}, J_{1}=8.4, J_{2}=6.4,1 \mathrm{H}, \mathrm{OCH}_{2}\right), 3.72\left(\mathrm{dd}, J_{1}=8.2, J_{2}=6.2,1 \mathrm{H}, \mathrm{OCH}_{2}\right), 1.32\left(\mathrm{~s}, 3 \mathrm{H}, \mathrm{CH}_{3}\right), 1.24(\mathrm{~s}$, $\left.3 \mathrm{H}, \mathrm{CH}_{3}\right)$; ES-MS 401.1(M + H) ${ }^{+}$; HRMS Calcd. for $\mathrm{C}_{17} \mathrm{H}_{20} \mathrm{~F}_{3} \mathrm{~N}_{4} \mathrm{O}_{4}{ }^{+} 401.1437$, found 401.1440.

(S)-2,4-Diamino-5-(3-trifluoromethoxyphenyl)-6-[4-(2,2-dimethyl-1,3-dioxolane)methoxy]pyrimidine (9h). Method A. Yellow solid 0.73 g, yield $67 \%$; m.p. 33.7-34.7 ${ }^{\circ} \mathrm{C}$; IR: $v_{\max } / \mathrm{cm}^{-1} 3490(\mathrm{NH}), 3360(\mathrm{NH})$, 1611 (C=N), 1561 (C=C), 1379 (C-F), 1158 (C-O-C), 1082 (C-O-C), 1047 (C-O-C); ${ }^{1} \mathrm{H}-\mathrm{NMR}\left(\mathrm{CDCl}_{3}\right) \delta 7.41$ $(\mathrm{t}, J=8.0,1 \mathrm{H}, \mathrm{Ar}-H), 7.28-7.26(\mathrm{~m}, 1 \mathrm{H} \mathrm{Ar}-H), 7.21(\mathrm{~s}, 1 \mathrm{H}, \mathrm{Ar}-H) 7.14\left(\mathrm{dt}, J_{1}=8.4, J_{2}=1.2,1 \mathrm{H}, \mathrm{Ar}-H\right)$, $4.75\left(\mathrm{~s}, 2 \mathrm{H}, \mathrm{NH}_{2}\right), 4.60\left(\mathrm{~s}, 2 \mathrm{H}, \mathrm{NH}_{2}\right), 4.36\left(\mathrm{dd}, J_{1}=10.8, J_{2}=4.2,1 \mathrm{H}, \mathrm{OCH}_{2}\right), 4.32-4.26(\mathrm{~m}, 1 \mathrm{H}, \mathrm{CH}), 4.21$ $\left(\mathrm{dd}, J_{1}=10.8, J_{2}=5.6,1 \mathrm{H}, \mathrm{OCH}_{2}\right), 3.97\left(\mathrm{dd}, J_{1}=8.4, J_{2}=6.4,1 \mathrm{H}, \mathrm{OCH}_{2}\right), 3.72\left(\mathrm{dd}, J_{1}=8.4, J_{2}=6.0,1 \mathrm{H}\right.$, $\left.\mathrm{OCH}_{2}\right), 1.32\left(\mathrm{~s}, 3 \mathrm{H}, \mathrm{CH}_{3}\right), 1.27\left(\mathrm{~s}, 3 \mathrm{H}, \mathrm{CH}_{3}\right)$; ES-MS 401.1(M + H) ${ }^{+}$; HRMS Calcd. for $\mathrm{C}_{17} \mathrm{H}_{20} \mathrm{~F}_{3} \mathrm{~N}_{4} \mathrm{O}_{4}{ }^{+}$ 401.1437, found 401.1435 .

(S)-2,4-Diamino-5-(4-cyanophenyl)-6-[4-(2,2-dimethyl-1,3-dioxolane)methoxy]pyrimidine (9i). Method A. White solid 0.66 g, yield 71\%; m.p. 221.4-221.9 ${ }^{\circ} \mathrm{C}$; IR: $v_{\max } / \mathrm{cm}^{-1} 3482(\mathrm{NH}), 3456(\mathrm{NH}), 3371(\mathrm{NH})$, $3332(\mathrm{NH}), 2228(\mathrm{CN}), 1654(\mathrm{C}=\mathrm{N}), 1620(\mathrm{C}=\mathrm{N}), 1586(\mathrm{C}=\mathrm{C}), 1564(\mathrm{C}=\mathrm{C}), 1157$ (C-O-C), 1091 (C-O-C), 1051 (C-O-C); ${ }^{1} \mathrm{H}-\mathrm{NMR}\left(\mathrm{CDCl}_{3}\right) \delta 7.67(\mathrm{~d}, J=8.4,2 \mathrm{H}, \mathrm{Ar}-H), 7.47(\mathrm{~d}, J=8.4,2 \mathrm{H} \mathrm{Ar}-H), 4.75\left(\mathrm{~s}, 2 \mathrm{H}, \mathrm{NH}_{2}\right)$, $4.57\left(\mathrm{~s}, 2 \mathrm{H}, \mathrm{NH}_{2}\right), 4.36\left(\mathrm{dd}, J_{1}=10.8, J_{2}=4.0,1 \mathrm{H}, \mathrm{OCH}_{2}\right), 4.32-4.27(\mathrm{~m}, 1 \mathrm{H}, \mathrm{CH}), 4.23\left(\mathrm{dd}, J_{1}=10.4\right.$, $\left.J_{2}=4.2,1 \mathrm{H}, \mathrm{OCH}_{2}\right), 3.97\left(\mathrm{dd}, J_{1}=8.4, J_{2}=6.4,1 \mathrm{H}, \mathrm{OCH}_{2}\right), 3.70\left(\mathrm{dd}, J_{1}=8.4, J_{2}=6.0,1 \mathrm{H}, \mathrm{OCH}_{2}\right)$, $1.32\left(\mathrm{~s}, 3 \mathrm{H}, \mathrm{CH}_{3}\right), 1.28\left(\mathrm{~s}, 3 \mathrm{H}, \mathrm{CH}_{3}\right)$; ES-MS $342.1(\mathrm{M}+\mathrm{H})^{+}$; HRMS Calcd. for $\mathrm{C}_{17} \mathrm{H}_{20} \mathrm{~N}_{5} \mathrm{O}_{3}{ }^{+} 342.1566$, found 342.1564 .

(S)-2,4-Diamino-5-(4-methoxyphenyl)-6-[4-(2,2-dimethyl-1,3-dioxolane)methoxy]pyrimidine (9j). Method A. White solid 0.57 g, yield $60 \%$; m.p. 120.1-121.3 ${ }^{\circ} \mathrm{C}$; IR: $v_{\max } / \mathrm{cm}^{-1} 3458(\mathrm{NH}), 3349(\mathrm{NH}), 1620(\mathrm{C}=\mathrm{N})$, $1594(\mathrm{C}=\mathrm{C}), 1558$ (C=C), $1513(\mathrm{C}=\mathrm{C}), 1157$ (C-O-C), 1085 (C-O-C), $1046(\mathrm{C}-\mathrm{O}-\mathrm{C}){ }^{1} \mathrm{H}-\mathrm{NMR}\left(\mathrm{CDCl}_{3}\right) \delta$ $7.21(\mathrm{~d}, J=8.8,2 \mathrm{H}, \mathrm{Ar}-H), 6.93(\mathrm{~d}, J=8.8,2 \mathrm{H}, \mathrm{Ar}-H), 4.65\left(\mathrm{~s}, 2 \mathrm{H}, \mathrm{NH}_{2}\right), 4.53\left(\mathrm{~s}, 2 \mathrm{H}, \mathrm{NH}_{2}\right), 4.37(\mathrm{dd}$, $\left.J_{1}=10.8, J_{2}=4.0,1 \mathrm{H}, \mathrm{OCH}_{2}\right), 4.32-4.26(\mathrm{~m}, 1 \mathrm{H}, \mathrm{CH}), 4.19\left(\mathrm{dd}, J_{1}=10.8, J_{2}=6.0,1 \mathrm{H}, \mathrm{OCH}_{2}\right), 3.96(\mathrm{dd}$, $\left.J_{1}=8.4, J_{2}=6.0,1 \mathrm{H}, \mathrm{OCH}_{2}\right), 3.82\left(\mathrm{~s}, 3 \mathrm{H}, \mathrm{OCH}_{3}\right), 3.74\left(\mathrm{dd}, J_{1}=8.4, J_{2}=6.0,1 \mathrm{H}, \mathrm{OCH}_{2}\right), 1.32\left(\mathrm{~s}, 3 \mathrm{H}, \mathrm{CH}_{3}\right)$, $1.28\left(\mathrm{~s}, 3 \mathrm{H}, \mathrm{CH}_{3}\right)$; ES-MS $347.2(\mathrm{M}+\mathrm{H})^{+}$; HRMS Calcd. for $\mathrm{C}_{17} \mathrm{H}_{23} \mathrm{~N}_{4} \mathrm{O}_{4}{ }^{+} 347.1719$, found 347.1721.

(S)-2,4-Diamino-5-(3,4,5-trimethoxyphenyl)-6-[4-(2,2-dimethyl-1,3-dioxolane)methoxy]pyrimidine (9k). Method A. White solid $0.61 \mathrm{~g}$, yield 55\%; m.p. 181.7-183.0 ${ }^{\circ} \mathrm{C}$; IR: $v_{\max } / \mathrm{cm}^{-1} 3458(\mathrm{NH}), 3421(\mathrm{NH})$, $3339(\mathrm{NH}), 1660(\mathrm{C}=\mathrm{N}), 1631(\mathrm{C}=\mathrm{N}), 1586(\mathrm{C}=\mathrm{C}), 1557(\mathrm{C}=\mathrm{C}), 1510(\mathrm{C}=\mathrm{C}), 1163$ (C-O-C), 1129 (C-O-), $1075(\mathrm{C}-\mathrm{O}-\mathrm{C}) ;{ }^{1} \mathrm{H}-\mathrm{NMR}\left(\mathrm{CDCl}_{3}\right) \delta 6.55(\mathrm{~s}, 2 \mathrm{H}, \mathrm{Ar}-\mathrm{H}), 4.66\left(\mathrm{~s}, 2 \mathrm{H}, \mathrm{NH}_{2}\right), 4.61\left(\mathrm{~s}, 2 \mathrm{H}, \mathrm{NH}_{2}\right), 4.38-4.31(\mathrm{~m}$, $\left.2 \mathrm{H}, \mathrm{OCH}_{2}\right), 4.2-4.21(\mathrm{~m}, 1 \mathrm{H}, \mathrm{CH}), 4.00\left(\mathrm{dd}, J_{1}=8.4, J_{2}=6.4,1 \mathrm{H}, \mathrm{OCH}_{2}\right), 3.87\left(\mathrm{~s}, 3 \mathrm{H}, \mathrm{OCH}_{3}\right), 3.84(\mathrm{~s}, 6 \mathrm{H}$, $\left.\mathrm{OCH}_{3} \times 2\right), 3.77\left(\mathrm{dd}, J_{1}=8.0, J_{2}=6.0,1 \mathrm{H}, \mathrm{OCH}_{2}\right), 1.32\left(\mathrm{~s}, 3 \mathrm{H}, \mathrm{CH}_{3}\right), 1.28\left(\mathrm{~s}, 3 \mathrm{H}, \mathrm{CH}_{3}\right) ; \mathrm{ES}-\mathrm{MS} 407.2$ $(\mathrm{M}+\mathrm{H})^{+}$; HRMS Calcd. for $\mathrm{C}_{19} \mathrm{H}_{27} \mathrm{~N}_{4} \mathrm{O}_{6}{ }^{+}$407.1931, found 407.1933.

(S)-2,4-Diamino-5-[3-(2,2,2-trifluoroethoxymethyl)phenyl]-6-[4-(2,2-dimethyl-1,3-dioxolane)methoxy]pyrimidine (91). Method A. Yellow solid 0.73 g, yield $62 \%$; m.p. $32.8-33.7{ }^{\circ} \mathrm{C}$; IR: $v_{\max } / \mathrm{cm}^{-1} 3482$ (NH), $3372(\mathrm{NH}), 1611$ (C=N), 1559 (C=C), 1377 (C-F), 1159 (C-O-C), 1121 (C-O-C), 1093 (C-O-C), 1049 (C-O-C); ${ }^{1} \mathrm{H}-\mathrm{NMR}\left(\mathrm{CDCl}_{3}\right) \delta 7.40(\mathrm{t}, J=7.6,1 \mathrm{H}, \mathrm{Ar}-\mathrm{H}), 7.30-7.27(\mathrm{~m}, 3 \mathrm{H}, \mathrm{Ar}-\mathrm{H}), 4.68(\mathrm{~s}, 4 \mathrm{H}, \mathrm{OCH} 2$ and $\left.\mathrm{NH}_{2}\right), 4.55\left(\mathrm{~s}, 2 \mathrm{H}, \mathrm{NH}_{2}\right), 4.35\left(\mathrm{dd}, J_{1}=10.4, J_{2}=4.0,1 \mathrm{H}, \mathrm{OCH}_{2}\right), 4.31-4.26(\mathrm{~m}, 1 \mathrm{H}, \mathrm{CH}), 4.22(\mathrm{dd}$, $\left.J_{1}=10.8, J_{2}=5.6,1 \mathrm{H}, \mathrm{OCH}_{2}\right), 3.96\left(\mathrm{dd}, J_{1}=8.4, J_{2}=6.0,1 \mathrm{H}, \mathrm{OCH}_{2}\right), 3.86\left(\mathrm{q}, J=8.8,2 \mathrm{H}, \mathrm{CF}_{3} \mathrm{CH}_{2}\right), 3.73$ $\left(\mathrm{dd}, J_{1}=8.4, J_{2}=6.0,1 \mathrm{H}, \mathrm{OCH}_{2}\right), 1.31\left(\mathrm{~s}, 3 \mathrm{H}, \mathrm{CH}_{3}\right), 1.25\left(\mathrm{~s}, 3 \mathrm{H}, \mathrm{CH}_{3}\right)$; ES-MS 429.2(M + H) ${ }^{+}$; HRMS Calcd. for $\mathrm{C}_{19} \mathrm{H}_{24} \mathrm{~F}_{3} \mathrm{~N}_{4} \mathrm{O}_{4}{ }^{+} 429.1750$, found 429.1752 . 
(S)-2,4-Diamino-5-[3,5-dimethyl-4-(N-methoxyaminosulfonyl)phenyl]-6-[4-(2,2-dimethyl-1,3-dioxolane)methoxy]pyrimidine (9m). Method A. Light yellow solid 0.75 g, yield 61\%; m.p. 160.5-160.8 ${ }^{\circ} \mathrm{C}$; IR: $v_{\max } / \mathrm{cm}^{-1} 3484(\mathrm{NH}), 3446(\mathrm{NH}), 3347(\mathrm{NH}), 3223\left(\mathrm{SO}_{2} \mathrm{NH}\right), 1641(\mathrm{C}=\mathrm{N}), 1619(\mathrm{C}=\mathrm{N}), 1591(\mathrm{C}=\mathrm{C})$, 1562 (C=C), 1492 (C=C), 1173 (C-O-C), 1149 (C-O-C), 1099 (C-O-C), 1054 (C-O-C); ${ }^{1} \mathrm{H}-\mathrm{NMR}\left(\mathrm{CDCl}_{3}\right) \delta$ $\left.7.42(\mathrm{~s}, 1 \mathrm{H}, \mathrm{NH}), 7.18(\mathrm{~s}, 2 \mathrm{H}, \mathrm{Ar}-\mathrm{H}), 4.73(\mathrm{~s}, 2 \mathrm{H}, \mathrm{NH})_{2}, 4.60(\mathrm{~s}, 2 \mathrm{H}, \mathrm{NH})_{2}\right), 4.35\left(\mathrm{dd}, J_{1}=10.4, J_{2}=4.0,1 \mathrm{H}\right.$, $\left.\mathrm{OCH}_{2}\right), 4.32-4.27(\mathrm{~m}, 1 \mathrm{H}, \mathrm{CH}), 4.24\left(\mathrm{dd}, J_{1}=10.4, J_{2}=4.8,1 \mathrm{H}, \mathrm{OCH}_{2}\right), 3.99\left(\mathrm{dd}, J_{1}=8.2, J_{2}=6.2,1 \mathrm{H}\right.$, $\left.\mathrm{OCH}_{2}\right), 3.75-3.72\left(\mathrm{~m}, 4 \mathrm{H}, \mathrm{OCH}_{3}\right.$ and $\left.\mathrm{OCH}_{2}\right), 2.69\left(\mathrm{~s}, 6 \mathrm{H}, \mathrm{CH}_{3} \times 2\right), 1.33\left(\mathrm{~s}, 3 \mathrm{H}, \mathrm{CH}_{3}\right), 1.29\left(\mathrm{~s}, 3 \mathrm{H}, \mathrm{CH}_{3}\right)$; ES-MS 454.2 $(\mathrm{M}+\mathrm{H})^{+}$; HRMS Calcd. for $\mathrm{C}_{19} \mathrm{H}_{28} \mathrm{~N}_{5} \mathrm{O}_{6} \mathrm{~S}^{+} 454.1760$, found 454.1762 .

(S)-2,4-Diamino-5-[4-(morpholino-4-carbonyl)phenyl]-6-[4-(2,2-dimethyl-1,3-dioxolane)methoxy]pyrimidine (9n). Method A. White solid 0.64 g, yield 55\%; m.p. 186.1-187.2 ${ }^{\circ}$ C; IR: $v_{\max } / \mathrm{cm}^{-1} 3492$ (NH), 3430 (NH), $3332(\mathrm{NH}), 1659(\mathrm{C}=\mathrm{N}), 1610(\mathrm{C}=\mathrm{N}), 1588(\mathrm{C}=\mathrm{C}), 1558(\mathrm{C}=\mathrm{C}), 1516(\mathrm{C}=\mathrm{C}), 1488(\mathrm{C}=\mathrm{C}), 1156$ (C-O-C), 1114 (C-O-C), 1070 (C-O-C), 1050 (C-O-C); ${ }^{1} \mathrm{H}-\mathrm{NMR}\left(\mathrm{CDCl}_{3}\right) \delta 7.45$ (d, J = 8.4, 2H, Ar-H), $7.38(\mathrm{~d}, J=8.4,2 \mathrm{H}, \mathrm{Ar}-H), 4.82\left(\mathrm{~s}, 2 \mathrm{H}, \mathrm{NH} \mathrm{H}_{2}\right), 4.67\left(\mathrm{~s}, 2 \mathrm{H}, \mathrm{NH}_{2}\right), 4.38\left(\mathrm{dd}, J_{1}=10.8, J_{2}=4.4,1 \mathrm{H}, \mathrm{OCH}_{2}\right)$, $4.32-4.28(\mathrm{~m}, 1 \mathrm{H}, \mathrm{CH}), 4.23\left(\mathrm{dd}, J_{1}=10.8, J_{2}=5.6,1 \mathrm{H}, \mathrm{OCH}_{2}\right), 3.97\left(\mathrm{dd}, J_{1}=8.2, J_{2}=6.2,1 \mathrm{H}, \mathrm{OCH}_{2}\right)$, 3.82-3.51 (m, 8H, CH $\times$ 4), $3.72\left(\mathrm{dd}, J_{1}=8.4, J_{2}=6.0,1 \mathrm{H}, \mathrm{OCH}_{2}\right), 1.32\left(\mathrm{~s}, 3 \mathrm{H}, \mathrm{CH}_{3}\right), 1.28\left(\mathrm{~s}, 3 \mathrm{H}, \mathrm{CH}_{3}\right)$; ES-MS $430.2(\mathrm{M}+\mathrm{H})^{+}$; HRMS Calcd. for $\mathrm{C}_{21} \mathrm{H}_{28} \mathrm{~N}_{5} \mathrm{O}_{5}{ }^{+} 430.2090$, found 430.2088 .

(S)-2,4-Diamino-5-[4-(3-trifluoromethoxyanilinocarbonyl)phenyl]-6-[4-(2,2-dimethyl-1,3-dioxolane)-methoxy] pyrimidine (9o). Method A. White solid 0.74 g, yield 52\%; m.p. 83.7-85 ${ }^{\circ} \mathrm{C}$; IR: $v_{\max } / \mathrm{cm}^{-1} 3488(\mathrm{NH})$, $3351(\mathrm{NH}), 3202(\mathrm{CONH}), 1657(\mathrm{C}=\mathrm{N}), 1606(\mathrm{C}=\mathrm{C}), 1565(\mathrm{C}=\mathrm{C}), 1548(\mathrm{C}=\mathrm{C}), 1492(\mathrm{C}=\mathrm{C}), 1156$ (C-O-C), $1082(\mathrm{C}-\mathrm{O}-\mathrm{C}) ;{ }^{1} \mathrm{H}-\mathrm{NMR}\left(\mathrm{CDCl}_{3}\right) \delta 8.04(\mathrm{~s}, 1 \mathrm{H}, \mathrm{NH}), 7.85(\mathrm{~d}, J=8.4,2 \mathrm{H}, \mathrm{Ar}-\mathrm{H}), 7.71(\mathrm{~s}, 1 \mathrm{H}, \mathrm{Ar}-\mathrm{H})$, $7.54\left(\mathrm{dd}, J_{1}=8.0, J_{2}=1.2,1 \mathrm{H}, \mathrm{Ar}-\mathrm{H}\right), 7.45(\mathrm{~d}, J=8.4,2 \mathrm{H}, \mathrm{Ar}-\mathrm{H}), 7.39(\mathrm{t}, J=8.0,1 \mathrm{H}, \mathrm{Ar}-H), 7.02(\mathrm{dt}$, $\left.J_{1}=8.0, J_{2}=1.0,1 \mathrm{H}, \mathrm{Ar}-H\right), 4.74\left(\mathrm{~s}, 2 \mathrm{H}, \mathrm{NH} H_{2}\right), 4.59\left(\mathrm{~s}, 2 \mathrm{H}, \mathrm{NH}_{2}\right), 4.35\left(\mathrm{dd}, J_{1}=10.0, J_{2}=4.0,1 \mathrm{H}, \mathrm{OCH}_{2}\right)$, $4.32-4.29(\mathrm{~m}, 1 \mathrm{H}, \mathrm{CH}), 4.26\left(\mathrm{dd}, J_{1}=10.0, J_{2}=4.8,1 \mathrm{H}, \mathrm{OCH}_{2}\right), 3.99\left(\mathrm{dd}, J_{1}=8.4, J_{2}=6.0,1 \mathrm{H}, \mathrm{OCH}_{2}\right)$, $3.73\left(\mathrm{dd}, J_{1}=8.2, J_{2}=5.4,1 \mathrm{H}, \mathrm{OCH}_{2}\right), 1.30\left(\mathrm{~s}, 3 \mathrm{H}, \mathrm{CH}_{3}\right), 1.29\left(\mathrm{~s}, 3 \mathrm{H}, \mathrm{CH}_{3}\right)$; ES-MS $520.2(\mathrm{M}+\mathrm{H})^{+}$; HRMS Calcd. for $\mathrm{C}_{24} \mathrm{H}_{25} \mathrm{~F}_{3} \mathrm{~N}_{5} \mathrm{O}_{5}{ }^{+} 520.1808$, found 520.1811 .

(S)-2,4-Diamino-5-(4-methoxycarbonylphenyl)-6-[4-(2,2-dimethyl-1,3-dioxolane)methoxy]pyrimidine (9p). Method B. White solid 0.70 g, yield 69\%; m.p. 146.3-147.4 ${ }^{\circ} \mathrm{C}$; IR: $v_{\max } / \mathrm{cm}^{-1} 3501(\mathrm{NH}), 3442$ (NH), $3392(\mathrm{NH}), 3336(\mathrm{NH}), 1708(\mathrm{C}=\mathrm{O}), 1658(\mathrm{C}=\mathrm{N}), 1610(\mathrm{C}=\mathrm{N}), 1555(\mathrm{C}=\mathrm{C}), 1515(\mathrm{C}=\mathrm{C}), 1153$ (C-O-C), 1115 (C-O-C), 1067 (C-O-C); ${ }^{1} \mathrm{H}-\mathrm{NMR}\left(\mathrm{CDCl}_{3}\right) \delta 8.05$ (d, J = 8.4, 2H, Ar-H), $7.29(\mathrm{~d}, \mathrm{~J}=8.4,2 \mathrm{H}$, Ar- $H), 4.72\left(\mathrm{~s}, 2 \mathrm{H}, \mathrm{NH}_{2}\right), 4.58\left(\mathrm{~s}, 2 \mathrm{H}, \mathrm{NH}_{2}\right), 4.36\left(\mathrm{dd}, J_{1}=10.6, J_{2}=4.2,1 \mathrm{H}, \mathrm{OCH}_{2}\right), 4.31-4.26(\mathrm{~m}, 1 \mathrm{H}$, $\mathrm{CH}), 4.22\left(\mathrm{dd}, J_{1}=10.6, J_{2}=5.8,1 \mathrm{H}, \mathrm{OCH}_{2}\right), 3.96\left(\mathrm{dd}, J_{1}=8.4, J_{2}=6.0,1 \mathrm{H}, \mathrm{OCH}_{2}\right), 3.93\left(\mathrm{~s}, 3 \mathrm{H}, \mathrm{OCH}_{3}\right)$, $3.71\left(\mathrm{dd}, J_{1}=8.0, J_{2}=6.0,1 \mathrm{H}, \mathrm{OCH}_{2}\right), 1.32\left(\mathrm{~s}, 3 \mathrm{H}, \mathrm{CH}_{3}\right), 1.27\left(\mathrm{~s}, 3 \mathrm{H}, \mathrm{CH}_{3}\right) ; \mathrm{ES}-\mathrm{MS} 375.2(\mathrm{M}+\mathrm{H})^{+} ; \mathrm{HRMS}$ Calcd. for $\mathrm{C}_{18} \mathrm{H}_{23} \mathrm{~N}_{4} \mathrm{O}_{5}{ }^{+} 375.1668$, found 375.1670 .

(S)-2,4-Diamino-5-(3-methoxycarbonylphenyl)-6-[4-(2,2-dimethyl-1,3-dioxolane)methoxy]pyrimidine (9q). Method B. White solid 0.80 g, yield 78\%; m.p. 179.2-180.3 ${ }^{\circ} \mathrm{C}$; IR: $v_{\max } / \mathrm{cm}^{-1} 3480(\mathrm{NH}), 3371$ (NH), $3326(\mathrm{NH}), 1708(\mathrm{C}=\mathrm{O}), 1652(\mathrm{C}=\mathrm{N}), 1626(\mathrm{C}=\mathrm{N}), 1601(\mathrm{C}=\mathrm{C}), 1592(\mathrm{C}=\mathrm{C}), 1557(\mathrm{C}=\mathrm{C}), 1158$ (C-O-C), 1115 (C-O-C), 1084 (C-O-C), 1049 (C-O-C); ${ }^{1} \mathrm{H}-\mathrm{NMR}\left(\mathrm{CDCl}_{3}\right) \delta 8.00$ (t, J = 1.6, 1H, Ar-H), 7.96 $\left(\mathrm{dt}, J_{1}=7.6, J_{2}=1.6,1 \mathrm{H}, \mathrm{Ar}-H\right), 7.52\left(\mathrm{dt}, J_{1}=7.6, J_{2}=1.6,1 \mathrm{H}, \mathrm{Ar}-H\right), 7.47(\mathrm{t}, J=7.6,1 \mathrm{H}, \mathrm{Ar}-\mathrm{H}), 4.71$ $\left(\mathrm{s}, 2 \mathrm{H}, \mathrm{NH}_{2}\right), 4.54\left(\mathrm{~s}, 2 \mathrm{H}, \mathrm{NH}_{2}\right), 4.37\left(\mathrm{dd}, J_{1}=10.8, J_{2}=4.0,1 \mathrm{H}, \mathrm{OCH}_{2}\right), 4.30-4.25(\mathrm{~m}, 1 \mathrm{H}, \mathrm{CH}), 4.19$ $\left(\mathrm{dd}, J_{1}=10.8, J_{2}=6.0,1 \mathrm{H}, \mathrm{OCH}_{2}\right), 3.96\left(\mathrm{dd}, J_{1}=8.4, J_{2}=6.4,1 \mathrm{H}, \mathrm{OCH}_{2}\right), 3.92\left(\mathrm{~s}, 3 \mathrm{H}, \mathrm{OCH}_{3}\right), 3.72(\mathrm{dd}$, $\left.J_{1}=8.4, J_{2}=6.0,1 \mathrm{H}, \mathrm{OCH}_{2}\right), 1.31\left(\mathrm{~s}, 3 \mathrm{H}, \mathrm{CH}_{3}\right), 1.25\left(\mathrm{~s}, 3 \mathrm{H}, \mathrm{CH}_{3}\right)$; ES-MS 375.2(M + H $)^{+}$; HRMS Calcd. for $\mathrm{C}_{18} \mathrm{H}_{23} \mathrm{~N}_{4} \mathrm{O}_{5}+375.1668$, found 375.1666 .

General Procedure for the Synthesis of Compounds 10a-q and 11a-q

The compounds 8a-q or 9a-q $(1.42 \mathrm{mmol})$ was added to $0.25 \mathrm{M} \mathrm{H}_{2} \mathrm{SO}_{4}(20 \mathrm{~mL})$ and stirred at room temperature overnight. After the completion of the reaction as indicated by TLC analysis, the reaction solution was adjusted the $\mathrm{pH}$ to 9 and extracted with EtOAc $(30 \mathrm{~mL} \times 3)$. The combined organic layers were washed by $\mathrm{H}_{2} \mathrm{O}$ and dried with $\mathrm{Na}_{2} \mathrm{SO}_{4}$, filtered and concentrated. The residue was purified by 
column chromatography on silica gel using $\mathrm{CH}_{2} \mathrm{Cl}_{2} / \mathrm{CH}_{3} \mathrm{OH}(80: 1, v / v)$ as the eluting solvent to the desired compounds.

(R)-2,4-Diamino-5-(4-chlorophenyl)-6-(1,2-dihydroxypropyl)pyrimidine (10a). White solid $0.37 \mathrm{~g}$, yield 84\%; m.p. 164.4-166.3 ${ }^{\circ} \mathrm{C}$; IR: $v_{\max } / \mathrm{cm}^{-1} 3443(\mathrm{OH}), 3396(\mathrm{OH}), 3335(\mathrm{NH}), 3224(\mathrm{NH}), 1658(\mathrm{C}=\mathrm{N}), 1627$ $(\mathrm{C}=\mathrm{N}), 1604(\mathrm{C}=\mathrm{C}), 1591(\mathrm{C}=\mathrm{C}), 1569(\mathrm{C}=\mathrm{C}), 1555(\mathrm{C}=\mathrm{C}), 1503(\mathrm{C}=\mathrm{C}), 1483(\mathrm{C}=\mathrm{C}), 796$ (C-Cl); ${ }^{1} \mathrm{H}-\mathrm{NMR}$ (DMSO- $\left.d_{6}\right) \delta 7.38(\mathrm{~d}, J=8.4,2 \mathrm{H}, \mathrm{Ar}-H), 7.27(\mathrm{~d}, J=8.4,2 \mathrm{H}, \mathrm{Ar}-H), 6.02\left(\mathrm{~s}, 2 \mathrm{H}, \mathrm{NH} \mathrm{H}_{2}\right), 5.63\left(\mathrm{~s}, 2 \mathrm{H}, \mathrm{NH}_{2}\right)$, $4.72(\mathrm{~d}, J=4.8,1 \mathrm{H}, \mathrm{CHOH}), 4.50\left(\mathrm{t}, J=5.8,1 \mathrm{H}, \mathrm{CH}_{2} \mathrm{OH}\right), 4.08\left(\mathrm{~d}, J=5.2,2 \mathrm{H}, \mathrm{OCH}_{2}\right), 3.62-3.56(\mathrm{~m}, 1 \mathrm{H}$, $\mathrm{CH})$, 3.29-3.23 (m, 2H, OCH $\left.{ }_{2}\right)$; ES-MS $311.1(\mathrm{M}+\mathrm{H})^{+}$; HRMS Calcd. for $\mathrm{C}_{13} \mathrm{H}_{16} \mathrm{ClN}_{4} \mathrm{O}_{3}{ }^{+} 311.0911$, found 311.0909 .

(R)-2,4-Diamino-5-(4-fluorophenyl)-6-(1,2-dihydroxypropyl)pyrimidine (10b). White solid $0.30 \mathrm{~g}$, yield 68\%; m.p. 122.4-122.8 ${ }^{\circ} \mathrm{C}$; IR: $v_{\max } / \mathrm{cm}^{-1} 3520(\mathrm{OH}), 3472(\mathrm{OH}), 3407(\mathrm{NH}), 3349(\mathrm{NH}), 1651(\mathrm{C}=\mathrm{N}), 1617$ $(\mathrm{C}=\mathrm{N}), 1592(\mathrm{C}=\mathrm{C}), 1570(\mathrm{C}=\mathrm{C}), 1484(\mathrm{C}=\mathrm{C}), 1397(\mathrm{C}-\mathrm{F}) ;{ }^{1} \mathrm{H}-\mathrm{NMR}\left(\mathrm{DMSO}-d_{6}\right) \delta 7.28\left(\mathrm{dd}, J_{1}=8.8\right.$, $\left.J_{2}=5.6,2 \mathrm{H}, \mathrm{Ar}-H\right), 7.15(\mathrm{t}, J=8.8,2 \mathrm{H}, \mathrm{Ar}-H), 5.99\left(\mathrm{~s}, 2 \mathrm{H}, \mathrm{NH}_{2}\right), 5.57(\mathrm{~s}, 2 \mathrm{H}, \mathrm{NH} 2), 4.72(\mathrm{~d}, J=4.8,1 \mathrm{H}$, $\mathrm{CHOH}), 4.49\left(\mathrm{t}, J=5.6,1 \mathrm{H}, \mathrm{CH}_{2} \mathrm{OH}\right), 4.08\left(\mathrm{~d}, J=5.6,2 \mathrm{H}, \mathrm{OCH}_{2}\right), 3.63-3.55(\mathrm{~m}, 1 \mathrm{H}, \mathrm{CH}), 3.31-3.24(\mathrm{~m}$, 2H, OCH $H_{2}$; ES-MS 295.1 $(\mathrm{M}+\mathrm{H})^{+}$; HRMS Calcd. for $\mathrm{C}_{13} \mathrm{H}_{16} \mathrm{FN}_{4} \mathrm{O}_{3}{ }^{+}$295.1206, found 295.1204.

(R)-2,4-Diamino-5-(3,4-dichlorophenyl)-6-(1,2-dihydroxypropyl)pyrimidine (10c). White solid $0.32 \mathrm{~g}$, yield 71\%; m.p. 159.5-160.2 ${ }^{\circ} \mathrm{C}$; IR: $v_{\max } / \mathrm{cm}^{-1} 3504(\mathrm{OH}), 3476(\mathrm{OH}), 3344(\mathrm{NH}), 3229(\mathrm{NH}), 1650(\mathrm{C}=\mathrm{N})$, 1619(C=N), $1593(\mathrm{C}=\mathrm{C}), 1570(\mathrm{C}=\mathrm{C}), 1490(\mathrm{C}=\mathrm{C}), 792(\mathrm{C}-\mathrm{Cl}) ;{ }^{1} \mathrm{H}-\mathrm{NMR}\left(\mathrm{DMSO}-d_{6}\right) \delta 7.56(\mathrm{~d}, J=8.0,1 \mathrm{H}$, Ar-H), $7.47(\mathrm{~d}, J=2.0,1 \mathrm{H}, \mathrm{Ar}-H), 7.24\left(\mathrm{dd}, J_{1}=8.0, J_{2}=2.0,1 \mathrm{H}, \mathrm{Ar}-H\right), 6.07\left(\mathrm{~s}, 2 \mathrm{H}, \mathrm{NH}_{2}\right), 5.79(\mathrm{~s}, 2 \mathrm{H}$, $\left.\mathrm{NH}_{2}\right), 4.74(\mathrm{~d}, 1 \mathrm{H}, J=4.8, \mathrm{CHOH}), 4.52\left(\mathrm{t}, J=5.8,1 \mathrm{H}, \mathrm{CH}_{2} \mathrm{OH}\right), 4.14-4.06\left(\mathrm{~m}, 2 \mathrm{H}, \mathrm{OCH}_{2}\right), 3.63-3.57(\mathrm{~m}$, $1 \mathrm{H}, \mathrm{CH}), 3.28-3.31\left(\mathrm{~m}, 2 \mathrm{H}, \mathrm{OCH}_{2}\right)$; ES-MS $345.1(\mathrm{M}+\mathrm{H})^{+}$; HRMS Calcd. for $\mathrm{C}_{13} \mathrm{H}_{15} \mathrm{Cl}_{2} \mathrm{~N}_{4} \mathrm{O}_{3}{ }^{+} 345.0521$, found 345.0519 .

(R)-2,4-Diamino-5-(3-chloro-4-fluorophenyl)-6-(1,2-dihydroxypropyl)pyrimidine (10d). White solid $0.39 \mathrm{~g}$, yield 88\%; m.p. $158.0-159.9{ }^{\circ} \mathrm{C}$; IR: $v_{\max } / \mathrm{cm}^{-1} 3484(\mathrm{OH}), 3437(\mathrm{OH}), 3318(\mathrm{NH}), 3209(\mathrm{NH}), 1627$ $(\mathrm{C}=\mathrm{N}), 1586(\mathrm{C}=\mathrm{C}), 1560(\mathrm{C}=\mathrm{C}), 1349(\mathrm{C}-\mathrm{F}), 801(\mathrm{C}-\mathrm{Cl}) ;{ }^{1} \mathrm{H}-\mathrm{NMR}\left(\mathrm{DMSO}-d_{6}\right) \delta 7.40\left(\mathrm{dd}, J_{1}=7.6, J_{2}=2.4\right.$, $1 \mathrm{H}, \mathrm{Ar}-H), 7.36(\mathrm{t}, J=9.0,1 \mathrm{H}, \mathrm{Ar}-H), 7.23\left(\mathrm{ddd}, J_{1}=8.4, J_{2}=4.8, J_{3}=2.0,1 \mathrm{H}, \mathrm{Ar}-H\right), 6.04(\mathrm{~s}, 2 \mathrm{H}$, $\left.\mathrm{NH}_{2}\right), 5.74\left(\mathrm{~s}, 2 \mathrm{H}, \mathrm{NH}_{2}\right), 4.74(\mathrm{~d}, J=4.8,1 \mathrm{H}, \mathrm{CHOH}), 4.51\left(\mathrm{t}, J=5.8,1 \mathrm{H}, \mathrm{CH}_{2} \mathrm{OH}\right), 4.13-4.05(\mathrm{~m}, 2 \mathrm{H}$, $\left.\mathrm{OCH}_{2}\right), 3.63-3.56(\mathrm{~m}, 1 \mathrm{H}, \mathrm{CH}), 3.30-3.26\left(\mathrm{~m}, 2 \mathrm{H}, \mathrm{OCH}_{2}\right)$; ES-MS 329.1(M + H) ${ }^{+}$; HRMS Calcd. for $\mathrm{C}_{13} \mathrm{H}_{15} \mathrm{ClFN}_{4} \mathrm{O}_{3}{ }^{+}$329.0817, found 329.0820.

(R)-2,4-Diamino-5-(4-trifluoromethylphenyl)-6-(1,2-dihydroxypropyl)pyrimidine (10e). White solid $0.37 \mathrm{~g}$, yield 83\%; m.p. $170.5-171.0^{\circ} \mathrm{C}$; IR: $v_{\max } / \mathrm{cm}^{-1} 3587(\mathrm{OH}), 3506(\mathrm{OH}), 3378(\mathrm{NH}), 3226(\mathrm{NH}), 1631$ $(\mathrm{C}=\mathrm{N}), 1591(\mathrm{C}=\mathrm{C}), 1559(\mathrm{C}=\mathrm{C}), 1520(\mathrm{C}=\mathrm{C}), 1322(\mathrm{C}-\mathrm{F}) ;{ }^{1} \mathrm{H}-\mathrm{NMR}\left(\mathrm{DMSO}-d_{6}\right) \delta 7.67(\mathrm{~d}, J=8.4,2 \mathrm{H}$, Ar- $H), 7.50(\mathrm{~d}, J=8.0,2 \mathrm{H}, \mathrm{Ar}-H), 6.09\left(\mathrm{~s}, 2 \mathrm{H}, \mathrm{NH}_{2}\right), 5.75\left(\mathrm{~s}, 2 \mathrm{H}, \mathrm{NH}_{2}\right), 4.74(\mathrm{~d}, J=5.2,1 \mathrm{H}, \mathrm{CHOH}), 4.52$ $\left(\mathrm{t}, J=5.8,1 \mathrm{H}, \mathrm{CH}_{2} \mathrm{OH}\right), 4.15-4.07\left(\mathrm{~m}, 2 \mathrm{H}, \mathrm{OCH}_{2}\right), 3.64-3.57(\mathrm{~m}, 1 \mathrm{H}, \mathrm{CH}), 3.24-3.30\left(\mathrm{~m}, 2 \mathrm{H}, \mathrm{OCH}_{2}\right)$; ES-MS 345.1 $(\mathrm{M}+\mathrm{H})^{+}$; HRMS Calcd. for $\mathrm{C}_{14} \mathrm{H}_{16} \mathrm{~F}_{3} \mathrm{~N}_{4} \mathrm{O}_{3}{ }^{+}$345.1175, found 345.1173.

(R)-2,4-Diamino-5-(3-trifluoromethylphenyl)-6-(1,2-dihydroxypropyl)pyrimidine (10f). White solid $0.41 \mathrm{~g}$, yield 92\%; m.p. $137.8-138.9^{\circ} \mathrm{C}$; IR: $v_{\max } / \mathrm{cm}^{-1} 3521(\mathrm{OH}), 3474(\mathrm{OH}), 3349(\mathrm{NH}), 3235(\mathrm{NH}), 1650$ $(\mathrm{C}=\mathrm{N}), 1621(\mathrm{C}=\mathrm{N}), 1594(\mathrm{C}=\mathrm{C}), 1569(\mathrm{C}=\mathrm{C}), 1495(\mathrm{C}=\mathrm{C}), 1341(\mathrm{C}-\mathrm{F}) ;{ }^{1} \mathrm{H}-\mathrm{NMR}\left(\mathrm{DMSO}-d_{6}\right) \delta$ 7.58-7.55 $(\mathrm{m}, 4 \mathrm{H}, \mathrm{Ar}-\mathrm{H}), 6.08\left(\mathrm{~s}, 2 \mathrm{H}, \mathrm{NH}_{2}\right), 5.74\left(\mathrm{~s}, 2 \mathrm{H}, \mathrm{NH}_{2}\right), 4.72(\mathrm{~d}, 1 \mathrm{H}, J=5.2, \mathrm{CHOH}), 4.50(\mathrm{t}, J=5.8,1 \mathrm{H}$, $\left.\mathrm{CH}_{2} \mathrm{OH}\right), 4.11\left(\mathrm{~d}, J=4.8,2 \mathrm{H}, \mathrm{OCH}_{2}\right), 3.62-3.56(\mathrm{~m}, 1 \mathrm{H}, \mathrm{CH}), 3.31-3.26\left(\mathrm{~m}, 2 \mathrm{H}, \mathrm{OCH}_{2}\right) ; \mathrm{ES}-\mathrm{MS} 345.1$ $(\mathrm{M}+\mathrm{H})^{+}$; HRMS Calcd. for $\mathrm{C}_{14} \mathrm{H}_{16} \mathrm{~F}_{3} \mathrm{~N}_{4} \mathrm{O}_{3}{ }^{+} 345.1175$, found 345.1172 .

(R)-2,4-Diamino-5-(4-trifluoromethoxyphenyl)-6-(1,2-dihydroxypropyl)pyrimidine (10g). White solid $0.42 \mathrm{~g}$, yield 85\%; m.p. $181.4-182.1{ }^{\circ} \mathrm{C}$; IR: $v_{\max } / \mathrm{cm}^{-1} 3579(\mathrm{OH}), 3457(\mathrm{OH}), 3341(\mathrm{NH}), 3231(\mathrm{NH}), 1636$ $(\mathrm{C}=\mathrm{N}), 1590(\mathrm{C}=\mathrm{C}), 1557(\mathrm{C}=\mathrm{C}), 1549(\mathrm{C}=\mathrm{C}), 1501(\mathrm{C}=\mathrm{C}), 1316(\mathrm{C}-\mathrm{F}){ }^{1} \mathrm{H}-\mathrm{NMR}$ (DMSO-d 6 ) $\delta 7.38(\mathrm{~d}$, $J=8.4,2 \mathrm{H}, \mathrm{Ar}-\mathrm{H}), 7.31(\mathrm{~d}, J=8.4,2 \mathrm{H}, \mathrm{Ar}-\mathrm{H}), 6.06\left(\mathrm{~s}, 2 \mathrm{H}, \mathrm{NH}_{2}\right), 5.69\left(\mathrm{~s}, 2 \mathrm{H}, \mathrm{NH}_{2}\right), 4.77(\mathrm{~d}, J=5.2,1 \mathrm{H}$, $\mathrm{CHOH}), 4.53\left(\mathrm{t}, J=5.8,1 \mathrm{H}, \mathrm{CH}_{2} \mathrm{OH}\right), 4.10\left(\mathrm{~d}, J=5.2,2 \mathrm{H}, \mathrm{OCH}_{2}\right), 3.63-3.57(\mathrm{~m}, 1 \mathrm{H}, \mathrm{CH}), 3.32-3.23(\mathrm{~m}$, $\left.2 \mathrm{H}, \mathrm{OCH}_{2}\right)$; ES-MS $361.1(\mathrm{M}+\mathrm{H})^{+}$; HRMS Calcd. for $\mathrm{C}_{14} \mathrm{H}_{16} \mathrm{~F}_{3} \mathrm{~N}_{4} \mathrm{O}_{4}{ }^{+} 361.1124$, found 361.1120. 
(R)-2,4-Diamino-5-(3-trifluoromethoxyphenyl)-6-(1,2-dihydroxypropyl)pyrimidine (10h). White solid $0.44 \mathrm{~g}$, yield 89\%; m.p. 58.5-59.6 ${ }^{\circ} \mathrm{C}$; IR: $v_{\max } / \mathrm{cm}^{-1} 3467(\mathrm{OH}), 3379(\mathrm{OH}), 3350(\mathrm{NH}), 1612(\mathrm{C}=\mathrm{N}), 1562$ $(\mathrm{C}=\mathrm{C}), 1495(\mathrm{C}=\mathrm{C}), 1348(\mathrm{C}-\mathrm{F}) ;{ }^{1} \mathrm{H}-\mathrm{NMR}\left(\mathrm{DMSO}-d_{6}\right) \delta 7.46(\mathrm{t}, J=8.0,2 \mathrm{H}, \mathrm{Ar}-H), 7.31(\mathrm{~d}, J=8.0,2 \mathrm{H}$, Ar-H), 7.23 (s, 1H, Ar-H), $\left.7.20(\mathrm{~d}, J=8.0,1 \mathrm{H}, \mathrm{Ar}-\mathrm{H}), 6.09\left(\mathrm{~s}, 2 \mathrm{H}, \mathrm{NH}_{2}\right), 5.73(\mathrm{~s}, 2 \mathrm{H}, \mathrm{NH})_{2}\right), 4.75(\mathrm{~d}, J=4.8$, $1 \mathrm{H}, \mathrm{CHOH}), 4.52\left(\mathrm{t}, J=5.6,1 \mathrm{H}, \mathrm{CH}_{2} \mathrm{OH}\right), 4.10\left(\mathrm{~d}, J=5.2,2 \mathrm{H}, \mathrm{OCH}_{2}\right), 3.63-3.56(\mathrm{~m}, 1 \mathrm{H}, \mathrm{CH}), 3.31-3.24$ $\left(\mathrm{m}, 2 \mathrm{H}, \mathrm{OCH}_{2}\right)$; ES-MS 361.1 (M + H) ${ }^{+}$; HRMS Calcd. for $\mathrm{C}_{14} \mathrm{H}_{16} \mathrm{~F}_{3} \mathrm{~N}_{4} \mathrm{O}_{4}{ }^{+}$361.1124, found 361.1128.

(R)-2,4-Diamino-5-(4-cyanophenyl)-6-(1,2-dihydroxypropyl)pyrimidine (10i). White solid 0.39 g, yield 88\%; m.p. 199.7-200.8 ${ }^{\circ} \mathrm{C}$; IR: $v_{\max } / \mathrm{cm}^{-1} 3459(\mathrm{OH}), 3382(\mathrm{NH}), 2228(\mathrm{CN}), 1658(\mathrm{C}=\mathrm{N}), 1624(\mathrm{C}=\mathrm{N}), 1592$ $(\mathrm{C}=\mathrm{C}), 1563(\mathrm{C}=\mathrm{C}), 1549$ (C=C), $1510(\mathrm{C}=\mathrm{C}) ;{ }^{1} \mathrm{H}-\mathrm{NMR}\left(\mathrm{DMSO}-d_{6}\right) \delta 7.77(\mathrm{~d}, J=8.4,2 \mathrm{H}, \mathrm{Ar}-H), 7.48$ $(\mathrm{d}, J=8.0,2 \mathrm{H}, \mathrm{Ar}-\mathrm{H}), 6.15\left(\mathrm{~s}, 2 \mathrm{H}, \mathrm{NH}_{2}\right), 5.82\left(\mathrm{~s}, 2 \mathrm{H}, \mathrm{NH}_{2}\right), 4.77(\mathrm{~d}, J=4.8,1 \mathrm{H}, \mathrm{CHOH}), 4.55(\mathrm{t}, J=5.6$, $\left.1 \mathrm{H}, \mathrm{CH}_{2} \mathrm{OH}\right), 4.14-4.06\left(\mathrm{~m}, 2 \mathrm{H}, \mathrm{OCH}_{2}\right), 3.63-3.57$ (m, 1H, CH), 3.31-3.25 (m, 2H, OCH $)$; ES-MS 302.1 $(\mathrm{M}+\mathrm{H})^{+}$; HRMS Calcd. for $\mathrm{C}_{14} \mathrm{H}_{16} \mathrm{~N}_{5} \mathrm{O}_{3}{ }^{+}$302.1253, found 302.1250.

(R)-2,4-Diamino-5-(4-methoxyphenyl)-6-(1,2-dihydroxypropyl)pyrimidine (10j). White solid 0.37 g, yield 84\%; m.p. 188.4-188.9 ${ }^{\circ} \mathrm{C}$; IR: $v_{\max } / \mathrm{cm}^{-1} 3544(\mathrm{OH}), 3497(\mathrm{OH}), 3466(\mathrm{NH}), 3339(\mathrm{NH}), 1639(\mathrm{C}=\mathrm{N})$, $1621(\mathrm{C}=\mathrm{N}), 1591(\mathrm{C}=\mathrm{C}), 1557(\mathrm{C}=\mathrm{C}) ;{ }^{1} \mathrm{H}-\mathrm{NMR}\left(\mathrm{DMSO}-\mathrm{d}_{6}\right) \delta 7.16(\mathrm{~d}, J=8.8,2 \mathrm{H}, \mathrm{Ar}-H), 6.92(\mathrm{~d}, J=8.8$, $2 \mathrm{H}, \mathrm{Ar}-\mathrm{H}), 5.94\left(\mathrm{~s}, 2 \mathrm{H}, \mathrm{NH}_{2}\right), 5.46\left(\mathrm{~s}, 2 \mathrm{H}, \mathrm{NH}_{2}\right), 4.73(\mathrm{~d}, 1 \mathrm{H}, J=4.8, \mathrm{CHOH}), 4.49\left(\mathrm{t}, J=5.8,1 \mathrm{H}, \mathrm{CH}_{2} \mathrm{OH}\right)$, 4.11-4.04 (m, 2H, OCH $), 3.76\left(\mathrm{~s}, 3 \mathrm{H}, \mathrm{OCH}_{3}\right), 3.62-3.55(\mathrm{~m}, 1 \mathrm{H}, \mathrm{CH}), 3.33-3.24\left(\mathrm{~m}, 2 \mathrm{H}, \mathrm{OCH}_{2}\right)$; ES-MS 307.1 $(\mathrm{M}+\mathrm{H})^{+}$; HRMS Calcd. for $\mathrm{C}_{14} \mathrm{H}_{19} \mathrm{~N}_{4} \mathrm{O}_{4}{ }^{+}$307.1406, found 307.1404.

(R)-2,4-Diamino-5-(3,4,5-trimethoxyphenyl)-6-(1,2-dihydroxypropyl)pyrimidine (10k). White solid $0.34 \mathrm{~g}$, yield 75\%; m.p. 198.6-199.7 ${ }^{\circ} \mathrm{C}$; IR: $v_{\max } / \mathrm{cm}^{-1} 3489(\mathrm{OH}), 3439(\mathrm{OH}), 3356(\mathrm{NH}), 3208(\mathrm{NH}), 1626$ $(\mathrm{C}=\mathrm{N}), 1589$ (C=C), 1569 (C=C), 1489 (C=C); ${ }^{1} \mathrm{H}-\mathrm{NMR}$ (DMSO-d $) \delta 6.55$ (s, 2H, Ar-H), 5.96 (s, $2 \mathrm{H}$, $\left.\mathrm{NH}_{2}\right), 5.69\left(\mathrm{~s}, 2 \mathrm{H}, \mathrm{NH}_{2}\right), 4.76(\mathrm{~d}, J=5.2,1 \mathrm{H}, \mathrm{CHOH}), 4.53\left(\mathrm{t}, J=5.6,1 \mathrm{H}, \mathrm{CH}_{2} \mathrm{OH}\right), 4.16-4.05(\mathrm{~m}, 2 \mathrm{H}$, $\left.\mathrm{OCH}_{2}\right), 3.75\left(\mathrm{~s}, 6 \mathrm{H}, \mathrm{OCH}_{3} \times 2\right), 3.68\left(\mathrm{~s}, 3 \mathrm{H}, \mathrm{OCH}_{3}\right), 3.67-3.60(\mathrm{~m}, 1 \mathrm{H}, \mathrm{CH}), 3.38-3.28\left(\mathrm{~m}, 2 \mathrm{H}, \mathrm{OCH}_{2}\right)$; ES-MS 367.2 $(\mathrm{M}+\mathrm{H})^{+}$; HRMS Calcd. for $\mathrm{C}_{16} \mathrm{H}_{23} \mathrm{~N}_{4} \mathrm{O}_{6}{ }^{+} 367.1618$, found 367.1616.

(R)-2,4-Diamino-5-[3-(2,2,2-trifluoroethoxymethyl)phenyl]-6-(1,2-dihydroxypropyl)pyrimidine

(101). White solid $0.41 \mathrm{~g}$, yield 82\%; m.p. $48.2-49.3{ }^{\circ} \mathrm{C}$; IR: $v_{\max } / \mathrm{cm}^{-1} 3478(\mathrm{OH}), 3347(\mathrm{NH}), 3215(\mathrm{NH})$, $1612(\mathrm{C}=\mathrm{N}), 1562(\mathrm{C}=\mathrm{C}), 1492(\mathrm{C}=\mathrm{C}), 1348(\mathrm{C}-\mathrm{F}) ;{ }^{1} \mathrm{H}-\mathrm{NMR}\left(\mathrm{DMSO}-d_{6}\right) \delta 7.36(\mathrm{t}, J=7.8,1 \mathrm{H}, \mathrm{Ar}-\mathrm{H})$, 7.20-7.23 (m,3H, Ar-H), $6.02\left(\mathrm{~s}, 2 \mathrm{H}, \mathrm{NH}_{2}\right), 5.59\left(\mathrm{~s}, 2 \mathrm{H}, \mathrm{NH}_{2}\right), 4.74(\mathrm{~d}, J=5.2,1 \mathrm{H}, \mathrm{CHOH}), 4.65(\mathrm{~s}, 2 \mathrm{H}$, $\left.\mathrm{CH}_{2}\right), 4.51\left(\mathrm{t}, J=5.6,1 \mathrm{H}, \mathrm{CH}_{2} \mathrm{OH}\right), 4.09\left(\mathrm{dd}, J_{1}=18.8, J_{2}=9.6,2 \mathrm{H}, \mathrm{CF}_{3} \mathrm{CH}_{2}\right), 4.08(\mathrm{~d}, J=5.2,2 \mathrm{H}$, $\left.\mathrm{OCH}_{2}\right), 3.62-3.55(\mathrm{~m}, 1 \mathrm{H}, \mathrm{CH}), 3.34-3.23\left(\mathrm{~m}, 2 \mathrm{H}, \mathrm{OCH}_{2}\right)$; ES-MS 389.1(M + H ${ }^{+}$; HRMS Calcd. for $\mathrm{C}_{16} \mathrm{H}_{20} \mathrm{~F}_{3} \mathrm{~N}_{4} \mathrm{O}_{4}+389.1437$, found 389.1435.

(R)-2,4-Diamino-5-[3,5-dimethyl-4-(N-methoxyaminosulfonyl)phenyl]-6-(1,2-dihydroxypropyl)pyrimidine (10m). White solid 0.40 g, yield 88\%; m.p. 98.3-99.3 ${ }^{\circ} \mathrm{C}$; IR: $v_{\max } / \mathrm{cm}^{-1} 3475(\mathrm{OH}), 3378(\mathrm{NH}), 3216$ $(\mathrm{NH}), 1610(\mathrm{C}=\mathrm{N}), 1594(\mathrm{C}=\mathrm{C}), 1562(\mathrm{C}=\mathrm{C}), 1482(\mathrm{C}=\mathrm{C}) ;{ }^{1} \mathrm{H}-\mathrm{NMR}\left(\mathrm{DMSO}-d_{6}\right) \delta 10.29(\mathrm{~s}, 1 \mathrm{H}, \mathrm{NH}), 7.18$ $(\mathrm{s}, 2 \mathrm{H}, \mathrm{Ar}-\mathrm{H}), 6.12\left(\mathrm{~s}, 2 \mathrm{H}, \mathrm{NH}_{2}\right), 5.80\left(\mathrm{~s}, 2 \mathrm{H}, \mathrm{NH}_{2}\right), 4.79(\mathrm{~d}, J=4.8,1 \mathrm{H}, \mathrm{CHOH}), 4.56(\mathrm{t}, J=5.8,1 \mathrm{H}$, $\left.\mathrm{CH}_{2} \mathrm{OH}\right), 4.15-4.07\left(\mathrm{~m}, 2 \mathrm{H}, \mathrm{OCH}_{2}\right), 3.64-3.58\left(\mathrm{~m}, 1 \mathrm{H}, \mathrm{CH}\right.$ and $\left.\mathrm{OCH}_{3}\right), 3.33-3.27\left(\mathrm{~m}, 2 \mathrm{H}, \mathrm{OCH}_{2}\right), 2.59(\mathrm{~s}$, $\left.6 \mathrm{H}, \mathrm{CH}_{3}\right)$; ES-MS 414.1(M + H) ${ }^{+}$; HRMS Calcd. for $\mathrm{C}_{16} \mathrm{H}_{24} \mathrm{~N}_{5} \mathrm{O}_{6} \mathrm{~S}^{+}$414.1447, found 414.1450.

(R)-2,4-Diamino-5-[4-(morpholine-4-carbonyl)phenyl]-6-(1,2-dihydroxypropyl)pyrimidine (10n). White solid 0.53 g, yield 90\%; m.p. 210.1-211.3 ${ }^{\circ} \mathrm{C}$; IR (KBr): $v_{\max } / \mathrm{cm}^{-1} 3446(\mathrm{OH}), 3343(\mathrm{NH}), 3220(\mathrm{NH}), 1630$ $(\mathrm{C}=\mathrm{N}), 1606(\mathrm{C}=\mathrm{C}), 1591(\mathrm{C}=\mathrm{C}), 1569(\mathrm{C}=\mathrm{C}), 1511(\mathrm{C}=\mathrm{C}) ;{ }^{1} \mathrm{H}-\mathrm{NMR}\left(\mathrm{DMSO}-d_{6}\right) \delta 7.36(\mathrm{~d}, J=8.4,2 \mathrm{H}$, Ar-H), $7.32(\mathrm{~d}, J=8.4,2 \mathrm{H}, \mathrm{Ar}-\mathrm{H}), 6.04(\mathrm{~s}, 2 \mathrm{H}, \mathrm{NH})_{2}, 5.69\left(\mathrm{~s}, 2 \mathrm{H}, \mathrm{NH}_{2}\right), 4.77(\mathrm{~d}, J=5.2,1 \mathrm{H}, \mathrm{CHOH})$, $4.53\left(\mathrm{t}, J=5.6,1 \mathrm{H}, \mathrm{CH}_{2} \mathrm{OH}\right), 4.10\left(\mathrm{~d}, J=5.6,2 \mathrm{H}, \mathrm{OCH}_{2}\right), 3.63-3.59(\mathrm{~m}, 1 \mathrm{H}, \mathrm{CH}), 3.76-3.42(\mathrm{~m}, 8 \mathrm{H}$, $\left.\mathrm{CH}_{2} \times 4\right), 3.30-3.27\left(\mathrm{~m}, 2 \mathrm{H}, \mathrm{OCH}_{2}\right)$; ES-MS $390.2(\mathrm{M}+\mathrm{H})^{+}$; HRMS Calcd. for $\mathrm{C}_{18} \mathrm{H}_{24} \mathrm{~N}_{5} \mathrm{O}_{5}{ }^{+} 390.1777$, found 390.1774 .

(R)-2,4-Diamino-5-[4-(3-trifluoromethoxyanilinocarbonyl)phenyl]-6-(1,2-dihydroxypropyl)pyrimidine (10o). White solid 0.46 g, yield 91\%; m.p. $142.0-143.6^{\circ} \mathrm{C}$; IR: $v_{\max } / \mathrm{cm}^{-1} 3346(\mathrm{OH}), 3228(\mathrm{NH}), 1656(\mathrm{C}=\mathrm{N})$, 1632 (C=N), 1607 (C=C), 1549 (C=C), 1490 (C=C), $1349(\mathrm{C}-\mathrm{F}) ;{ }^{1} \mathrm{H}-\mathrm{NMR}\left(\mathrm{DMSO}-d_{6}\right) \delta 10.49$ (s, 1H, NH), 
7.98-7.96 (m, 3H, Ar-H), $7.80\left(\mathrm{dd}, J_{1}=8.0, J_{2}=1.2,1 \mathrm{H}, \mathrm{Ar}-H\right), 7.51-7.45(\mathrm{~m}, 3 \mathrm{H}, \mathrm{Ar}-H), 7.09\left(\mathrm{dt}, J_{1}=8.4\right.$, $\left.J_{2}=1.2,1 \mathrm{H}, \mathrm{Ar}-H\right), 6.10\left(\mathrm{~s}, 2 \mathrm{H}, \mathrm{NH}_{2}\right), 5.71\left(\mathrm{~s}, 2 \mathrm{H}, \mathrm{NH}_{2}\right), 4.77(\mathrm{~d}, J=5.2,1 \mathrm{H}, \mathrm{CHOH}), 4.55(\mathrm{t}, J=5.6,1 \mathrm{H}$, $\left.\mathrm{CH}_{2} \mathrm{OH}\right), 4.12\left(\mathrm{~d}, J=5.2,2 \mathrm{H}, \mathrm{OCH}_{2}\right), 3.65-3.59(\mathrm{~m}, 1 \mathrm{H}, \mathrm{CH}), 3.33-3.26\left(\mathrm{~m}, 2 \mathrm{H}, \mathrm{OCH}_{2}\right) ;$ ES-MS 480.1 $(\mathrm{M}+\mathrm{H})^{+}$; HRMS Calcd. for $\mathrm{C}_{21} \mathrm{H}_{21} \mathrm{~F}_{3} \mathrm{~N}_{5} \mathrm{O}_{5}{ }^{+} 480.1495$, found 480.1492 .

(R)-2,4-Diamino-5-(4-methoxycarbonylphenyl)-6-(1,2-dihydroxypropyl)pyrimidine (10p). White solid $0.40 \mathrm{~g}$, yield 90\%; m.p. 186.7-188.2 ${ }^{\circ} \mathrm{C}$; IR: $v_{\max } / \mathrm{cm}^{-1} 3449(\mathrm{OH}), 3330(\mathrm{NH}), 3219(\mathrm{NH}), 1705(\mathrm{C}=\mathrm{O}), 1631$ $(\mathrm{C}=\mathrm{N}), 1592(\mathrm{C}=\mathrm{C}), 1514(\mathrm{C}=\mathrm{C}){ }^{1}{ }^{1} \mathrm{H}-\mathrm{NMR}\left(\mathrm{DMSO}_{-} d_{6}\right) \delta 7.91(\mathrm{~d}, J=8.4,2 \mathrm{H}, \mathrm{Ar}-\mathrm{H}), 7.44(\mathrm{~d}, J=8.4,2 \mathrm{H}$, Ar- $H), 6.10\left(\mathrm{~s}, 2 \mathrm{H}, \mathrm{NH}_{2}\right), 5.73\left(\mathrm{~s}, 2 \mathrm{H}, \mathrm{NH}_{2}\right), 4.75(\mathrm{~d}, J=4.8,1 \mathrm{H}, \mathrm{CHOH}), 4.53\left(\mathrm{t}, J=5.8,1 \mathrm{H}, \mathrm{CH}_{2} \mathrm{OH}\right)$, $4.09\left(\mathrm{~d}, J=5.2,2 \mathrm{H}, \mathrm{OCH}_{2}\right), 3.86\left(\mathrm{~s}, 3 \mathrm{H}, \mathrm{OCH}_{3}\right), 3.63-3.55(\mathrm{~m}, 1 \mathrm{H}, \mathrm{CH}), 3.30-3.25\left(\mathrm{~m}, 2 \mathrm{H}, \mathrm{OCH}_{2}\right)$; ES-MS $335.1(\mathrm{M}+\mathrm{H})^{+}$; HRMS Calcd. for $\mathrm{C}_{15} \mathrm{H}_{19} \mathrm{~N}_{4} \mathrm{O}_{5}{ }^{+} 335.1355$, found 335.1350.

(R)-2,4-Diamino-5-(3-methoxycarbonylphenyl)-6-(1,2-dihydroxypropyl)pyrimidine (10q). White solid $0.40 \mathrm{~g}$, yield 90\%; m.p. $140.6-141.5^{\circ} \mathrm{C}$; IR: $v_{\max } / \mathrm{cm}^{-1} 3457(\mathrm{OH}), 3336(\mathrm{NH}), 3224(\mathrm{NH}), 1705(\mathrm{C}=\mathrm{O}), 1658$ $(\mathrm{C}=\mathrm{N}), 1600(\mathrm{C}=\mathrm{C}), 1560(\mathrm{C}=\mathrm{C}), 1490(\mathrm{C}=\mathrm{C}){ }^{1}{ }^{1} \mathrm{H}-\mathrm{NMR}\left(\mathrm{DMSO}-d_{6}\right) \delta 7.84(\mathrm{t}, J=1.2,1 \mathrm{H}, \mathrm{Ar}-H), 7.81(\mathrm{dt}$, $\left.J_{1}=7.6, J_{2}=1.6,1 \mathrm{H}, \mathrm{Ar}-H\right), 7.54\left(\mathrm{dt}, J_{1}=8.0, J_{2}=1.6,1 \mathrm{H}, \mathrm{Ar}-H\right), 7.49(\mathrm{t}, J=7.6,1 \mathrm{H}, \mathrm{Ar}-H), 6.06(\mathrm{~s}, 2 \mathrm{H}$, $\left.\mathrm{NH}_{2}\right), 5.68\left(\mathrm{~s}, 2 \mathrm{H}, \mathrm{NH}_{2}\right), 4.72(\mathrm{~d}, J=5.2,1 \mathrm{H}, \mathrm{CHOH}), 4.50\left(\mathrm{t}, J=5.6,1 \mathrm{H}, \mathrm{CH}_{2} \mathrm{OH}\right), 4.09(\mathrm{~d}, J=5.6,2 \mathrm{H}$, $\left.\mathrm{OCH}_{2}\right), 3.85\left(\mathrm{~s}, 3 \mathrm{H}, \mathrm{OCH}_{3}\right), 3.61-3.54(\mathrm{~m}, 1 \mathrm{H}, \mathrm{CH}), 3.30-3.24\left(\mathrm{~m}, 2 \mathrm{H}, \mathrm{OCH}_{2}\right)$; ES-MS $335.1(\mathrm{M}+\mathrm{H})^{+}$; HRMS Calcd. for $\mathrm{C}_{15} \mathrm{H}_{19} \mathrm{~N}_{4} \mathrm{O}_{5}{ }^{+} 335.1355$, found 335.1358 .

(S)-2,4-Diamino-5-(4-chlorophenyl)-6-(1,2-dihydroxypropyl)pyrimidine (11a). White solid 0.36 g, yield 85\%; m.p. 169.8-169.9 ${ }^{\circ} \mathrm{C}$; IR: $v_{\max } / \mathrm{cm}^{-1} 3446(\mathrm{OH}), 3396(\mathrm{OH}), 3336(\mathrm{NH}), 3214(\mathrm{NH}), 1606(\mathrm{C}=\mathrm{N}), 1589$ $(\mathrm{C}=\mathrm{C}), 1569(\mathrm{C}=\mathrm{C}), 1556(\mathrm{C}=\mathrm{C}), 1503(\mathrm{C}=\mathrm{C}), 797(\mathrm{C}-\mathrm{Cl}) ;{ }^{1} \mathrm{H}-\mathrm{NMR}\left(\mathrm{DMSO}-d_{6}\right) \delta 7.38(\mathrm{~d}, J=8.4,2 \mathrm{H}$, Ar- $H), 7.27(\mathrm{~d}, J=8.4,2 \mathrm{H}, \mathrm{Ar}-H), 6.03\left(\mathrm{~s}, 2 \mathrm{H}, \mathrm{NH}_{2}\right), 5.65\left(\mathrm{~s}, 2 \mathrm{H}, \mathrm{NH}_{2}\right), 4.74(\mathrm{~d}, J=5.2,1 \mathrm{H}, \mathrm{CHOH}), 4.51$ $\left(\mathrm{t}, J=5.6,1 \mathrm{H}, \mathrm{CH}_{2} \mathrm{OH}\right), 4.08\left(\mathrm{~d}, J=5.6,2 \mathrm{H}, \mathrm{OCH}_{2}\right), 3.63-3.56(\mathrm{~m}, 1 \mathrm{H}, \mathrm{CH}), 3.31-3.23\left(\mathrm{~m}, 2 \mathrm{H}, \mathrm{OCH}_{2}\right)$; ES-MS 311.1 $(\mathrm{M}+\mathrm{H})^{+}$; HRMS Calcd. for $\mathrm{C}_{13} \mathrm{H}_{16} \mathrm{ClN}_{4} \mathrm{O}_{3}{ }^{+}$311.0911, found 311.0908.

(S)-2,4-Diamino-5-(4-fluorophenyl)-6-(1,2-dihydroxypropyl)pyrimidine (11b). White solid 0.42 g, yield 95\%; m.p. $111.7-113.7^{\circ} \mathrm{C}$; IR: $v_{\max } / \mathrm{cm}^{-1} 3482(\mathrm{OH}), 3343(\mathrm{NH}), 3212(\mathrm{NH}), 1614(\mathrm{C}=\mathrm{N}), 1593(\mathrm{C}=\mathrm{C}), 1562$ $(\mathrm{C}=\mathrm{C}), 1509(\mathrm{C}=\mathrm{C}), 1398(\mathrm{C}-\mathrm{F}){ }^{1} \mathrm{H}-\mathrm{NMR}\left(\mathrm{DMSO}-d_{6}\right) \delta 7.27\left(\mathrm{dd}, J_{1}=8.8, J_{2}=6.0,2 \mathrm{H}, \mathrm{Ar}-H\right), 7.16(\mathrm{t}$, $J=8.8,2 \mathrm{H}, \mathrm{Ar}-\mathrm{H}), 6.00\left(\mathrm{~s}, 2 \mathrm{H}, \mathrm{NH}_{2}\right), 5.57\left(\mathrm{~s}, 2 \mathrm{H}, \mathrm{NH}_{2}\right), 4.73(\mathrm{~d}, J=5.2,1 \mathrm{H}, \mathrm{CHOH}), 4.50(\mathrm{t}, J=5.8,1 \mathrm{H}$, $\left.\mathrm{CH}_{2} \mathrm{OH}\right), 4.08\left(\mathrm{~d}, J=5.2,2 \mathrm{H}, \mathrm{OCH}_{2}\right), 3.62-3.55(\mathrm{~m}, 1 \mathrm{H}, \mathrm{CH}), 3.33-3.23\left(\mathrm{~m}, 2 \mathrm{H}, \mathrm{OCH}_{2}\right)$; ES-MS 295.1 $(\mathrm{M}+\mathrm{H})^{+}$; HRMS Calcd. for $\mathrm{C}_{13} \mathrm{H}_{16} \mathrm{FN}_{4} \mathrm{O}_{3}{ }^{+}$295.1206, found 295.1208 .

(S)-2,4-Diamino-5-(3,4-dichlorophenyl)-6-(1,2-dihydroxypropyl)pyrimidine (11c). White solid 0.35 g, yield 87\%; m.p. 160.6-160.8 ${ }^{\circ} \mathrm{C}$; IR: $v_{\max } / \mathrm{cm}^{-1} 3504(\mathrm{OH}), 3476(\mathrm{OH}), 3383(\mathrm{NH}), 3346(\mathrm{NH}), 1649(\mathrm{C}=\mathrm{N})$, $1617(\mathrm{C}=\mathrm{N}), 1592(\mathrm{C}=\mathrm{C}), 1569(\mathrm{C}=\mathrm{C}), 1491(\mathrm{C}=\mathrm{C}), 793(\mathrm{C}-\mathrm{Cl}) ;{ }^{1} \mathrm{H}-\mathrm{NMR}\left(\mathrm{DMSO}-d_{6}\right) \delta 7.56(\mathrm{~d}, J=8.0,2 \mathrm{H}$, Ar-H), $7.47(\mathrm{~d}, J=2.0,1 \mathrm{H}, \mathrm{Ar}-H), 7.24\left(\mathrm{dd}, J_{1}=8.0, J_{2}=2.0,1 \mathrm{H}, \mathrm{Ar}-H\right), 6.08\left(\mathrm{~s}, 2 \mathrm{H}, \mathrm{NH} H_{2}\right), 5.81(\mathrm{~s}, 2 \mathrm{H}$, $\left.\mathrm{NH}_{2}\right), 4.75(\mathrm{~d}, 1 \mathrm{H}, J=5.2, \mathrm{CHOH}), 4.53\left(\mathrm{t}, J=5.6,1 \mathrm{H}, \mathrm{CH}_{2} \mathrm{OH}\right), 4.14-4.06\left(\mathrm{~m}, 2 \mathrm{H}, \mathrm{OCH}_{2}\right), 3.63-3.57(\mathrm{~m}$, $1 \mathrm{H}, \mathrm{CH}), 3.31-3.25\left(\mathrm{~m}, 2 \mathrm{H}, \mathrm{OCH}_{2}\right)$; ES-MS $345.1(\mathrm{M}+\mathrm{H})^{+}$; HRMS Calcd. for $\mathrm{C}_{13} \mathrm{H}_{15} \mathrm{Cl}_{2} \mathrm{~N}_{4} \mathrm{O}_{3}{ }^{+} 345.0521$, found 345.0523 .

(S)-2,4-Diamino-5-(3-chloro-4-fluorophenyl)-6-(1,2-dihydroxypropyl)pyrimidine (11d). White solid $0.37 \mathrm{~g}$, yield 90\%; m.p. $157.7-158.1^{\circ} \mathrm{C}$; IR: $v_{\max } / \mathrm{cm}^{-1} 3484(\mathrm{OH}), 3329(\mathrm{NH}), 3210(\mathrm{NH}), 1622(\mathrm{C}=\mathrm{N}), 1605$ $(\mathrm{C}=\mathrm{C}), 1590(\mathrm{C}=\mathrm{C}), 1561(\mathrm{C}=\mathrm{C}), 1347(\mathrm{C}-\mathrm{F}), 799(\mathrm{C}-\mathrm{Cl}) ;{ }^{1} \mathrm{H}-\mathrm{NMR}\left(\mathrm{DMSO}-d_{6}\right) \delta 7.40\left(\mathrm{dd}, J_{1}=7.2, J_{2}=2.0\right.$, $1 \mathrm{H}, \operatorname{Ar}-H), 7.36(\mathrm{t}, J=8.8,1 \mathrm{H}, \mathrm{Ar}-H), 7.25-7.21\left(\mathrm{ddd}, J_{1}=8.8, J_{2}=4.8, J_{3}=2.0,1 \mathrm{H}, \mathrm{Ar}-H\right), 6.05(\mathrm{~s}, 2 \mathrm{H}$, $\left.\mathrm{NH}_{2}\right), 5.74\left(\mathrm{~s}, 2 \mathrm{H}, \mathrm{NH}_{2}\right), 4.74(\mathrm{~d}, J=5.2,1 \mathrm{H}, \mathrm{CHOH}), 4.52\left(\mathrm{t}, J=5.6,1 \mathrm{H}, \mathrm{CH}_{2} \mathrm{OH}\right), 4.13-4.06(\mathrm{~m}, 2 \mathrm{H}$, $\left.\mathrm{OCH}_{2}\right), 3.63-3.56(\mathrm{~m}, 1 \mathrm{H}, \mathrm{CH}), 3.30-3.26\left(\mathrm{~m}, 2 \mathrm{H}, \mathrm{OCH}_{2}\right)$; ES-MS 329.1(M + H $)^{+}$; HRMS Calcd. for $\mathrm{C}_{13} \mathrm{H}_{15} \mathrm{ClFN}_{4} \mathrm{O}_{3}{ }^{+}$329.0817, found 329.0821.

(S)-2,4-Diamino-5-(4-trifluoromethylphenyl)-6-(1,2-dihydroxypropyl)pyrimidine (11e). White solid $0.37 \mathrm{~g}$, yield 83\%; m.p. $170.8-171.5^{\circ} \mathrm{C}$; IR: $v_{\max } / \mathrm{cm}^{-1} 3620(\mathrm{OH}), 3512(\mathrm{OH}), 3334(\mathrm{NH}), 3225(\mathrm{NH}), 1661$ $(\mathrm{C}=\mathrm{N}), 1632(\mathrm{C}=\mathrm{N}), 1598(\mathrm{C}=\mathrm{C}), 1554(\mathrm{C}=\mathrm{C}), 1493(\mathrm{C}=\mathrm{C}), 1339(\mathrm{C}-\mathrm{F}){ }^{1} \mathrm{H}-\mathrm{NMR}\left(\mathrm{DMSO}-d_{6}\right) \delta 7.67(\mathrm{~d}$, $J=8.0,2 \mathrm{H}, \mathrm{Ar}-H), 7.50(\mathrm{~d}, J=8.0,2 \mathrm{H}, \mathrm{Ar}-H), 6.10\left(\mathrm{~s}, 2 \mathrm{H}, \mathrm{NH}_{2}\right), 5.77\left(\mathrm{~s}, 2 \mathrm{H}, \mathrm{NH}_{2}\right), 4.75(\mathrm{~d}, J=5.2,1 \mathrm{H}$, 
$\mathrm{CHOH}), 4.53\left(\mathrm{t}, J=5.6,1 \mathrm{H}, \mathrm{CH}_{2} \mathrm{OH}\right), 4.15-4.07\left(\mathrm{~m}, 2 \mathrm{H}, \mathrm{OCH}_{2}\right), 3.64-3.57(\mathrm{~m}, 1 \mathrm{H}, \mathrm{CH}), 3.31-3.26(\mathrm{~m}$, $\left.2 \mathrm{H}, \mathrm{OCH}_{2}\right)$; ES-MS $345.1(\mathrm{M}+\mathrm{H})^{+}$; HRMS Calcd. for $\mathrm{C}_{14} \mathrm{H}_{16} \mathrm{~F}_{3} \mathrm{~N}_{4} \mathrm{O}_{3}{ }^{+}$345.1175, found 345.1180 .

(S)-2,4-Diamino-5-(3-trifluoromethylphenyl)-6-(1,2-dihydroxypropyl)pyrimidine (11f). White solid $0.37 \mathrm{~g}$, yield 83\%; m.p. $144.2-144.3{ }^{\circ} \mathrm{C}$; IR: $v_{\max } / \mathrm{cm}^{-1} 3474(\mathrm{OH}), 3389(\mathrm{OH}), 3348(\mathrm{NH}), 3224(\mathrm{NH}), 1617$ $(\mathrm{C}=\mathrm{N}), 1594(\mathrm{C}=\mathrm{C}), 1564(\mathrm{C}=\mathrm{C}), 1496(\mathrm{C}=\mathrm{C}), 1336(\mathrm{C}-\mathrm{F}){ }^{1} \mathrm{H}-\mathrm{NMR}$ (DMSO-d $\left.{ }_{6}\right) \delta$ 7.59-7.55 (m, 4H, Ar-H), $6.09\left(\mathrm{~s}, 2 \mathrm{H}, \mathrm{NH}_{2}\right), 5.74\left(\mathrm{~s}, 2 \mathrm{H}, \mathrm{NH}_{2}\right), 4.72(\mathrm{~d}, J=4.8,1 \mathrm{H}, \mathrm{CHOH}), 4.50\left(\mathrm{t}, J=5.8,1 \mathrm{H}, \mathrm{CH}_{2} \mathrm{OH}\right), 4.12(\mathrm{~d}$, $\left.J=5.2,2 \mathrm{H}, \mathrm{OCH}_{2}\right), 3.63-3.54(\mathrm{~m}, 1 \mathrm{H}, \mathrm{CH}), 3.31-3.25\left(\mathrm{~m}, 2 \mathrm{H}, \mathrm{OCH}_{2}\right)$; ES-MS $345.1(\mathrm{M}+\mathrm{H})^{+}$; HRMS Calcd. for $\mathrm{C}_{14} \mathrm{H}_{16} \mathrm{~F}_{3} \mathrm{~N}_{4} \mathrm{O}_{3}{ }^{+}$345.1175, found 345.1177.

(S)-2,4-Diamino-5-(4-trifluoromethoxyphenyl)-6-(1,2-dihydroxypropyl)pyrimidine (11g). White solid $0.44 \mathrm{~g}$, yield 90\%; m.p. $141.7-143.2{ }^{\circ} \mathrm{C}$; IR: $v_{\max } / \mathrm{cm}^{-1} 3345(\mathrm{OH}), 3216(\mathrm{NH}), 1614(\mathrm{C}=\mathrm{N}), 1595(\mathrm{C}=\mathrm{C}), 1561$ $(\mathrm{C}=\mathrm{C}), 1349$ (C-F); ${ }^{1} \mathrm{H}-\mathrm{NMR}\left(\mathrm{DMSO}_{\mathrm{d}}\right) \delta 7.39(\mathrm{~d}, J=8.4,2 \mathrm{H}, \mathrm{Ar}-\mathrm{H}), 7.31(\mathrm{~d}, J=8.4,2 \mathrm{H}, \mathrm{Ar}-\mathrm{H}), 6.05(\mathrm{~s}$, $\left.2 \mathrm{H}, \mathrm{NH}_{2}\right), 5.68\left(\mathrm{~s}, 2 \mathrm{H}, \mathrm{NH}_{2}\right), 4.76(\mathrm{~d}, J=4.8,1 \mathrm{H}, \mathrm{CHOH}), 4.52\left(\mathrm{t}, J=5.6,1 \mathrm{H}, \mathrm{CH}_{2} \mathrm{OH}\right), 4.10(\mathrm{~d}, J=5.2$, $\left.2 \mathrm{H}, \mathrm{OCH}_{2}\right), 3.64-3.57(\mathrm{~m}, 1 \mathrm{H}, \mathrm{CH}), 3.31-3.24\left(\mathrm{~m}, 2 \mathrm{H}, \mathrm{OCH}_{2}\right)$; ES-MS $361.1(\mathrm{M}+\mathrm{H})^{+}$; HRMS Calcd. for $\mathrm{C}_{14} \mathrm{H}_{16} \mathrm{~F}_{3} \mathrm{~N}_{4} \mathrm{O}_{4}{ }^{+}$361.1124, found 361.1127.

(S)-2,4-Diamino-5-(3-trifluoromethoxyphenyl)-6-(1,2-dihydroxypropyl)pyrimidine (11h). White solid $0.44 \mathrm{~g}$, yield 90\%; m.p. $120.5-122.0^{\circ} \mathrm{C}$; IR: $v_{\max } / \mathrm{cm}^{-1} 3621(\mathrm{OH}), 3340(\mathrm{OH}), 3224(\mathrm{NH}), 1656(\mathrm{C}=\mathrm{N}), 1629$ $(\mathrm{C}=\mathrm{N}), 1609(\mathrm{C}=\mathrm{C}), 1563(\mathrm{C}=\mathrm{C}), 1499(\mathrm{C}=\mathrm{C}), 1354(\mathrm{C}-\mathrm{F}) ;{ }^{1} \mathrm{H}-\mathrm{NMR}\left(\mathrm{DMSO}-d_{6}\right) \delta 7.46(\mathrm{t}, J=7.8,2 \mathrm{H}, \mathrm{Ar}-H)$, $7.31(\mathrm{~d}, J=7.8,2 \mathrm{H}, \mathrm{Ar}-H), 7.23(\mathrm{~s}, 1 \mathrm{H}, \mathrm{Ar}-H), 7.19(\mathrm{~d}, J=7.8,1 \mathrm{H}, \mathrm{Ar}-H), 6.09\left(\mathrm{~s}, 2 \mathrm{H}, \mathrm{NH}_{2}\right), 5.73(\mathrm{~s}, 2 \mathrm{H}$, $\left.\mathrm{NH}_{2}\right), 4.74(\mathrm{~d}, J=4.8,1 \mathrm{H}, \mathrm{CHOH}), 4.51\left(\mathrm{t}, J=5.6,1 \mathrm{H}, \mathrm{CH}_{2} \mathrm{OH}\right), 4.10\left(\mathrm{~d}, J=5.2,2 \mathrm{H}, \mathrm{OCH}_{2}\right), 3.63-3.56(\mathrm{~m}$, $1 \mathrm{H}, \mathrm{CH}), 3.31-3.25\left(\mathrm{~m}, 2 \mathrm{H}, \mathrm{OCH}_{2}\right)$; ES-MS $361.1(\mathrm{M}+\mathrm{H})^{+}$; HRMS Calcd. for $\mathrm{C}_{14} \mathrm{H}_{16} \mathrm{~F}_{3} \mathrm{~N}_{4} \mathrm{O}_{4}{ }^{+} 361.1124$, found 361.1122 .

(S)-2,4-Diamino-5-(4-cyanophenyl)-6-(1,2-dihydroxypropyl)pyrimidine (11i). White solid $0.38 \mathrm{~g}$, yield 86\%; m.p. 201.6-203.0 ${ }^{\circ} \mathrm{C}$; IR: $v_{\max } / \mathrm{cm}^{-1} 3458(\mathrm{OH}), 3359(\mathrm{NH}), 2230(\mathrm{CN}), 1631(\mathrm{C}=\mathrm{N}), 1604(\mathrm{C}=\mathrm{C}) 1586$ $(\mathrm{C}=\mathrm{C}), 1563(\mathrm{C}=\mathrm{C}), 1550(\mathrm{C}=\mathrm{C}){ }^{1} \mathrm{H}-\mathrm{NMR}\left(\mathrm{DMSO}-d_{6}\right) \delta 7.77(\mathrm{~d}, J=8.8,2 \mathrm{H}, \mathrm{Ar}-H), 7.48(\mathrm{~d}, J=8.8,2 \mathrm{H}$, $\operatorname{Ar}-H), 6.15\left(\mathrm{~s}, 2 \mathrm{H}, \mathrm{NH}_{2}\right), 5.83\left(\mathrm{~s}, 2 \mathrm{H}, \mathrm{NH}_{2}\right), 4.76(\mathrm{~d}, J=5.2,1 \mathrm{H}, \mathrm{CHOH}), 4.54\left(\mathrm{t}, J=5.6,1 \mathrm{H}, \mathrm{CH}_{2} \mathrm{OH}\right)$, 4.14-4.07 (m, 2H, OCH $)_{2}, 3.62-3.58(\mathrm{~m}, 1 \mathrm{H}, \mathrm{CH}), 3.31-3.3124\left(\mathrm{~m}, 2 \mathrm{H}, \mathrm{OCH}_{2}\right)$; ES-MS $302.1(\mathrm{M}+\mathrm{H})^{+}$; HRMS Calcd. for $\mathrm{C}_{14} \mathrm{H}_{16} \mathrm{~N}_{5} \mathrm{O}_{3}{ }^{+} 302.1253$, found 302.1251.

(S)-2,4-Diamino-5-(4-methoxyphenyl)-6-(1,2-dihydroxypropyl)pyrimidine (11j). White solid $0.36 \mathrm{~g}$, yield 91\%; m.p. 187.4-188.7 ${ }^{\circ} \mathrm{C}$; IR: $v_{\max } / \mathrm{cm}^{-1} 3542(\mathrm{OH}), 3496(\mathrm{OH}), 3467(\mathrm{NH}), 3339(\mathrm{NH}), 1639(\mathrm{C}=\mathrm{N})$, $1621(\mathrm{C}=\mathrm{N}), 1608(\mathrm{C}=\mathrm{C}), 1591(\mathrm{C}=\mathrm{C}), 1558(\mathrm{C}=\mathrm{C}) ;{ }^{1} \mathrm{H}-\mathrm{NMR}\left(\mathrm{DMSO}-\mathrm{d}_{6}\right) \delta 7.15(\mathrm{~d}, J=8.8,2 \mathrm{H}, \mathrm{Ar}-H)$, $6.92(\mathrm{~d}, J=8.8,2 \mathrm{H}, \mathrm{Ar}-H), 5.94\left(\mathrm{~s}, 2 \mathrm{H}, \mathrm{NH}_{2}\right), 5.46\left(\mathrm{~s}, 2 \mathrm{H}, \mathrm{NH}_{2}\right), 4.73(\mathrm{~d}, J=4.8,1 \mathrm{H}, \mathrm{CHOH}), 4.50(\mathrm{t}$, $\left.J=5.6,1 \mathrm{H}, \mathrm{CH}_{2} \mathrm{OH}\right), 4.11-4.04\left(\mathrm{~m}, 2 \mathrm{H}, \mathrm{OCH}_{2}\right), 3.76\left(\mathrm{~s}, 3 \mathrm{H}, \mathrm{OCH}_{3}\right), 3.62-3.56(\mathrm{~m}, 1 \mathrm{H}, \mathrm{CH}), 3.32-3.25(\mathrm{~m}$, $\left.2 \mathrm{H}, \mathrm{OCH}_{2}\right)$; ES-MS 307.1 (M + H) ${ }^{+}$; HRMS Calcd. for $\mathrm{C}_{14} \mathrm{H}_{19} \mathrm{~N}_{4} \mathrm{O}_{4}{ }^{+}$307.1406, found 307.1408.

(S)-2,4-Diamino-5-(3,4,5-trimethoxyphenyl)-6-(1,2-dihydroxypropyl)pyrimidine (11k). White solid $0.40 \mathrm{~g}$, yield 89\%; m.p. 199.1-200.3 ${ }^{\circ} \mathrm{C}$; IR: $v_{\max } / \mathrm{cm}^{-1} 3489(\mathrm{OH}), 3439(\mathrm{OH}), 3356(\mathrm{NH}), 3208(\mathrm{NH}), 1626$ $(\mathrm{C}=\mathrm{N}), 1589(\mathrm{C}=\mathrm{C}), 1569(\mathrm{C}=\mathrm{C}), 1489(\mathrm{C}=\mathrm{C}) ;{ }^{1} \mathrm{H}-\mathrm{NMR}\left(\mathrm{DMSO}-d_{6}\right) \delta 6.55(\mathrm{~s}, 2 \mathrm{H}, \mathrm{Ar}-H), 5.96(\mathrm{~s}, 2 \mathrm{H}$, $\left.\mathrm{NH}_{2}\right), 5.64\left(\mathrm{~s}, 2 \mathrm{H}, \mathrm{NH}_{2}\right), 4.76(\mathrm{~d}, J=4.8,1 \mathrm{H}, \mathrm{CHOH}), 4.53\left(\mathrm{t}, J=5.8,1 \mathrm{H}, \mathrm{CH}_{2} \mathrm{OH}\right), 4.14-4.07(\mathrm{~m}, 2 \mathrm{H}$, $\left.\mathrm{OCH}_{2}\right), 3.75\left(\mathrm{~s}, 6 \mathrm{H}, \mathrm{OCH}_{3}\right), 3.68\left(\mathrm{~s}, 3 \mathrm{H}, \mathrm{OCH}_{3}\right), 3.65-3.60(\mathrm{~m}, 1 \mathrm{H}, \mathrm{CH}), 3.38-3.28\left(\mathrm{~m}, 2 \mathrm{H}, \mathrm{OCH}_{2}\right)$; ES-MS 367.2 (M + H) $)^{+}$; HRMS Calcd. for $\mathrm{C}_{16} \mathrm{H}_{23} \mathrm{~N}_{4} \mathrm{O}_{6}{ }^{+}$367.1618, found 367.1620.

(S)-2,4-Diamino-5-[3-(2,2,2-trifluoroethoxymethyl)phenyl]-6-(1,2-dihydroxypropyl)pyrimidine

White solid 0.38 g, yield 84\%; m.p. 42.7-43.5 ${ }^{\circ} \mathrm{C}$; IR: $v_{\max } / \mathrm{cm}^{-1} 3477(\mathrm{OH}), 3346(\mathrm{NH}), 3215(\mathrm{NH}), 1613$ $(\mathrm{C}=\mathrm{N}), 1561(\mathrm{C}=\mathrm{C}), 1495(\mathrm{C}=\mathrm{C}), 1346(\mathrm{C}-\mathrm{F}) ;{ }^{1} \mathrm{H}-\mathrm{NMR}\left(\mathrm{DMSO}-d_{6}\right) \delta 7.36(\mathrm{t}, J=7.8,1 \mathrm{H}, \mathrm{Ar}-\mathrm{H}), 7.23-7.20$ $(\mathrm{m}, 3 \mathrm{H}, \mathrm{Ar}-\mathrm{H}), 6.01\left(\mathrm{~s}, 2 \mathrm{H}, \mathrm{NH}_{2}\right), 5.57\left(\mathrm{~s}, 2 \mathrm{H}, \mathrm{NH}_{2}\right), 4.73(\mathrm{~d}, J=5.2,1 \mathrm{H}, \mathrm{CHOH}), 4.66\left(\mathrm{~s}, 2 \mathrm{H}, \mathrm{OCH}_{2}\right), 4.50$ $\left(\mathrm{t}, J=5.6,1 \mathrm{H}, \mathrm{CH}_{2} \mathrm{OH}\right), 4.13-4.06\left(\mathrm{~m}, 4 \mathrm{H}, \mathrm{OCH}_{2}\right.$ and $\left.\mathrm{CF}_{3} \mathrm{CH}_{2}\right), 3.62-3.55(\mathrm{~m}, 1 \mathrm{H}, \mathrm{CH}), 3.31-3.23(\mathrm{~m}, 2 \mathrm{H}$, $\left.\mathrm{OCH}_{2}\right)$; ES-MS 389.1(M + H) ${ }^{+}$; HRMS Calcd. for $\mathrm{C}_{16} \mathrm{H}_{20} \mathrm{~F}_{3} \mathrm{~N}_{4} \mathrm{O}_{4}{ }^{+} 389.1437$, found 389.1440.

(S)-2,4-Diamino-5-[3,5-dimethyl-4-(N-methoxyaminosulfonyl)phenyl]-6-(1,2-dihydroxypropyl)pyrimidine (11m). White solid 0.31 g, yield 85\%; m.p. 93.0-93.8 ${ }^{\circ} \mathrm{C}$; IR: $v_{\max } / \mathrm{cm}^{-1} 3463(\mathrm{OH}), 3379(\mathrm{NH}), 3215$ 
$(\mathrm{NH}), 1612(\mathrm{C}=\mathrm{N}), 1594(\mathrm{C}=\mathrm{C}), 1563(\mathrm{C}=\mathrm{C}){ }^{1} \mathrm{H}-\mathrm{NMR}\left(\mathrm{DMSO}-d_{6}\right) \delta 10.29(\mathrm{~s}, 1 \mathrm{H}, \mathrm{NH}), 7.18(\mathrm{~s}, 2 \mathrm{H}, \mathrm{Ar}-\mathrm{H})$, $6.11\left(\mathrm{~s}, 2 \mathrm{H}, \mathrm{NH}_{2}\right), 5.78\left(\mathrm{~s}, 2 \mathrm{H}, \mathrm{NH}_{2}\right), 4.77(\mathrm{~d}, J=5.2,1 \mathrm{H}, \mathrm{CHOH}), 4.55\left(\mathrm{t}, J=5.6,1 \mathrm{H}, \mathrm{CH}_{2} \mathrm{OH}\right), 4.15-4.07$ $\left(\mathrm{m}, 2 \mathrm{H}, \mathrm{OCH}_{2}\right), 3.62-3.58\left(\mathrm{~m}, 4 \mathrm{H}, \mathrm{OCH}_{3}\right.$ and $\left.\mathrm{CH}\right), 3.32-3.28\left(\mathrm{~m}, 2 \mathrm{H}, \mathrm{OCH}_{2}\right), 2.59\left(\mathrm{~s}, 6 \mathrm{H}, \mathrm{CH}_{3} \times 2\right)$; ES-MS 414.1( $\mathrm{M}+\mathrm{H})^{+}$; HRMS Calcd. for $\mathrm{C}_{16} \mathrm{H}_{24} \mathrm{~N}_{5} \mathrm{O}_{6} \mathrm{~S}^{+}$414.1447, found 414.1449.

(S)-2,4-Diamino-5-[4-(morpholino-4-carbonyl)phenyl]-6-(1,2-dihydroxypropyl)pyrimidine (11n). White solid 0.35 g, yield 86\%; m.p. 209.6-210.2 ${ }^{\circ} \mathrm{C}$; IR: $v_{\max } / \mathrm{cm}^{-1} 3443(\mathrm{OH}), 3342(\mathrm{NH}), 3220(\mathrm{NH}), 1629(\mathrm{C}=\mathrm{N})$, 1609 (C=C), $1590(\mathrm{C}=\mathrm{C}), 1568(\mathrm{C}=\mathrm{C}), 1511(\mathrm{C}=\mathrm{C}) ;{ }^{1} \mathrm{H}-\mathrm{NMR}$ (DMSO-d $\left.\mathrm{d}_{6}\right) \delta 7.36(\mathrm{~d}, J=8.4,2 \mathrm{H}, \mathrm{Ar}-\mathrm{H}), 7.34$ $(\mathrm{d}, J=8.4,2 \mathrm{H}, \mathrm{Ar}-\mathrm{H}), 6.04\left(\mathrm{~s}, 2 \mathrm{H}, \mathrm{NH}_{2}\right), 5.69\left(\mathrm{~s}, 2 \mathrm{H}, \mathrm{NH} \mathrm{H}_{2}\right), 4.77(\mathrm{~d}, J=5.2,1 \mathrm{H}, \mathrm{CHOH}), 4.53(\mathrm{t}, J=5.6$, $\left.1 \mathrm{H}, \mathrm{CH}_{2} \mathrm{OH}\right), 4.10\left(\mathrm{~d}, J=5.2,2 \mathrm{H}, \mathrm{OCH}_{2}\right), 3.63-3.59(\mathrm{~m}, 1 \mathrm{H}, \mathrm{CH}), 3.74-3.38\left(\mathrm{~m}, 8 \mathrm{H}, \mathrm{CH}_{2} \times 4\right), 3.32-3.25$ $\left(\mathrm{m}, 2 \mathrm{H}, \mathrm{OCH}_{2}\right)$; ES-MS $390.2(\mathrm{M}+\mathrm{H})^{+}$; HRMS Calcd. for $\mathrm{C}_{18} \mathrm{H}_{24} \mathrm{~N}_{5} \mathrm{O}_{5}{ }^{+}$390.1777, found 390.1779.

(S)-2,4-Diamino-5-[4-(3-trifluoromethoxyanilinocarbonyl)phenyl]-6-(1,2-dihydroxypropyl)pyrimidine (11o). White soilid 0.44 g, 87\%; m.p. $143.2-145.0^{\circ} \mathrm{C}$; IR: $v_{\max } / \mathrm{cm}^{-1} 3336(\mathrm{OH}), 3225(\mathrm{NH}), 1658(\mathrm{C}=\mathrm{N}), 1606$ $(\mathrm{C}=\mathrm{C}), 1549(\mathrm{C}=\mathrm{C}), 1491(\mathrm{C}=\mathrm{C}), 1350(\mathrm{C}-\mathrm{F}) ;{ }^{1} \mathrm{H}-\mathrm{NMR}\left(\mathrm{DMSO}-d_{6}\right) \delta 10.49(\mathrm{~s}, 1 \mathrm{H}, \mathrm{NH}), 7.98-7.96$ ( m, $3 \mathrm{H}, \mathrm{Ar}-H), 7.80\left(\mathrm{dd}, J_{1}=8.2, J_{2}=1.0,1 \mathrm{H}, \mathrm{Ar}-H\right), 7.51-7.45(\mathrm{~m}, 3 \mathrm{H}, \mathrm{Ar}-H), 7.09\left(\mathrm{dt}, J_{1}=8.4, J_{2}=1.2,1 \mathrm{H}\right.$, $\mathrm{Ar}-\mathrm{H}), 6.10\left(\mathrm{~s}, 2 \mathrm{H}, \mathrm{NH}_{2}\right), 5.70\left(\mathrm{~s}, 2 \mathrm{H}, \mathrm{NH}_{2}\right), 4.77(\mathrm{~d}, J=5.2,1 \mathrm{H}, \mathrm{CHOH}), 4.55\left(\mathrm{t}, J=5.8,1 \mathrm{H}, \mathrm{CH}_{2} \mathrm{OH}\right)$, $4.12\left(\mathrm{~d}, J=5.2,2 \mathrm{H}, \mathrm{CH}_{2}\right), 3.58-3.65(\mathrm{~m}, 1 \mathrm{H}, \mathrm{CH}), 3.28-3.33(\mathrm{~m}, 2 \mathrm{H}, \mathrm{OH})$; ES-MS $480.1(\mathrm{M}+\mathrm{H})^{+}$; HRMS Calcd. for $\mathrm{C}_{21} \mathrm{H}_{21} \mathrm{~F}_{3} \mathrm{~N}_{5} \mathrm{O}_{5}{ }^{+} 480.1495$, found 480.1497 .

(S)-2,4-Diamino-5-(4-methoxycarbonylphenyl)-6-(1,2-dihydroxypropyl)pyrimidine (11p). White solid $0.32 \mathrm{~g}$, yield 90\%; m.p. 211.3-212.4 ${ }^{\circ} \mathrm{C}$; IR: $v_{\max } / \mathrm{cm}^{-1} 3562(\mathrm{OH}), 3450(\mathrm{NH}), 3227(\mathrm{NH}), 3217(\mathrm{NH}), 1712$ $(\mathrm{C}=\mathrm{O}), 1629(\mathrm{C}=\mathrm{N}), 1592(\mathrm{C}=\mathrm{C}), 1573(\mathrm{C}=\mathrm{C}), 1555(\mathrm{C}=\mathrm{C}), 1515(\mathrm{C}=\mathrm{C}){ }^{1}{ }^{1} \mathrm{H}-\mathrm{NMR}\left(\mathrm{DMSO}-d_{6}\right) \delta 7.92(\mathrm{~d}$, $J=8.4,2 \mathrm{H}, \mathrm{Ar}-H), 7.44(\mathrm{~d}, J=8.4,2 \mathrm{H}, \mathrm{Ar}-\mathrm{H}), 6.10\left(\mathrm{~s}, 2 \mathrm{H}, \mathrm{NH}_{2}\right), 5.74\left(\mathrm{~s}, 2 \mathrm{H}, \mathrm{NH}_{2}\right), 4.74(\mathrm{~d}, J=5.2$, $1 \mathrm{H}, \mathrm{CHOH}), 4.52\left(\mathrm{t}, J=5.6,1 \mathrm{H}, \mathrm{CH}_{2} \mathrm{OH}\right), 4.13-4.06\left(\mathrm{~m}, 2 \mathrm{H}, \mathrm{OCH}_{2}\right), 3.86\left(\mathrm{~s}, 3 \mathrm{H}, \mathrm{OCH}_{3}\right) 3.6-3.57(\mathrm{~m}$, $1 \mathrm{H}, \mathrm{CH}), 3.3-3.24\left(\mathrm{~m}, 2 \mathrm{H}, \mathrm{OCH}_{2}\right)$; ES-MS $335.1(\mathrm{M}+\mathrm{H})^{+}$; HRMS Calcd. for $\mathrm{C}_{15} \mathrm{H}_{19} \mathrm{~N}_{4} \mathrm{O}_{5}{ }^{+} 335.1355$, found 335.1357 .

(S)-2,4-Diamino-5-(3-methoxycarbonylphenyl)-6-(1,2-dihydroxypropyl)pyrimidine (11q). White solid $0.38 \mathrm{~g}$, yield 85\%; m.p. $181.4-182.3{ }^{\circ} \mathrm{C}$; IR: $v_{\max } / \mathrm{cm}^{-1} 3577(\mathrm{OH}), 3525(\mathrm{OH}), 3453(\mathrm{NH}), 3338(\mathrm{NH}), 1705$ $(\mathrm{C}=\mathrm{O}), 1637(\mathrm{C}=\mathrm{N}), 1590(\mathrm{C}=\mathrm{C}), 1558(\mathrm{C}=\mathrm{C}), 1501(\mathrm{C}=\mathrm{C}) ;{ }^{1} \mathrm{H}-\mathrm{NMR}\left(\mathrm{DMSO}-d_{6}\right) \delta 7.84(\mathrm{~s}, 1 \mathrm{H}, \mathrm{Ar}-H), 7.81$ $(\mathrm{d}, J=7.2,1 \mathrm{H}, \mathrm{Ar}-H) 7.54(\mathrm{~d}, J=7.6,1 \mathrm{H}, \mathrm{Ar}-H), 7.49(\mathrm{t}, J=7.6,1 \mathrm{H}, \mathrm{Ar}-H), 6.06\left(\mathrm{~s}, 2 \mathrm{H}, \mathrm{NH}_{2}\right), 5.69(\mathrm{~s}$, $\left.2 \mathrm{H}, \mathrm{NH}_{2}\right), 4.72(\mathrm{~d}, J=4.8,1 \mathrm{H}, \mathrm{CHOH}), 4.50\left(\mathrm{t}, J=5.8,1 \mathrm{H}, \mathrm{CH}_{2} \mathrm{OH}\right), 4.09\left(\mathrm{~d}, J=5.2,2 \mathrm{H}, \mathrm{OCH}_{2}\right), 3.85(\mathrm{~s}$, $\left.3 \mathrm{H}, \mathrm{OCH}_{3}\right) 3.61-3.54(\mathrm{~m}, 1 \mathrm{H}, \mathrm{CH}), 3.30-3.22\left(\mathrm{~m}, 2 \mathrm{H}, \mathrm{OCH}_{2}\right)$; ES-MS $335.1(\mathrm{M}+\mathrm{H})^{+}$; HRMS Calcd. for $\mathrm{C}_{15} \mathrm{H}_{19} \mathrm{~N}_{4} \mathrm{O}_{5}{ }^{+}$335.1355, found 335.1353.

General Procedure for the Synthesis of 2,4-Diamino-6-substituted Pyrimidine Derivatives 13a-d

Under argon, to a solution of substituted methanol 12a-d $(17.45 \mathrm{mmol})$ in dry DMSO or THF $(30 \mathrm{~mL})$ was added $\mathrm{NaH}(60 \%, 21.82 \mathrm{mmol})$ and stirred at room temperature for $1 \mathrm{~h}$. 2,4-Diamino-6-chloropyrimidine (2) $(8.73 \mathrm{mmol})$ was added and stirred at room temperature for $11 \mathrm{~h}$. The reaction solution was quenched with sat $\mathrm{NH}_{4} \mathrm{Cl}(50 \mathrm{~mL})$ and extracted with EtOAc $(150 \mathrm{~mL} \times 3)$, and the combined organic layers dried with $\mathrm{Na}_{2} \mathrm{SO}_{4}$, filtered and concentrated. The residue was purified by column chromatography on silica gel using $\mathrm{CH}_{2} \mathrm{Cl}_{2} / \mathrm{CH}_{3} \mathrm{OH}(50: 1, v / v)$ as the eluting solvent to give compounds 13a-d.

2,4-Diamino-6-(2-methoxyethoxy)pyrimidine (13a). White solid 1.04 g, yield 65\%. m.p. 152.9-153.9 ${ }^{\circ} \mathrm{C}$; IR: $v_{\max } / \mathrm{cm}^{-1} 3440(\mathrm{NH}), 3368(\mathrm{NH}), 1636(\mathrm{C}=\mathrm{N}), 1563(\mathrm{C}=\mathrm{C}), 1118(\mathrm{C}-\mathrm{O}-\mathrm{C}) ;{ }^{1} \mathrm{H}-\mathrm{NMR}\left(\mathrm{DMSO}-d_{6}\right) \delta 6.00$ $\left(\mathrm{s}, 2 \mathrm{H}, \mathrm{NH}_{2}\right), 5.85\left(\mathrm{~s}, 2 \mathrm{H}, \mathrm{NH}_{2}\right), 5.02(\mathrm{~s}, 1 \mathrm{H}, \mathrm{Ar}-\mathrm{H}), 4.23-4.17\left(\mathrm{~m}, 2 \mathrm{H}, \mathrm{CH}_{2}\right), 3.59-3.51\left(\mathrm{~m}, 2 \mathrm{H}, \mathrm{CH}_{2}\right), 3.27$ (s, 3H, CH $)_{3}$; ES-MS $185.1(\mathrm{M}+\mathrm{H})^{+}$; HRMS Calcd. for $\mathrm{C}_{16} \mathrm{H}_{20} \mathrm{ClN}_{4} \mathrm{O}_{3}{ }^{+}$185.1039, found 185.1040.

2,4-Diamino-6-(3-methoxylpropoxy)pyrimidine (13b). White solid 1.07 g, yield $62 \%$. m.p. 104.2-104.8 ${ }^{\circ} \mathrm{C}$; IR: $v_{\max } / \mathrm{cm}^{-1} 3456(\mathrm{NH}), 3343(\mathrm{NH}), 1656(\mathrm{C}=\mathrm{N}), 1572(\mathrm{C}=\mathrm{C}), 1207$ (C-O-C); ${ }^{1} \mathrm{H}-\mathrm{NMR}$ (DMSO- $d_{6}$ ) $\delta 5.98\left(\mathrm{~s}, 2 \mathrm{H}, \mathrm{NH}_{2}\right), 5.84\left(\mathrm{~s}, 2 \mathrm{H}, \mathrm{NH}_{2}\right), 5.02(\mathrm{~s}, 1 \mathrm{H}, \mathrm{Ar}-\mathrm{H}), 4.11\left(\mathrm{t}, J=6.6,2 \mathrm{H}, \mathrm{CH}_{2}\right), 3.40(\mathrm{t}, J=6.3,2 \mathrm{H}$, 
$\left.\mathrm{CH}_{2}\right), 3.23\left(\mathrm{~s}, 3 \mathrm{H}, \mathrm{CH}_{3}\right), 1.84\left(\mathrm{~m}, 2 \mathrm{H}, \mathrm{CH}_{2}\right)$; ES-MS $199.1(\mathrm{M}+\mathrm{H})^{+}$; HRMS Calcd. for $\mathrm{C}_{16} \mathrm{H}_{20} \mathrm{ClN}_{4} \mathrm{O}_{3}{ }^{+}$ 199.1195, found 199.1198 .

2,4-Diamino-6-(thiazole-5-methoxy)pyrimidine (13c). Yellow solid 1.44 g, yield 74\%. m.p. 156.8-161.3 ${ }^{\circ} \mathrm{C}$; IR: $v_{\max } / \mathrm{cm}^{-1} 3466(\mathrm{NH}), 3320(\mathrm{NH}), 1625(\mathrm{C}=\mathrm{N}), 1570(\mathrm{C}=\mathrm{C}), 1454(\mathrm{C}=\mathrm{C}), 1138$ (C-O-C), 1061 (C-O-C); ${ }^{1} \mathrm{H}-\mathrm{NMR}\left(\mathrm{DMSO}-d_{6}\right) \delta 9.06(\mathrm{~s}, 1 \mathrm{H}, \mathrm{Ar}-\mathrm{H}), 7.97(\mathrm{~s}, 1 \mathrm{H}, \mathrm{Ar}-\mathrm{H}), 6.07$ (s, 2H, NH $\left.\mathrm{H}_{2}\right), 5.98\left(\mathrm{~s}, 2 \mathrm{H}, \mathrm{NH}_{2}\right), 5.44$ $\left(\mathrm{s}, 2 \mathrm{H}, \mathrm{CH}_{2}\right), 5.04(\mathrm{~s}, 1 \mathrm{H}, \mathrm{Ar}-\mathrm{H})$; ES-MS $224.0(\mathrm{M}+\mathrm{H})^{+}$; HRMS Calcd. for $\mathrm{C}_{16} \mathrm{H}_{20} \mathrm{ClN}_{4} \mathrm{O}_{3}{ }^{+} 224.0606$, found 224.0608 .

2,4-Diamino-6-(1-benzyl-1H-1,2,3-triazole-4-methoxy)pyrimidine (13d). White solid $2.05 \mathrm{~g}$, yield 79\%. m.p.131.4-135.7 ${ }^{\circ} \mathrm{C}$; IR: $v_{\max } / \mathrm{cm}^{-1} 3421(\mathrm{NH}), 3333(\mathrm{NH}), 1631(\mathrm{C}=\mathrm{N}), 1588(\mathrm{~N}=\mathrm{N}), 1451(\mathrm{C}=\mathrm{C}), 1422$ $(\mathrm{C}=\mathrm{C}), 1197(\mathrm{C}-\mathrm{O}-\mathrm{C}) ;{ }^{1} \mathrm{H}-\mathrm{NMR}\left(\mathrm{DMSO}-d_{6}\right) \delta 8.20(\mathrm{~s}, 1 \mathrm{H}, \mathrm{Ar}-H), 7.36(\mathrm{~m}, 5 \mathrm{H}, \mathrm{Ar}-\mathrm{H}), 6.04\left(\mathrm{~s}, 2 \mathrm{H}, \mathrm{NH}_{2}\right)$, $5.96\left(\mathrm{~s}, 2 \mathrm{H}, \mathrm{NH}_{2}\right), 5.59\left(\mathrm{~s}, 2 \mathrm{H}, \mathrm{CH}_{2}\right), 5.20\left(\mathrm{~s}, 2 \mathrm{H}, \mathrm{CH}_{2}\right), 5.02(\mathrm{~s}, 1 \mathrm{H}, \mathrm{Ar}-\mathrm{H})$; ES-MS $298.1(\mathrm{M}+\mathrm{H})^{+}$; HRMS Calcd. for $\mathrm{C}_{16} \mathrm{H}_{20} \mathrm{ClN}_{4} \mathrm{O}_{3}{ }^{+} 298.1416$, found 298.1412 .

General Procedure for the Synthesis of 2,4-Diamino-5-iodine-6-substitutedpyrimidine Derivatives 14a-d

Under argon, to a solution of 13-d $(6.06 \mathrm{mmol})$ in dry $\mathrm{CH}_{3} \mathrm{CN}(35 \mathrm{~mL})$ was added $\mathrm{N}$-iodosuccinimide $(9.09 \mathrm{mmol})$ and stirred at room temperature for $12 \mathrm{~h}$. The reaction solution was extracted with EtOAc $(150 \mathrm{~mL} \times 3)$, and the combined organic layers were washed by $\mathrm{NaHSO}_{3}$, sat. $\mathrm{NaHCO}_{3}$ and sat. $\mathrm{NaCl}$, and dried with $\mathrm{Na}_{2} \mathrm{SO}_{4}$, filtered and concentrated. The residue was purified by column chromatography on silica gel using $\mathrm{CH}_{2} \mathrm{Cl}_{2} / \mathrm{CH}_{3} \mathrm{OH}(80: 1, v / v)$ as the eluting solvent to give compounds 14a-d.

2,4-Diamino-5-iodo-6-(2-methoxyethoxy)pyrimidine (14a). Yellow solid 1.50 g, 80\%. m.p. 109.7-111.0 ${ }^{\circ} \mathrm{C}$; IR: $v_{\max } / \mathrm{cm}^{-1} 3424(\mathrm{NH}), 3345(\mathrm{NH}), 1705(\mathrm{C}=\mathrm{N}), 1554(\mathrm{C}=\mathrm{C}), 1116(\mathrm{C}-\mathrm{O}-\mathrm{C}), 523(\mathrm{C}-\mathrm{I}) ;{ }^{1} \mathrm{H}-\mathrm{NMR}$ (DMSO- $\left.d_{6}\right) \delta 6.10\left(\mathrm{~s}, 4 \mathrm{H}, \mathrm{NH}_{2}\right), 4.31-4.27\left(\mathrm{~m}, 2 \mathrm{H}, \mathrm{CH}_{2}\right), 3.61-3.57\left(\mathrm{~m}, 2 \mathrm{H}, \mathrm{CH}_{2}\right), 3.31\left(\mathrm{~s}, 3 \mathrm{H}, \mathrm{CH}_{3}\right)$; ES-MS $310.9(\mathrm{M}+\mathrm{H})^{+}$; HRMS Calcd. for $\mathrm{C}_{16} \mathrm{H}_{20} \mathrm{ClN}_{4} \mathrm{O}_{3}{ }^{+}$311.0005, found 311.0003 .

2,4-Diamino-5-iodo-6-(3-methoxypropoxy)pyrimidine (14b). Yellow solid 1.37 g, 70\%. m.p. 124.0-125.8 ${ }^{\circ} \mathrm{C}$; IR: $v_{\max } / \mathrm{cm}^{-1} 3472(\mathrm{NH}), 3357(\mathrm{NH}), 1631(\mathrm{C}=\mathrm{N}), 1553(\mathrm{C}=\mathrm{C}), 1145$ (C-O-C), $532(\mathrm{C}-\mathrm{I}) ;{ }^{1} \mathrm{H}-\mathrm{NMR}$ $\left(\mathrm{DMSO}_{-} d_{6}\right) \delta 6.09\left(\mathrm{~s}, 4 \mathrm{H}, \mathrm{NH}_{2}\right), 4.20\left(\mathrm{t}, J=6.4,2 \mathrm{H}, \mathrm{CH}_{2}\right), 3.45\left(\mathrm{t}, J=6.3,2 \mathrm{H}, \mathrm{CH}_{2}\right), 3.24\left(\mathrm{~s}, 3 \mathrm{H}, \mathrm{CH}_{3}\right)$, $1.86\left(\mathrm{~m}, 2 \mathrm{H}, \mathrm{CH}_{2}\right)$; ES-MS 325.0 (M + H) ${ }^{+}$; HRMS Calcd. for $\mathrm{C}_{16} \mathrm{H}_{20} \mathrm{ClN}_{4} \mathrm{O}_{3}{ }^{+} 325.0161$, found 325.0159.

2,4-Diamino-5-iodo-6-(thiazole-5-methoxy)pyrimidine (14c). Yellow solid 1.90 g, yield 90\%. m.p. 178.0-179.9 ${ }^{\circ} \mathrm{C}$; IR: $v_{\max } / \mathrm{cm}^{-1} 3436(\mathrm{NH}), 3305(\mathrm{NH}), 1624(\mathrm{C}=\mathrm{N}), 1541(\mathrm{C}=\mathrm{C}), 1442(\mathrm{C}=\mathrm{C}), 1127$ (C-O-C), 1103 (C-O-C), 545 (C-I); ${ }^{1} \mathrm{H}-\mathrm{NMR}$ (DMSO-d $\left.\mathrm{d}_{6}\right) \delta 9.08$ (d, J = 0.5, 1H, Ar-H), 8.01 (d, J = 0.6, 1H, $\mathrm{Ar}-\mathrm{H}), 6.24\left(\mathrm{~s}, 4 \mathrm{H}, \mathrm{NH}_{2}\right), 5.51\left(\mathrm{~s}, 2 \mathrm{H}, \mathrm{CH}_{2}\right)$; ES-MS $349.9(\mathrm{M}+\mathrm{H})^{+}$; HRMS Calcd. for $\mathrm{C}_{16} \mathrm{H}_{20} \mathrm{ClN}_{4} \mathrm{O}_{3}{ }^{+}$ 349.9572 , found 349.9572 .

2,4-Diamino-5-iodo-6-(1-benzyl-1H-1,2,3-triazole-4-methoxy)pyrimidine (14d). Yellow solid 2.38 g, yield 93\%. m.p. 156.4-159.1 ${ }^{\circ} \mathrm{C}$; IR: $v_{\max } / \mathrm{cm}^{-1} 3441(\mathrm{NH}), 3340(\mathrm{NH}), 1618(\mathrm{C}=\mathrm{N}), 1552(\mathrm{~N}=\mathrm{N}), 1446(\mathrm{C}=\mathrm{C})$, 1280 (C-O-C); ${ }^{1} \mathrm{H}-\mathrm{NMR}$ (DMSO- $\left.d_{6}\right) \delta 8.51(\mathrm{~s}, 1 \mathrm{H}, \mathrm{Ar}-H), 7.86-7.74(\mathrm{~m}, 5 \mathrm{H}, \mathrm{Ar}-H), 6.28\left(\mathrm{~s}, 2 \mathrm{H}, \mathrm{NH}_{2}\right)$, $6.20\left(\mathrm{~s}, 2 \mathrm{H}, \mathrm{NH}_{2}\right), 6.08\left(\mathrm{~s}, 2 \mathrm{H}, \mathrm{CH}_{2}\right), 5.81\left(\mathrm{~s}, 2 \mathrm{H}, \mathrm{CH}_{2}\right)$; ES-MS $424.0(\mathrm{M}+\mathrm{H})^{+}$; HRMS Calcd. for $\mathrm{C}_{16} \mathrm{H}_{20} \mathrm{ClN}_{4} \mathrm{O}_{3}{ }^{+} 424.0383$, found 424.0380 .

General Procedure for the Synthesis of 2,4-Diamino-5-aryl-6-substitutedpyrimidine Derivatives 16a-p

(A) Under argon, to a mixed solution of $\mathrm{EtOH} /$ toluene $/ \mathrm{H}_{2} \mathrm{O}(1: 2: 1,60 \mathrm{~mL})$ was added compounds 14a-d (2.36 mmol), substituted phenylboronic acid 15 ( $3.55 \mathrm{mmol}), \mathrm{Pd}(\mathrm{dbpf}) \mathrm{Cl}_{2}(0.02 \mathrm{mmol})$ and $\mathrm{K}_{2} \mathrm{CO}_{3}$ (3.55 mmol) consecutively and then stirred at $90^{\circ} \mathrm{C}$ for $24 \mathrm{~h}$. The reaction solution was extracted with EtOAc $(150 \mathrm{~mL} \times 3)$, and the combined organic layers were washed by $\mathrm{H}_{2} \mathrm{O}$ and dried with $\mathrm{Na}_{2} \mathrm{SO}_{4}$, filtered and concentrated. The residue was purified by column chromatography on silica gel using $\mathrm{CH}_{2} \mathrm{Cl}_{2} / \mathrm{CH}_{3} \mathrm{OH}(80: 1, v / v)$ as the eluting solvent to the desired compounds. 
(B) In a pressure tube, to a mixed solution of THF $/ \mathrm{H}_{2} \mathrm{O}(1: 1,50 \mathrm{~mL})$ was added compounds 14a-d (2.40 mmol), substituted phenylboronic acid $15(3.60 \mathrm{mmol}), \mathrm{Pd}(\mathrm{dbpf}) \mathrm{Cl}_{2}(0.03 \mathrm{mmol})$ and $\mathrm{K}_{2} \mathrm{CO}_{3}$ $(3.60 \mathrm{mmol})$ consecutively and then stirred at $70{ }^{\circ} \mathrm{C}$ for $20 \mathrm{~h}$. The reaction solution was extracted with EtOAc $(150 \mathrm{~mL} \times 3)$, and the combined organic layers were washed by $\mathrm{H}_{2} \mathrm{O}$ and dried with $\mathrm{Na}_{2} \mathrm{SO}_{4}$, filtered and concentrated. The residue was purified by column chromatography on silica gel using $\mathrm{CH}_{2} \mathrm{Cl}_{2} / \mathrm{CH}_{3} \mathrm{OH}(60: 1, v / v)$ as the eluting solvent to the desired compounds.

2,4-Diamino-5-(4-trifluoromethoxyphenyl)-6-(2-methoxyethoxy)pyrimidine (16a). Method A. White solid 0.60 g, yield 74\%. m.p. 178.3-179.0 ${ }^{\circ} \mathrm{C}$; IR: $v_{\max } / \mathrm{cm}^{-1} 3477(\mathrm{NH}), 3349(\mathrm{NH}), 1619(\mathrm{C}=\mathrm{N}), 1553(\mathrm{C}=\mathrm{C})$, 1486 (C=C), 1447 (C=C), 1275 (C-F), 1222 (C-O-C), 1143 (C-O-C); ${ }^{1} \mathrm{H}-\mathrm{NMR}$ (DMSO- $\left.d_{6}\right) \delta$ 7.38-7.29 (m, $4 \mathrm{H}, \mathrm{Ar}-\mathrm{H}), 6.04\left(\mathrm{~s}, 2 \mathrm{H}, \mathrm{NH}_{2}\right), 5.67\left(\mathrm{~s}, 2 \mathrm{H}, \mathrm{NH}_{2}\right), 4.28-4.23\left(\mathrm{~m}, 2 \mathrm{H}, \mathrm{CH}_{2}\right), 3.52-3.46\left(\mathrm{~m}, 2 \mathrm{H}, \mathrm{CH}_{2}\right), 3.18(\mathrm{~s}$, $\left.3 \mathrm{H}, \mathrm{CH}_{3}\right)$; ES-MS 345.1 (M+ H) ${ }^{+}$; HRMS Calcd. for $\mathrm{C}_{16} \mathrm{H}_{20} \mathrm{ClN}_{4} \mathrm{O}_{3}{ }^{+}$345.1175, found 345.1176.

2,4-Diamino-5-(3-trifluoromethoxyphenyl)-6-(2-methoxyethoxy)pyrimidine (16b). Method A. White solid $0.60 \mathrm{~g}$, yield $74 \%$. m.p. 80.1-81.7 ${ }^{\circ} \mathrm{C}$; IR: $v_{\max } / \mathrm{cm}^{-1} 3347(\mathrm{NH}), 3393(\mathrm{NH}), 1620(\mathrm{C}=\mathrm{N}), 1561(\mathrm{C}=\mathrm{C})$, 1451 (C=C), 1292 (C-F), 1207 (C-O-C), 1157 (C-O-C); ${ }^{1} \mathrm{H}-\mathrm{NMR}$ (DMSO-d $)$ 7.49-7.44 (m, 1H, Ar-H), $7.29(\mathrm{~d}, J=7.8,1 \mathrm{H}, \mathrm{Ar}-\mathrm{H}), 7.20(\mathrm{~d}, J=6.4,2 \mathrm{H}, \mathrm{Ar}-H), 6.08(\mathrm{~s}, 2 \mathrm{H}, \mathrm{NH} 2), 5.73\left(\mathrm{~s}, 2 \mathrm{H}, \mathrm{NH}_{2}\right), 4.28-4.23$ $\left(\mathrm{m}, 2 \mathrm{H}, \mathrm{CH}_{2}\right), 3.51-3.46\left(\mathrm{~m}, 2 \mathrm{H}, \mathrm{CH}_{2}\right), 3.18\left(\mathrm{~s}, 3 \mathrm{H}, \mathrm{CH}_{3}\right)$; ES-MS $345.1(\mathrm{M}+\mathrm{H})^{+}$; HRMS Calcd. for $\mathrm{C}_{16} \mathrm{H}_{20} \mathrm{ClN}_{4} \mathrm{O}_{3}+345.1175$, found 345.1177.

2,4-Diamino-5-[3-(2,2,2-trifluoroethoxymethyl)phenyl]-6-(2-methoxyethoxy)pyrimidine (16c). Method A. Colorless oil $0.61 \mathrm{~g}$, yield 70\%; IR: $v_{\max } / \mathrm{cm}^{-1} 3480(\mathrm{NH}), 3383(\mathrm{NH}), 1607(\mathrm{C}=\mathrm{N}), 1558(\mathrm{C}=\mathrm{C}), 1437$ (C=C), 1279 (C-F), 1160 (C-O-C), 1121 (C-O-C); ${ }^{1} \mathrm{H}-\mathrm{NMR}$ (DMSO-d 6 ) 8 7.40-7.34 (m, 1H, Ar-H), 7.25-7.17 $(\mathrm{m}, 3 \mathrm{H}, \mathrm{Ar}-\mathrm{H}), 6.01\left(\mathrm{~s}, 2 \mathrm{H}, \mathrm{NH}_{2}\right), 5.57\left(\mathrm{~s}, 2 \mathrm{H}, \mathrm{NH} \mathrm{N}_{2}\right), 4.65\left(\mathrm{~s}, 2 \mathrm{H}, \mathrm{CH}_{2}\right), 4.27-4.22\left(\mathrm{~m}, 2 \mathrm{H}, \mathrm{CH}_{2}\right), 4.09(\mathrm{q}$, $\left.J=9.4,2 \mathrm{H}, \mathrm{CH}_{2}\right), 3.51-3.45\left(\mathrm{~m}, 2 \mathrm{H}, \mathrm{CH}_{2}\right), 3.18\left(\mathrm{~s}, 3 \mathrm{H}, \mathrm{CH}_{3}\right)$; ES-MS $373.1(\mathrm{M}+\mathrm{H})^{+}$; HRMS Calcd. for $\mathrm{C}_{16} \mathrm{H}_{20} \mathrm{ClN}_{4} \mathrm{O}_{3}+373.1488$, found 373.1486 .

2,4-Diamino-5-[3,5-dimethyl-4-(N-methoxyaminosulfonyl)phenyl]-6-(2-methoxyethoxy)pyrimidine (16d). Method A. White solid 0.68 g, yield 73\%. m.p. 167.3-171.4 ${ }^{\circ} \mathrm{C}$; IR: $v_{\max } / \mathrm{cm}^{-1} 3466(\mathrm{NH}), 3364$ $(\mathrm{NH}), 1633(\mathrm{C}=\mathrm{N}), 1587(\mathrm{C}=\mathrm{C}), 1507(\mathrm{NH}), 1435(\mathrm{C}=\mathrm{C}), 1157\left(\mathrm{SO}_{2}\right), 1078\left(\mathrm{SO}_{2}\right), 1014\left(\mathrm{SO}_{2}\right) ;{ }^{1} \mathrm{H}-\mathrm{NMR}$ $\left(\mathrm{DMSO}_{6}\right) \delta 10.26(\mathrm{~s}, 1 \mathrm{H}, \mathrm{NH}), 7.15(\mathrm{~s}, 2 \mathrm{H}, \mathrm{Ar}-\mathrm{H}), 6.09\left(\mathrm{~s}, 2 \mathrm{H}, \mathrm{NH} \mathrm{d}_{2}\right), 5.77\left(\mathrm{~s}, 2 \mathrm{H}, \mathrm{NH}_{2}\right), 4.29-4.23(\mathrm{~m}$, $\left.2 \mathrm{H}, \mathrm{CH}_{2}\right), 3.62\left(\mathrm{~s}, 3 \mathrm{H}, \mathrm{CH}_{3}\right), 3.53-3.47\left(\mathrm{~m}, 2 \mathrm{H}, \mathrm{CH}_{2}\right), 3.22\left(\mathrm{~s}, 3 \mathrm{H}, \mathrm{CH}_{3}\right), 2.59\left(\mathrm{~s}, 6 \mathrm{H}, \mathrm{CH}_{3}\right)$; ES-MS 398.1 $(\mathrm{M}+\mathrm{H})^{+} ; \mathrm{HRMS}$ Calcd. for $\mathrm{C}_{16} \mathrm{H}_{20} \mathrm{ClN}_{4} \mathrm{O}_{3}{ }^{+}$398.1498, found 398.1497.

2,4-Diamino-5-[4-(3-trifluoromethoxyanilinoformoxyl)phenyl)-6-(2-methoxyethoxy)pyrimidine (16e). Method A. White solid 0.77 g, yield 70\%. m.p. 96.50-100.1 ${ }^{\circ} \mathrm{C}$; IR: $v_{\max } / \mathrm{cm}^{-1} 3424(\mathrm{NH}), 3345(\mathrm{NH})$, $1705(\mathrm{C}=\mathrm{N}), 1554$ (C=C), 1116 (C-O-C), $523(\mathrm{C}-\mathrm{I}) ;{ }^{1} \mathrm{H}-\mathrm{NMR}$ (DMSO-d $)_{6} \delta 10.48(\mathrm{~d}, J=10.3,1 \mathrm{H}, \mathrm{NH})$, $7.94(\mathrm{dd}, J=17.0,4.9,4 \mathrm{H}, \mathrm{Ar}-H), 7.49(\mathrm{t}, J=8.2,1 \mathrm{H}, \mathrm{Ar}-H), 7.43(\mathrm{~d}, J=8.4,2 \mathrm{H}, \mathrm{Ar}-\mathrm{H}), 7.09(\mathrm{~d}, J=8.3$, $1 \mathrm{H}, \mathrm{Ar}-\mathrm{H}), 6.09\left(\mathrm{~s}, 2 \mathrm{H}, \mathrm{NH}_{2}\right), 5.70\left(\mathrm{~s}, 2 \mathrm{H}, \mathrm{NH}_{2}\right), 4.31-4.25\left(\mathrm{~m}, 2 \mathrm{H}, \mathrm{CH}_{2}\right), 3.53-3.48\left(\mathrm{~m}, 2 \mathrm{H}, \mathrm{CH}_{2}\right), 3.21(\mathrm{~s}$, $\left.3 \mathrm{H}, \mathrm{CH}_{3}\right)$; ES-MS $464.1(\mathrm{M}+\mathrm{H})^{+}$; HRMS Calcd. for $\mathrm{C}_{16} \mathrm{H}_{20} \mathrm{ClN}_{4} \mathrm{O}_{3}{ }^{+} 464.4252$, found 464.4250 .

2,4-Diamino-5-(4-trifluoromethoxyphenyl)-6-(3-methoxypropoxy)pyrimidine (16f). Method A. White solid 0.63 g, yield 75\%. m.p. 189.3-190.9 ${ }^{\circ} \mathrm{C}$; IR: $v_{\max } / \mathrm{cm}^{-1} 3471(\mathrm{NH}), 3365(\mathrm{NH}), 1632(\mathrm{C}=\mathrm{N}), 1557(\mathrm{C}=\mathrm{C})$, 1451 (C=C), 1276 (C-F), 1207 (C-O-C), 1160 (C-O-C); ${ }^{1} \mathrm{H}-\mathrm{NMR}$ (DMSO-d 6 ) $\delta 7.33$ (m, 4H, Ar-H), 6.02 (s, $\left.2 \mathrm{H}, \mathrm{NH}_{2}\right), 5.64\left(\mathrm{~s}, 2 \mathrm{H}, \mathrm{NH}_{2}\right), 4.15\left(\mathrm{t}, \mathrm{J}=6.5,2 \mathrm{H}, \mathrm{CH}_{2}\right), 3.27\left(\mathrm{t}, J=6.3,2 \mathrm{H}, \mathrm{CH}_{2}\right), 3.16\left(\mathrm{~s}, 3 \mathrm{H}, \mathrm{CH}_{3}\right), 1.74$ $\left(\mathrm{m}, 2 \mathrm{H}, \mathrm{CH}_{2}\right)$; ES-MS 359.1 $(\mathrm{M}+\mathrm{H})^{+}$; HRMS Calcd. for $\mathrm{C}_{16} \mathrm{H}_{20} \mathrm{ClN}_{4} \mathrm{O}_{3}{ }^{+}$359.1331, found 359.1333.

2,4-Diamino-5-(3-trifluoromethoxyphenyl)-6-(3-methoxypropoxy)pyrimidine (16g). Method A. White solid 0.79 g, yield $94 \%$. m.p. $165.1-165.4^{\circ} \mathrm{C}$; IR: $v_{\max } / \mathrm{cm}^{-1} 3470(\mathrm{NH}), 3364(\mathrm{NH}), 1633(\mathrm{C}=\mathrm{N}), 1559(\mathrm{C}=\mathrm{C})$, 1454 (C=C), 1283 (C-F), 1205 (C-O-C), 1154 (C-O-C); ${ }^{1} \mathrm{H}-\mathrm{NMR}$ (DMSO-d $) \delta 7.47$ (t, J = 8.0, 1H, Ar-H), $7.27(\mathrm{~d}, J=7.8,1 \mathrm{H}, \mathrm{Ar}-H), 7.21(\mathrm{dd}, J=8.3,1.0,1 \mathrm{H}, \mathrm{Ar}-H), 7.17(\mathrm{~s}, 1 \mathrm{H}, \mathrm{Ar}-H), 6.06(\mathrm{~s}, 2 \mathrm{H}, \mathrm{NH}), 5.70$ $\left(\mathrm{s}, 2 \mathrm{H}, \mathrm{NH}_{2}\right), 4.15\left(\mathrm{t}, J=6.4,2 \mathrm{H}, \mathrm{CH}_{2}\right), 3.29\left(\mathrm{t}, \mathrm{J}=6.3,2 \mathrm{H}, \mathrm{CH}_{2}\right), 3.17\left(\mathrm{~s}, 3 \mathrm{H}, \mathrm{CH}_{3}\right), 1.74\left(\mathrm{~m}, 2 \mathrm{H}, \mathrm{CH}_{2}\right)$; ES-MS $359.1(\mathrm{M}+\mathrm{H})^{+}$; HRMS Calcd. for $\mathrm{C}_{16} \mathrm{H}_{20} \mathrm{ClN}_{4} \mathrm{O}_{3}{ }^{+} 359.1331$, found 359.1330. 
2,4-Diamino-5-(4-trifluoromethoxyphenyl)-6-(thiazole-5-methoxy)pyrimidine (16h). Method A. Yellow solid 0.79 g, yield 87\%. m.p. 188.3-189.6 ${ }^{\circ} \mathrm{C}$; IR: $v_{\max } / \mathrm{cm}^{-1} 3429(\mathrm{NH}), 3327(\mathrm{NH}), 1601(\mathrm{C}=\mathrm{N}), 1556(\mathrm{C}=\mathrm{C})$, 1449 (C=C), 1245 (C-F), 1105 (C-O-C), 1025 (C-O-C); ${ }^{1} \mathrm{H}-\mathrm{NMR}$ (DMSO-d 6 ) $\delta 9.03$ (s, 1H, Ar-H), 7.91 (s, $1 \mathrm{H}, \mathrm{Ar}-H), 7.30(\mathrm{~s}, 4 \mathrm{H}, \mathrm{Ar}-H), 6.16\left(\mathrm{~s}, 2 \mathrm{H}, \mathrm{NH}_{2}\right), 5.75\left(\mathrm{~s}, 2 \mathrm{H}, \mathrm{NH}_{2}\right), 5.45\left(\mathrm{~s}, 2 \mathrm{H}, \mathrm{CH}_{2}\right)$; ES-MS 384.0 $(\mathrm{M}+\mathrm{H})^{+}$; HRMS Calcd. for $\mathrm{C}_{16} \mathrm{H}_{20} \mathrm{ClN}_{4} \mathrm{O}_{3}{ }^{+} 384.0742$, found 384.0745.

2,4-Diamino-5-(3-trifluoromethoxyphenyl)-6-(thiazole-5-methoxy)pyrimidine (16i). Method A. Yellow solid 0.66 g, yield $73 \%$. m.p. $142.8-143.2{ }^{\circ} \mathrm{C}$; IR $(\mathrm{KBr}): v_{\max } / \mathrm{cm}^{-1} 3467(\mathrm{NH}), 3361(\mathrm{NH}), 1628(\mathrm{C}=\mathrm{N})$, 1556 (C=C), 1452 (C=C), 1261 (C-F), 1106 (C-O-C), 1042 (C-O-C); ${ }^{1} \mathrm{H}-\mathrm{NMR}$ (DMSO-d $\left.d_{6}\right) \delta 9.01$ (s, 1H, Ar-H), $7.87(\mathrm{~s}, 1 \mathrm{H}, \operatorname{Ar}-H), 7.50-7.45(\mathrm{~m}, 1 \mathrm{H}, \operatorname{Ar}-H), 7.30(\mathrm{~d}, J=7.8,1 \mathrm{H}, \operatorname{Ar}-H), 7.21(\mathrm{~d}, J=6.4,2 \mathrm{H}$, Ar- $H), 6.20\left(\mathrm{~s}, 2 \mathrm{H}, \mathrm{NH}_{2}\right), 5.79\left(\mathrm{~s}, 2 \mathrm{H}, \mathrm{NH}_{2}\right), 5.45\left(\mathrm{~s}, 2 \mathrm{H}, \mathrm{CH}_{2}\right)$; ES-MS $384.0(\mathrm{M}+\mathrm{H})^{+}$; HRMS Calcd. for $\mathrm{C}_{16} \mathrm{H}_{20} \mathrm{ClN}_{4} \mathrm{O}_{3}+384.0742$, found 384.0740 .

2,4-Diamino-5-[3-(2,2,2-trifluoroethoxymethyl)phenyl]-6-(thiazole-5-methoxy)pyrimidine (16j). Method A. Yellow solid 0.88 g, yield 91\%. m.p. $126.3-129.0^{\circ} \mathrm{C}$; IR: $v_{\max } / \mathrm{cm}^{-1} 3478(\mathrm{NH}), 3316(\mathrm{NH}), 1624(\mathrm{C}=\mathrm{N})$, $1553(\mathrm{C}=\mathrm{C}), 1442(\mathrm{C}=\mathrm{C}), 1282(\mathrm{C}-\mathrm{F}), 1158(\mathrm{C}-\mathrm{O}-\mathrm{C}) ;{ }^{1} \mathrm{H}-\mathrm{NMR}$ (DMSO-d $\left.d_{6}\right) \delta 9.02$ (s, 1H, Ar-H), 7.90 (s, 1H, Ar-H), $7.35(\mathrm{t}, J=7.6,1 \mathrm{H}, \mathrm{Ar}-H), 7.21(\mathrm{~d}, J=7.7,1 \mathrm{H}, \mathrm{Ar}-H), 7.14(\mathrm{~d}, J=8.6,2 \mathrm{H}, \mathrm{Ar}-H), 6.12\left(\mathrm{~s}, 2 \mathrm{H}, \mathrm{NH}_{2}\right)$, $5.64\left(\mathrm{~s}, 2 \mathrm{H}, \mathrm{NH}_{2}\right), 5.44\left(\mathrm{~s}, 2 \mathrm{H}, \mathrm{CH}_{2}\right), 4.64\left(\mathrm{~s}, 2 \mathrm{H}, \mathrm{CH}_{2}\right), 4.08\left(\mathrm{q}, \mathrm{J}=9.4,2 \mathrm{H}, \mathrm{CH}_{2}\right)$; ES-MS $412.1(\mathrm{M}+\mathrm{H})^{+}$; HRMS Calcd. for $\mathrm{C}_{16} \mathrm{H}_{20} \mathrm{ClN}_{4} \mathrm{O}_{3}{ }^{+} 412.1055$, found 412.1056.

2,4-Diamino-5-[3,5-dimethyl-4-(N-methoxyaminosulfonyl)phenyl]-6-(thiazole-5-methoxy)pyrimidine (16k). Method A. White solid 0.74 g, yield $72 \%$. m.p. $139.2-142.6{ }^{\circ} \mathrm{C}$; IR: $v_{\max } / \mathrm{cm}^{-1} 3463(\mathrm{NH}), 3358$ $(\mathrm{NH}), 1616(\mathrm{C}=\mathrm{N}), 1589(\mathrm{C}=\mathrm{C}), 1490(\mathrm{C}=\mathrm{C}), 1448(\mathrm{C}=\mathrm{C}), 1168\left(\mathrm{SO}_{2}\right), 1076\left(\mathrm{SO}_{2}\right), 1009\left(\mathrm{SO}_{2}\right) ;{ }^{1} \mathrm{H}-\mathrm{NMR}$ (DMSO- $\left.d_{6}\right) \delta 10.26(\mathrm{~s}, 1 \mathrm{H}, \mathrm{NH}), 9.05(\mathrm{~s}, 1 \mathrm{H}, \mathrm{Ar}-H), 7.92(\mathrm{~s}, 1 \mathrm{H}, \mathrm{Ar}-H), 7.07(\mathrm{~s}, 2 \mathrm{H}, \mathrm{Ar}-H), 6.21(\mathrm{~s}, 2 \mathrm{H}$, $\left.\mathrm{NH}_{2}\right), 5.84\left(\mathrm{~s}, 2 \mathrm{H}, \mathrm{NH}_{2}\right), 5.46\left(\mathrm{~s}, 2 \mathrm{H}, \mathrm{CH}_{2}\right), 3.61\left(\mathrm{~s}, 3 \mathrm{H}, \mathrm{CH}_{3}\right), 2.57\left(\mathrm{~s}, 6 \mathrm{H}, \mathrm{CH}_{3}\right)$; ES-MS $437.1(\mathrm{M}+\mathrm{H})^{+}$; HRMS Calcd. for $\mathrm{C}_{16} \mathrm{H}_{20} \mathrm{ClN}_{4} \mathrm{O}_{3}{ }^{+} 437.1066$, found 437.1065.

2,4-Diamino-5-[4-(3-trifluoromethoxyanilinocarbonyl)phenyl]-6-(thiazole-5-methoxy)pyrimidine

(161). Method A. Yellow solid 1.17 g, yield 99\%. m.p. 180.9-182.9 ${ }^{\circ} \mathrm{C}$; IR: $v_{\max } / \mathrm{cm}^{-1} 3430(\mathrm{NH}), 3340$ $(\mathrm{NH}), 3200(\mathrm{NH}), 1654(\mathrm{C}=\mathrm{O}), 1608(\mathrm{C}=\mathrm{N}), 1551(\mathrm{C}=\mathrm{C}), 1484(\mathrm{C}=\mathrm{C}), 1442(\mathrm{C}=\mathrm{C}), 1257(\mathrm{C}-\mathrm{F}) ;{ }^{1} \mathrm{H}-\mathrm{NMR}$ $\left(\right.$ DMSO- $\left._{6}\right) \delta 10.46(\mathrm{~s}, 1 \mathrm{H}, \mathrm{NH}), 9.04(\mathrm{~s}, 1 \mathrm{H}, \mathrm{Ar}-H), 7.94(\mathrm{~d}, J=8.6,4 \mathrm{H}, \mathrm{Ar}-H), 7.79(\mathrm{~d}, J=8.2,1 \mathrm{H}, \mathrm{Ar}-H)$, $7.48(\mathrm{t}, J=8.2,1 \mathrm{H}, \mathrm{Ar}-H), 7.36(\mathrm{~d}, J=8.4,2 \mathrm{H}, \mathrm{Ar}-H), 7.09(\mathrm{~d}, J=8.2,1 \mathrm{H}, \mathrm{Ar}-H), 6.20\left(\mathrm{~s}, 2 \mathrm{H}, \mathrm{NH}_{2}\right), 5.77$ $\left(\mathrm{s}, 2 \mathrm{H}, \mathrm{NH}_{2}\right), 5.47\left(\mathrm{~s}, 2 \mathrm{H}, \mathrm{CH}_{2}\right)$; ES-MS $503.1(\mathrm{M}+\mathrm{H})^{+}$; HRMS Calcd. for $\mathrm{C}_{16} \mathrm{H}_{20} \mathrm{ClN}_{4} \mathrm{O}_{3}{ }^{+}$503.1113, found 503.1111.

2,4-Diamino-5-(4-trifluoromethoxyphenyl)-6-(1-benzyl-1H-1,2,3-triazole-4-methoxy)pyrimidine (16m). Method A. White solid 0.98 g, yield 91\%. m.p.159.5-160.6 ${ }^{\circ} \mathrm{C}$; IR: $v_{\max } / \mathrm{cm}^{-1} 3489(\mathrm{NH}), 3371(\mathrm{NH})$, $1608(\mathrm{C}=\mathrm{N}), 1556(\mathrm{~N}=\mathrm{N}), 1492(\mathrm{C}=\mathrm{C}), 1439$ (C=C), 1261 (C-O-C), 1219 (C-F); ${ }^{1} \mathrm{H}-\mathrm{NMR}$ (DMSO- $\left.d_{6}\right) \delta$ $8.15(\mathrm{~s}, 1 \mathrm{H}, \mathrm{Ar}-\mathrm{H}), 7.40-7.23(\mathrm{~m}, 9 \mathrm{H}, \mathrm{Ar}-\mathrm{H}), 6.17\left(\mathrm{~s}, 2 \mathrm{H}, \mathrm{NH}_{2}\right), 5.73\left(\mathrm{~s}, 2 \mathrm{H}, \mathrm{NH}_{2}\right), 5.57\left(\mathrm{~s}, 2 \mathrm{H}, \mathrm{CH}_{2}\right), 5.24$ $\left(\mathrm{s}, 2 \mathrm{H}, \mathrm{CH}_{2}\right)$; ES-MS $458.1(\mathrm{M}+\mathrm{H})^{+}$; HRMS Calcd. for $\mathrm{C}_{16} \mathrm{H}_{20} \mathrm{ClN}_{4} \mathrm{O}_{3}{ }^{+} 458.1552$, found 458.1555 .

2,4-Diamino-5-(3-trifluoromethoxyphenyl)-6-(1-benzyl-1H-1,2,3-triazole-4-methoxy)pyrimidine (16n). Method A. White solid 0.98 g, yield 91\%. m.p. 171.9-173.0 ${ }^{\circ} \mathrm{C}$; IR: $v_{\max } / \mathrm{cm}^{-1} 3495(\mathrm{NH}), 3376(\mathrm{NH})$, $1607(\mathrm{C}=\mathrm{N}), 1556(\mathrm{~N}=\mathrm{N}), 1491(\mathrm{C}=\mathrm{C}), 1431(\mathrm{C}=\mathrm{C}), 1278$ (C-O-C), 1219 (C-F); ${ }^{1} \mathrm{H}-\mathrm{NMR}\left(\mathrm{DMSO}-d_{6}\right) \delta$ $8.15(\mathrm{~s}, 1 \mathrm{H}, \mathrm{Ar}-\mathrm{H}), 7.40-7.23(\mathrm{~m}, 9 \mathrm{H}, \mathrm{Ar}-\mathrm{H}), 6.17\left(\mathrm{~s}, 2 \mathrm{H}, \mathrm{NH}_{2}\right), 5.73\left(\mathrm{~s}, 2 \mathrm{H}, \mathrm{NH}_{2}\right), 5.57\left(\mathrm{~s}, 2 \mathrm{H}, \mathrm{CH}_{2}\right), 5.24$ (s, 2H, CH $)$; ES-MS $458.1(\mathrm{M}+\mathrm{H})^{+}$; HRMS Calcd. for $\mathrm{C}_{16} \mathrm{H}_{20} \mathrm{ClN}_{4} \mathrm{O}_{3}{ }^{+} 458.1552$, found 458.1553 .

2,4-Diamino-5-(4-methoxycarbonylphenyl)-6-(1-benzyl-1H-1,2,3-triazole-4-methoxy)pyrimidine (16o). Method B. Gray solid 0.70 g, yield 68\%. m.p. 218.6-222.3 ${ }^{\circ} \mathrm{C}$; IR: $v_{\max } / \mathrm{cm}^{-1} 3487(\mathrm{NH}), 3440(\mathrm{NH})$, $1709(\mathrm{C}=\mathrm{O}), 1616(\mathrm{C}=\mathrm{N}), 1555(\mathrm{~N}=\mathrm{N}), 1483(\mathrm{C}=\mathrm{C}), 1440(\mathrm{C}=\mathrm{C}), 1285$ (C-O-C); ${ }^{1} \mathrm{H}-\mathrm{NMR}$ (DMSO-d $\left.d_{6}\right)$ : $8.16(\mathrm{~s}, 1 \mathrm{H}, \mathrm{Ar}-H), 7.87(\mathrm{~d}, J=8.4,2 \mathrm{H}, \mathrm{Ar}-H), 7.39-7.25(\mathrm{~m}, 7 \mathrm{H}, \mathrm{Ar}-H), 6.20(\mathrm{~s}, 2 \mathrm{H}, \mathrm{NH} 2), 5.77(\mathrm{~s}, 2 \mathrm{H}$, $\left.\mathrm{NH}_{2}\right), 5.57\left(\mathrm{~s}, 2 \mathrm{H}, \mathrm{CH}_{2}\right), 5.24\left(\mathrm{~s}, 2 \mathrm{H}, \mathrm{CH}_{2}\right), 3.86\left(\mathrm{~s}, 3 \mathrm{H}, \mathrm{CH}_{3}\right)$; ES-MS $432.1(\mathrm{M}+\mathrm{H})^{+}$; HRMS Calcd. for $\mathrm{C}_{16} \mathrm{H}_{20} \mathrm{ClN}_{4} \mathrm{O}_{3}{ }^{+} 432.1784$, found 432.1786 . 
2,4-Diamino-5-(3-methoxycarbonylphenyl)-6-(1-benzyl-1H-1,2,3-triazole-4-methoxy)pyrimidine

Method B. Yellow solid 0.53 g, yield 51\%. m.p. 210.4-213.7 ${ }^{\circ} \mathrm{C}$; IR: $v_{\max } / \mathrm{cm}^{-1} 3432(\mathrm{NH}), 3351(\mathrm{NH})$, $1706(\mathrm{C}=\mathrm{O}), 1619(\mathrm{C}=\mathrm{N}), 1564(\mathrm{~N}=\mathrm{N}), 1485(\mathrm{C}=\mathrm{C}), 1442(\mathrm{C}=\mathrm{C}), 1252(\mathrm{C}-\mathrm{O}-\mathrm{C}) ;{ }^{1} \mathrm{H}-\mathrm{NMR}\left(\mathrm{DMSO}-d_{6}\right) \delta$ $8.13(\mathrm{~s}, 1 \mathrm{H}, \mathrm{Ar}-H), 7.80(\mathrm{dd}, J=8.8,4.4,2 \mathrm{H}, \mathrm{Ar}-H), 7.44(\mathrm{~d}, J=5.1,2 \mathrm{H}, \mathrm{Ar}-H), 7.34(\mathrm{dd}, J=9.1,6.9,3 \mathrm{H}$, Ar-H), 7.28-7.24 (m, 2H, Ar-H), $6.16\left(\mathrm{~s}, 2 \mathrm{H}, \mathrm{NH}\right.$ ), $5.71\left(\mathrm{~s}, 2 \mathrm{H}, \mathrm{NH}_{2}\right), 5.56\left(\mathrm{~s}, 2 \mathrm{H}, \mathrm{CH}_{2}\right), 5.24\left(\mathrm{~s}, 2 \mathrm{H}, \mathrm{CH}_{2}\right)$, $3.82\left(\mathrm{~s}, 3 \mathrm{H}, \mathrm{CH}_{3}\right)$; ES-MS $432.1(\mathrm{M}+\mathrm{H})^{+}$; HRMS Calcd. for $\mathrm{C}_{16} \mathrm{H}_{20} \mathrm{ClN}_{4} \mathrm{O}_{3}{ }^{+}$432.1784, found 432.1785.

\subsection{Determination of Anti-Mycobacterial Activity}

The minimum inhibitory concentrations (MIC) and minimum bactericidal concentrations (MBC) of the test compounds were determined as described previously [19] with minor modifications. In brief, the MIC was determined using the microbroth dilution method in 96-well microtitre plates. Mycobacterium tuberculosis H37Ra (ATCC 25177) was used as the test strain, at a final inoculum of approximately $10^{5} \mathrm{cfu} / \mathrm{mL}$. The compounds were dissolved in DMSO and diluted in 1\% DMSO in 7H9 broth to obtain concentrations ranging from $100 \mu \mathrm{g} / \mathrm{mL}$ to $1.56 \mu \mathrm{g} / \mathrm{mL}$. All inoculated plates were sealed with Parafilm and incubated at $36^{\circ} \mathrm{C}$ for 28 days. On days 14 and 28 , all wells were observed for visible growth, and $10 \mu \mathrm{L}$ was removed from each well for subculturing on compound-free $7 \mathrm{H} 10$ agar plates which were incubated for six weeks at $36^{\circ} \mathrm{C}$. For each compound, the lowest concentration to inhibit the growth of H37Ra in broth culture was taken to be the MIC. The MBC was the lowest concentration to inhibit the formation of colonies on the agar subculture, up to six weeks of incubation.

\subsection{Molecular Docking}

The crystal structure of $m t$-DHFR in complex with NADPH and MTX (PDB ID: 1DF7) [20] was used as the receptor for molecular docking, which was performed by GOLD Docking: GOLD (v 5.2.2 Genetic Optimization for Ligand Docking) [21]. The bound ligand, MTX was used as a reference to indicate the binding site, and each molecule was docked 10 times with the default automatic genetic algorithm parameter settings and the results were evaluated by Gold Score.

\subsection{Molecular Dynamic Simulation}

The geometry of the docked ligand was optimized by using the B3LYP 6-31 G* basis set within Gaussian09 [22], and the atom-centered point charges were calculated to fit the electrostatic potential using RESP [23]. The parameters of NADPH were obtained from AMBER parameter database (http: //www.pharmacy.manchester.ac.uk/bryce/amber/, uploaded by U. Ryde).

The docked compound and $m t$-DHFR complex was explicitly solvated in a truncated octahedral box of TIP3P model water (at least $12 \AA$ from the complex to avoid periodic artifacts from occurring) by using Amber 16 with the amber ff14SB force field. The system charges were neutralized by adding enough $\mathrm{K}^{+}$ions by using the tleap module (AmberTools 16). The explicit solvent models and the NPT ensemble ( $\mathrm{T}=300 \mathrm{~K} ; \mathrm{P}=1 \mathrm{~atm}$ ) were performed on all molecular dynamic simulations. Periodic boundary conditions (PBC) and particle-mesh-Ewald method (PME) [24] were used to treat long-range electrostatic effects, with the temperature coupled to an external bath using a weak coupling algorithm [25]. The non-bonded interaction cutoff was set as $8 \AA$. The bond interactions involving $\mathrm{H}$-atoms were constrained by using the SHAKE algorithm. The time step necessary to solve the Newton's equations was chosen to be equal to $2 \mathrm{fs}$ and the trajectory files were collected every 10 ps. All trajectory analysis was performed with the Ptraj module in the AmberTools 16 and examined visually using VMD software [26].

The whole system was first optimized by energy minimization, followed by $110 \mathrm{~ns}$ molecular dynamic simulation, including $10 \mathrm{~ns}$ equilibration and $100 \mathrm{~ns}$ production simulations. The last 80 ns (1000 snapshots, 80 ps intervals) stable, equilibrated trajectories of the production simulation were taken for binding free energy calculations performed by using MM-PBSA [27-29] (included in AMBERTOOLS 16). 
The entropy was estimated by using the Normal Mode program [28,29] within the AMBER16 suite. Because the entropy calculations are computationally intensive, only 100 snapshots from the last $80 \mathrm{~ns}$ trajectories were used for the normal-mode analysis.

\section{Conclusions}

In conclusion, in order to occupy the GOL binding site on $m t$-DHFR and maintain proper hydrophobicities to allow the compounds to function in the $M t b$ whole cell assay, we designed and synthesized three series of compounds which contain a hydrophobic side chain. Among them, the compounds with a thiazole side chain significantly inhibited the growth of $M t b$, and the best inhibition effect was observed on compound 161. More interestingly, this compound showed selectivity for $M t b$ over vero cells, which makes it potentially useful as a lead compound for future studies on anti-TB drugs. Unfortunately, we are currently unable to confirm 161 as an $m t$-DHFR inhibitor by performing the binding assay on the pure $m t$-DHFR enzyme.

Sulfonamides were the first anti-bacterial agents to be used for the treatment of tuberculosis [30]. They were subsequently replaced by the standard first-line anti-TB drugs rifampicin, isoniazid, ethambutol and pyrazinamide, which had greater anti-TB activity. With the increase of multidrug resistant TB in the past two decades, and the therapeutic failures with standard anti-TB drugs, respiratory physicians have to resort the treatment with other antibiotics and chemotherapeutic agents including the trimethoprim-sulfamethoxazole combination [31]. While sulfamethoxazole competes with para-aminobenzoic acid (PABA) for the enzyme dihydropteroate synthetase, trimethoprim directly inhibits the dihydrofolate reductase for the reduction of dihydrofolic acid to tetrahydrofolic acid. This combination was found to have in vitro activity for up to $98 \%$ of $M t b$ isolates [32]. However, both drugs are bacteriostatic, and are associated with drug resistance. Sulfonamide resistance has been reported to result from a point mutation or the acquisition of a plasmid which enables the synthesis of a dihydropteroic synthetase that has poor affinity for sulfonamides. Similarly, trimethoprim can be rendered ineffective by plasmid- and transposon-mediated production of an altered dihydrofolate reductase that has markedly reduced affinity for the drug. In some studies, trimethoprim, when used by itself, has been shown to have little activity on some strains of $M t b$ [33]. The new compounds we synthesized appear to be bactericidal against $M t b$, making it a better drug for TB therapy in immunocompromised patients. Further studies are required to test for the frequency of mutation to resistance among clinical strains of $M t b$ and whether the compounds can be used in combination with other anti-TB drugs or antibiotics for synergistic activity or to retard the development of resistance.

Acknowledgments: This work was supported by National Natural Science Foundation of China (81773582) given to H.W.; National Natural Science Foundation of China $(81460538,81660588)$ given to W.H.; IPSR/RMC/UTARRF/2015-C1/NO3 awarded to Y.F.N. by Universiti Tunku Abdul Rahman (UTAR), Kuala Lumpur, Malaysia.

Author Contributions: Wei Hong, Hao Wang and Yun Fong Ngeow conceived and designed the experiments; Yifan Ouyang, Hao Yang, Peng Zhang, Yu Wang, Sargit Kaur, Xuanli Zhu, Zhe Wang, and Yutong Sun performed the experiments; Wei Hong and Hao Wang analyzed the data; Wei Hong, Hao Wang and Yun Fong Ngeow wrote the paper.

Conflicts of Interest: All authors declare no conflict of interest.

\section{References}

1. Zheng, J.; Rubin, E.J.; Bifani, P.; Mathys, V.; Lim, V.; Au, M.; Jang, J.C.; Nam, J.; Dick, T.; Walker, J.R.; et al. Para-Aminosalicylic Acid Is a Prodrug Targeting Dihydrofolate Reductase in Mycobacterium tuberculosis. J. Biol. Chem. 2013, 288, 23447-23456. [CrossRef] [PubMed]

2. Gangjee, A.; Jain, H.D.; Queener, S.F.; Kisliuk, R.L. The Effect of 5-Alkyl Modification on the Biological Activity of Pyrrolo[2,3-d]pyrimidine Containing Classical and Nonclassical Antifolates as Inhibitors of Dihydrofolate Reductase and as Antitumor and/or Antiopportunistic Infection Agents. J. Med. Chem. 2008, 51, 4589-4600. [CrossRef] [PubMed] 
3. Gangjee, A.; Yang, J.; Queener, S.F. Novel non-classical C9-methyl-5-substituted-2,4-diaminopyrrolo-[2,3d]pyrimidines as potential inhibitors of dihydrofolate reductase and as anti-opportunistic agents. Bioorg. Med. Chem. 2006, 14, 8341-8351. [CrossRef] [PubMed]

4. Cai, B.; Liao, A.; Lee, K.K.; Ban, J.S.; Yang, H.S.; Im, Y.J.; Chun, C.J. Design, synthesis of methotrexate-diosgenin conjugates and biological evaluation of their effect on methotrexate transport-resistant cells. Steroids 2016, 116, 45-51. [CrossRef] [PubMed]

5. Bertino, J.R. Karnofsky Memorial Lecture: Ode to methotrexate. J. Clin. Oncol. 1993, 11, 5-14. [CrossRef] [PubMed]

6. Assaraf, Y.G. Molecular basis of antifolate resistance. Cancer Metastasis Rev. 2007, 26, 153-181. [CrossRef] [PubMed]

7. Gangjee, A.; Elzein, E.; Kothare, M.; Vasudevan, A. Classical and Nonclassical Antifolates as Potential Antitumor, Antipneumocystis and Antitoxoplasma Agents. Curr. Pharm. Des. 1996, 2, 263-280.

8. Hawser, S.; Lociuro, S.; Islam, K. Dihydrofolate reductase inhibitors as antibacterial agents. Biochem Pharmacol. 2006, 71, 941-948. [CrossRef] [PubMed]

9. Then, R.L. Antimicrobial dihydrofolate reductase inhibitors-achievements and future options: Review. J. Chemother. 2004, 16, 3-12. [CrossRef] [PubMed]

10. El-Hamamsy, M.H.R.I.; Smith, A.W.; Thompson, A.S.; Threadgill, M.D. Structure-based design, synthesis and preliminary evaluation of selective inhibitors of dihydrofolate reductase from Mycobacterium tuberculosis. Bioorg. Med. Chem. 2007, 15, 4552-4576. [CrossRef] [PubMed]

11. Surineni, G.; Yogeeswari, P.; Sriram, D.; Kantevari, S. Design and synthesis of novel carbazole tethered pyrrole derivatives as potent inhibitors of Mycobacterium tuberculosis. Bioorg. Med. Chem. Lett. 2015, 25, 485-491. [CrossRef] [PubMed]

12. Wang, H.; Hong, W.; Zhang, P.; Wang, Y.; Tang, X.L.; Yang, H.; Ouyang, Y.F.; Sun, T.; Pu, J. The Synthesis of 2,4-Diaminopyrimidine Derivatives. Patent CN105566230A, 11 May 2016.

13. Zhang, L.; Jia, B.; Hu, C.F.; Wang, F.; Cui, Y.X. Synthesis and preliminary biological evaluation of the derivatives of $O^{6}$-benzylguanine as inactivators of $O^{6}$-alkylguanine-DNA alkyltransferase. Chin. Chem. Lett. 2008, 19, 801-804. [CrossRef]

14. Yang, Z.; Wang, T.J.; Wang, F.; Niu, T.; Liu, Z.W.; Chen, X.X.; Long, C.F.; Tang, M.H.; Cao, D.; Wang, X.Y.; et al. Discovery of Selective Histone Deacetylase 6 Inhibitors Using the Quinazoline as the Cap for the Treatment of Cancer. J. Med. Chem. 2016, 59, 1455-1470. [CrossRef] [PubMed]

15. Ganguly, N.C.; De, P.; Dutta, S. Mild Regioselective Monobromination of Activated Aromatics and Heteroaromatics with N-Bromosuccinimide in Tetrabutylammonium Bromide. Synthesis 2005, 7, 1103-1108. [CrossRef]

16. Hodgetts, K.J.; Kershaw, M.T. Regiocontrolled Synthesis of Substituted Thiazoles. Org. Lett. 2002, 4, $1363-1365$. [CrossRef] [PubMed]

17. Guillou, S.; Janin, Y.L. 5-Iodo-3-Ethoxypyrazoles: An Entry Point to New Chemical Entities. Chem. Eur. J. 2010, 16, 4669-4677. [CrossRef] [PubMed]

18. Wang, H.; Hong, W.; Tang, X.L.; Ouyang, Y.F.; Yang, H.; Wang, Y.; Zhang, P.; Chang, Z.; Li, J.Y.; Yang, Y.H.; et al. The Preparation and Application of 2,4-diaminopyrimidine Compounds and Their Salts as Anti-TB Drugs. Patent CN106220616A, 14 December 2016.

19. Hong, W.; Wang, Y.; Chang, Z.; Yang, Y.H.; Pu, J.; Sun, T.; Kaur, S.; Sacchettini, J.C.; Jung, H.; Wong, W.L.; et al. The identification of novel Mycobacterium tuberculosis DHFR inhibitors and the investigation of their binding preferences by using molecular modelling. Sci. Rep. 2015, 5, 15328. [CrossRef] [PubMed]

20. Li, R.; Sirawaraporn, R.; Chitnumsub, P.; Sirawaraporn, W.; Wooden, J.; Athappilly, F.; Turley, S.; Hol, W.G. Three-dimensional structure of $\mathrm{M}$. tuberculosis dihydrofolate reductase reveals opportunities for the design of novel tuberculosis drugs. J. Mol. Biol. 2000, 295, 307-323. [CrossRef] [PubMed]

21. Jones, G.; Willett, P.; Glen, R.C.; Leach, A.R.; Taylor, R. Development and validation of a genetic algorithm for flexible docking. J. Mol. Biol. 1997, 267, 727-748. [CrossRef] [PubMed]

22. Frisch, M.J.; Trucks, G.W.; Schlegel, H.B.; Scuseria, G.E.; Robb, M.A.; Cheeseman, J.R.; Scalmani, G.; Barone, V.; Mennucci, B.; Petersson, G.A.; et al. Gaussian 09, Revision C.01; Gaussian, Inc.: Wallingford, UK; New Haven, CT, USA, 2009. 
23. Bayly, C.I.; Cieplak, P.; Cornell, W.D.; Kollman, P.A. A well-behaved electrostatic potential based method using charge restraints for deriving atomic charges: The RESP model. J. Phys. Chem. 1993, 97, 10269-10280. [CrossRef]

24. Darden, T.; York, D.; Pedersen, L. Particle mesh Ewald: An N.log(N) method for Ewald sums in large systems. J. Chem. Phys. 1993, 98, 10089-10092. [CrossRef]

25. Berendsen, H.J.C.; Postma, J.P.M.; Van gunsteren, W.F.; Dinola, A.; Haak, J.R. Molecular dynamics with coupling to an external bath. J. Chem. Phys. 1984, 81, 3684-3690. [CrossRef]

26. Humphrey, W.; Dalke, A.; Schulten, K. VMD-Visual Molecular Dynamics. J. Mol. Graphics. 1996, 14, 33-38. [CrossRef]

27. Kollman, P.A.; Massova, I.; Reyes, C.; Kuhn, B.; Huo, S.H.; Chong, L.; Lee, M.; Lee, T.; Duan, Y.; Wang, W.; et al. Calculating structures and free energies of complex molecules: Combining molecular mechanics and continuum models. Acc. Chem. Res. 2000, 33, 889-897. [CrossRef] [PubMed]

28. Wang, H.; Laughton, C.A. Molecular modelling methods for prediction of sequence-selectivity in DNA recognition. Methods 2007, 42, 196-203. [CrossRef] [PubMed]

29. Wang, H.; Laughton, C.A. Evaluation of molecular modelling methods to predict the sequence selectivity of DNA minor groove. Phys. Chem. Chem. Phys. 2009, 11, 10722-10728. [CrossRef] [PubMed]

30. Freilich, E.B.; Coe, G.C.; Wien, N.A. The use of sulfanilamide in pulmonary tuberculosis: Preliminary report. Ann. Intern. Med. 1939, 13, 1042-1045.

31. Alsaad, N.; Wilffert, B.; van Altena, R.; de Lange, W.C.M.; van der Werf, T.S.; Kosterink, J.G.W.; Alffenaar, J.W.C. Potential antimicrobial agents for the treatment of multidrug-resistant tuberculosis. Eur. Respir. J. 2014, 43, 884-897. [CrossRef] [PubMed]

32. Forgacs, P.; Wengenack, N.L.; Hall, L.; Zimmerman, S.K.; Silverman, M.L.; Roberts, G.D. Tuberculosis and trimethoprim-sulfamethoxazole. Antimicrob. Agents Chemother. 2009, 53, 4789-4793. [CrossRef] [PubMed]

33. Macingwana, L.; Baker, B.; Ngwane, A.H.; Harper, C.; Cotton, M.F.; Hesseling, A.; Diacon, A.H.; van Helden, P.; Wiid, I. Sulfamethoxazole enhances the antimycobacterial activity of rifampicin. J. Antimicrob. Chemother. 2012, 67, 2908-2911. [CrossRef] [PubMed]

Sample Availability: Samples of the compounds 10a-q, 11a-q and 16a-p are available from the authors.

(c) 2017 by the authors. Licensee MDPI, Basel, Switzerland. This article is an open access article distributed under the terms and conditions of the Creative Commons Attribution (CC BY) license (http://creativecommons.org/licenses/by/4.0/). 